Florida International University FIU Digital Commons

$11-7-2016$

\title{
The Impacts of Telecommuting on The Time- Space Distribution of Daily Activities
}

\author{
Mario Benito Rojas IV \\ Florida International University, mroja032@fiu.edu
}

DOI: $10.25148 /$ etd.FIDC001225

Follow this and additional works at: https://digitalcommons.fiu.edu/etd

Part of the Civil Engineering Commons, Statistical Models Commons, Transportation Engineering Commons, and the Urban Studies and Planning Commons

\section{Recommended Citation}

Rojas, Mario Benito IV, "The Impacts of Telecommuting on The Time-Space Distribution of Daily Activities" (2016). FIU Electronic Theses and Dissertations. 2997.

https://digitalcommons.fiu.edu/etd/2997

This work is brought to you for free and open access by the University Graduate School at FIU Digital Commons. It has been accepted for inclusion in FIU Electronic Theses and Dissertations by an authorized administrator of FIU Digital Commons. For more information, please contact dcc@fiu.edu. 


\section{FLORIDA INTERNATIONAL UNIVERSITY \\ Miami, Florida}

THE IMPACTS OF TELECOMMUTING ON THE TIME-SPACE DISTRIBUTION OF DAILY ACTIVITIES

A thesis submitted in partial fulfillment of the requirements for the degree of

MASTER OF SCIENCE

in

CIVIL ENGINEERING

by

Mario Benito Rojas IV

2016 
To: Interim Dean Ranu Jung

College of Engineering and Computing

This thesis, written by Mario Benito Rojas IV, and entitled The Impacts of Telecommuting on the Time-Space Distribution of Daily Activities, having been approved in respect to style and intellectual content, is referred to you for judgment.

We have read this thesis and recommend that it be approved.

B. M. Golam Kibria

Mohammed Hadi

Xia Jin, Major Professor

Date of Defense: November 1, 2016

The thesis of Mario Benito Rojas IV is approved.

Interim Dean Ranu Jung College of Engineering and Computing

Andrés G. Gil

Vice President for Research and Economic Development and Dean of the University Graduate School

Florida International University, 2016 
C Copyright 2016 by Mario Benito Rojas IV

All rights reserved. 


\section{DEDICATION}

I dedicate this thesis to my family and friends; I was able to complete thesis due in large part to their patience, encouragement, understanding, support, and love. 


\section{ACKNOWLEDGMENTS}

I would like to take this opportunity to acknowledge all those who guided and assisted me as I embarked upon earning a Master of Science in Civil Engineering. In particular I would

like to thank my major advisor, Dr. Xia Jin, for fostering an atmosphere of curiosity and encouragement while working with her. Similarly, I would like to thank my thesis committee members Dr. Mohammed Hadi, and Dr. B. M. Golam Kibria for providing invaluable insight and suggestions while serving as members of my committee.

I also would like to acknowledge my co-researchers: Mr. Sakoat Hossan, Mr. Kollol Shams, Mr. Zhaohan Zang, Mr. Fengjiang Hu, Mrs. Nishat Zaman, Mr. Mohammad Lavasani, Mr. Eazaz Sadeghvaziri, and Mr. Seyedmirsajad Mokhtarimous. Throughout our time together we have been able to foster an environment in which we were able to grow professionally as well as personally. 


\title{
ABSTRACT OF THE THESIS \\ THE IMPACTS OF TELECOMMUTING ON THE \\ TIME-SPACE DISTRIBUTION OF DAILY ACTIVITIES
}

\author{
by \\ Mario Benito Rojas IV \\ Florida International University, 2016 \\ Miami, Florida \\ Professor Xia Jin, Major Professor
}

As major cities have aged, they have also met or exceeded their transportation infrastructure's capacity. This has led to many negative impacts such as increased greenhouse gas emissions, delay, travel time, congestion, as well as decreased energy independence, standard of living for the cities' inhabitants and the world as a whole. As a result, these cities will undoubtedly suffer and will struggle to meet the needs of their citizens.

It is becoming more evident, and relevant, that the solution to today's and tomorrow's transportation problems will be overcome through the use of policy as well as innovative strategies, one of which may be telecommuting. Due to this, this thesis investigates the impacts of telecommuting on the time-space distribution of daily activities as a potential transportation demand strategy. Herein, the thesis explores topics related to telecommuting, time-space constrains, time-space prisms, and the impact of telecommuting on time-space prisms. In order to do so, the author examines the applicability of stochastic frontier analyses to estimate the time-space prism's vertices for various telecommuting groups. 


\section{TABLE OF CONTENTS}

CHAPTER

PAGE

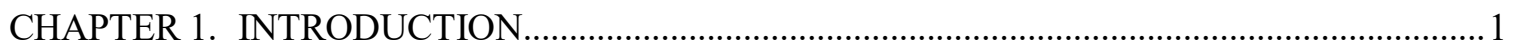

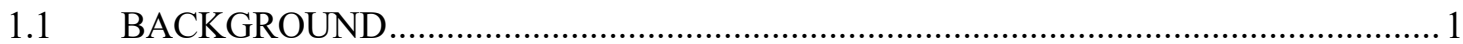

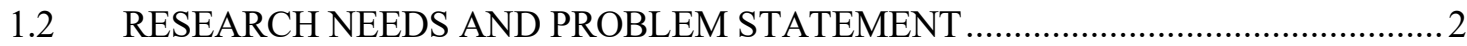

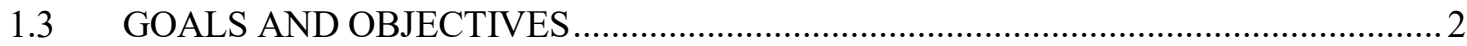

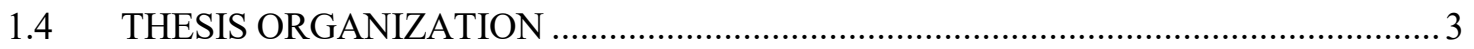

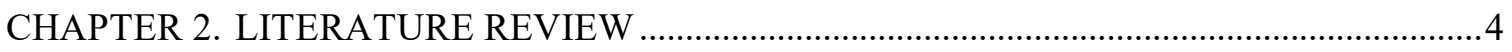

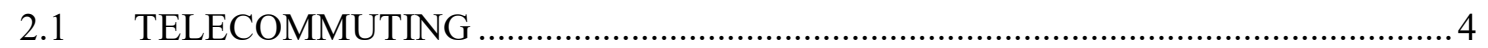

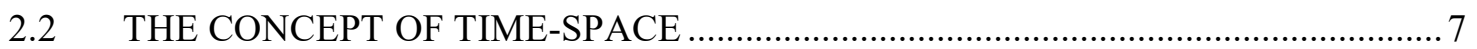

2.3 THE TIME-SPACE PRISM

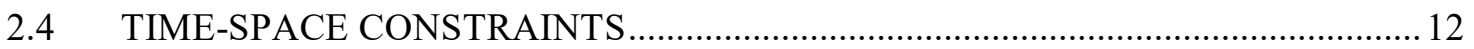

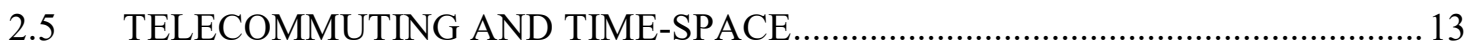

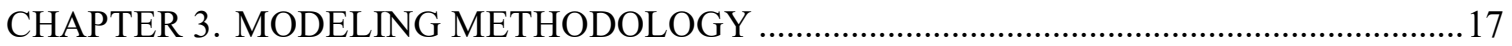

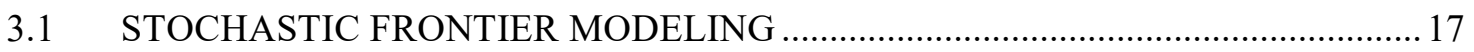

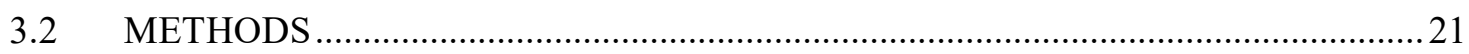

CHAPTER 4. DATASET AND SAMPLE CHARACTERISTICS …............................................23

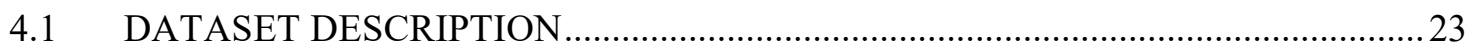

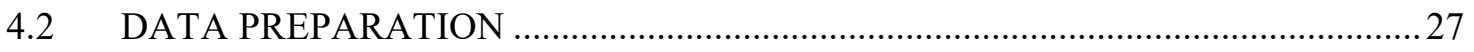

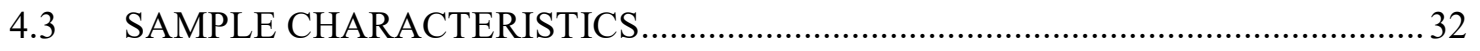

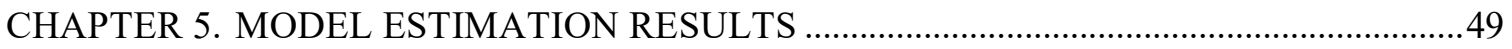

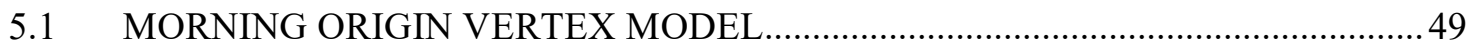

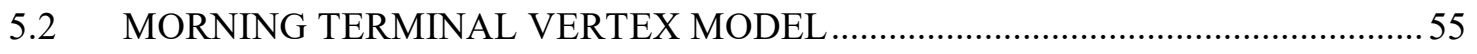

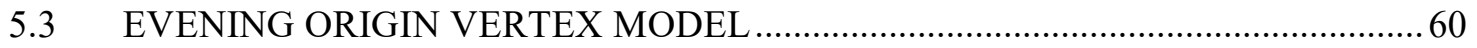

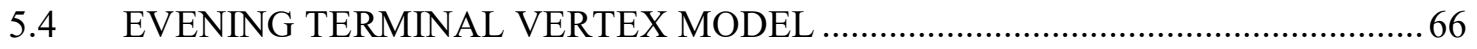

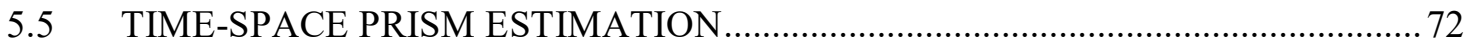

CHAPTER 6. CONCLUSION AND RECOMMENDATION

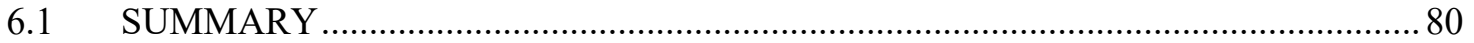

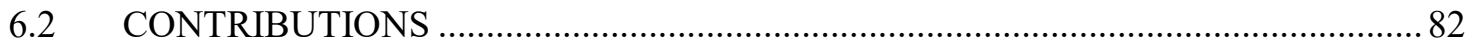

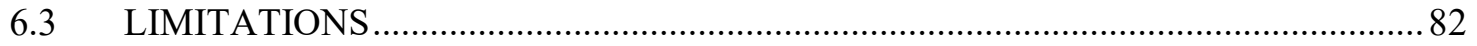

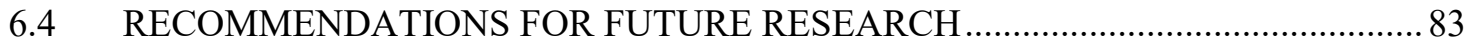

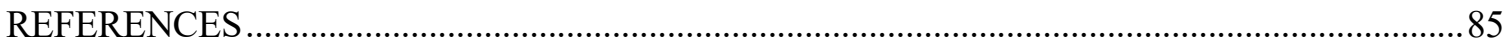

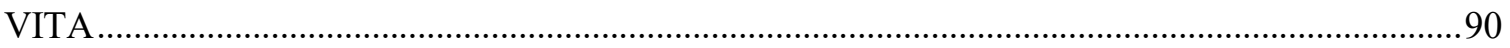




\section{LIST OF TABLES}

TABLE

PAGE

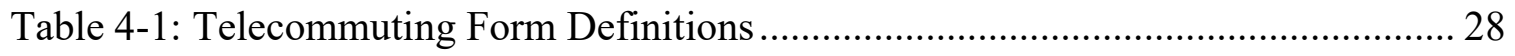

Table 4-2: Mandatory/Non-Mandatory Activities ...................................................... 29

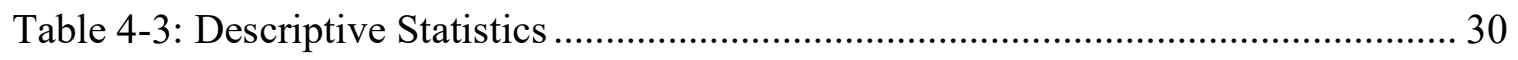

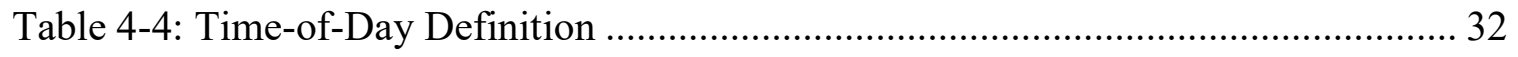

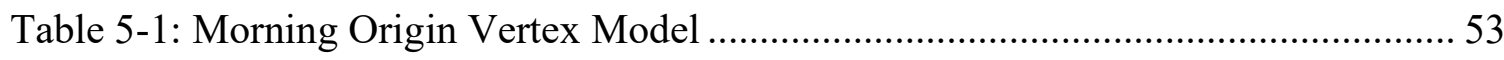

Table 5-2: Morning Terminal Vertex Model ........................................................... 58

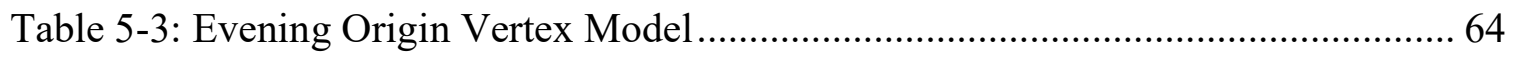

Table 5-4: Evening Terminal Vertex Model........................................................ 70

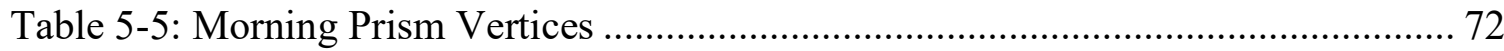

Table 5-6: Morning Prism Vertices ............................................................... 75

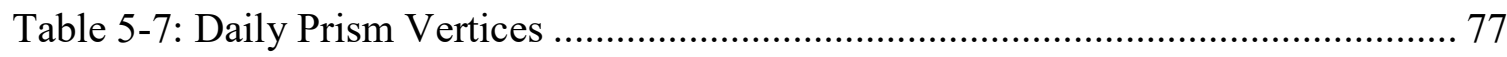




\section{LIST OF FIGURES}

TABLE

PAGE

Figure 2-1: Hägerstrand's Constraint Rings ......................................................... 8

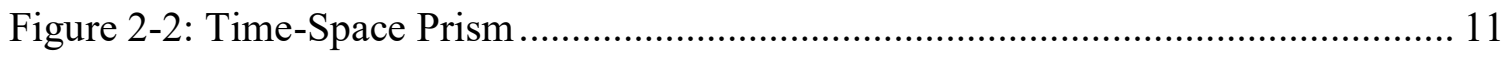

Figure 2-3: Movement within the Time-Space Prism.............................................. 12

Figure 4-1: RHTS Study Area for NYBPM Model ................................................. 25

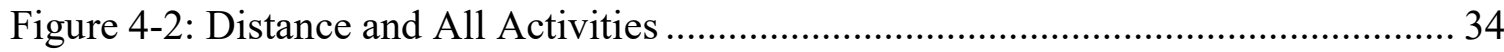

Figure 4-3: Distance and Mandatory/Non-Mandatory Activities ................................ 35

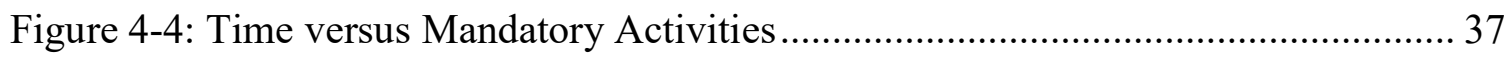

Figure 4-5: Time versus Non-Mandatory Activities............................................. 40

Figure 4-6: Time-of-Day and All Activities ..................................................... 42

Figure 4-7: Time-of-Day and Mandatory/Non-Mandatory Activities.......................... 43

Figure 4-8: Morning Departure from Home Distribution........................................ 45

Figure 4-9: Morning Arrival at Work Distribution ................................................ 46

Figure 4-10: Evening Departure from Work Distribution ...................................... 47

Figure 4-11: Evening Arrival at Home Distribution............................................... 48

Figure 5-1: Morning Time-Space Prisms ......................................................... 74

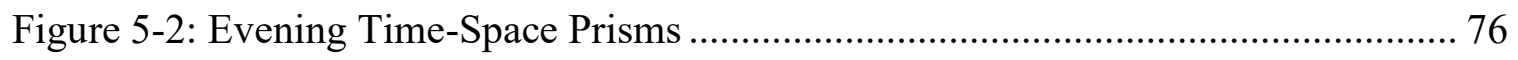

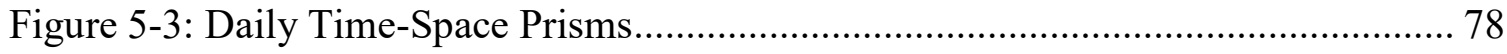




\section{LIST OF EQUATIONS}

(1)

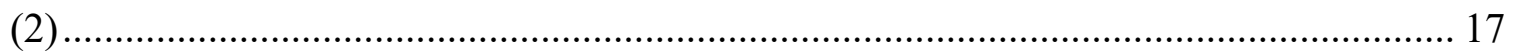

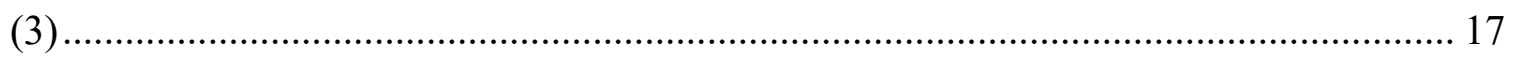

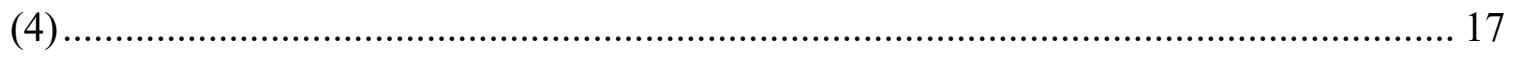

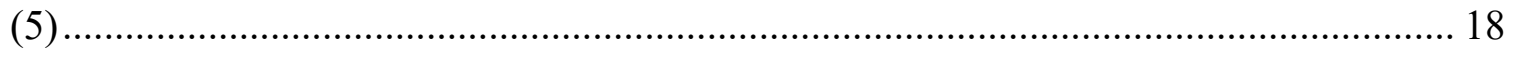

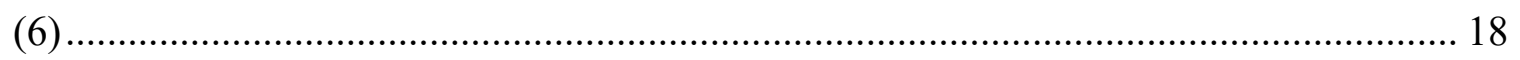

(7)

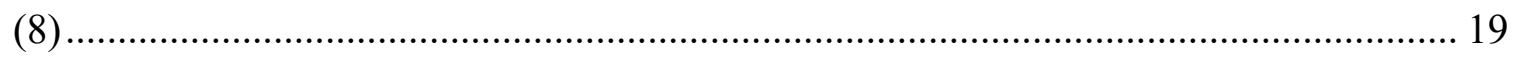

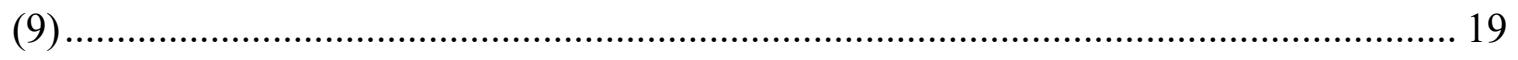

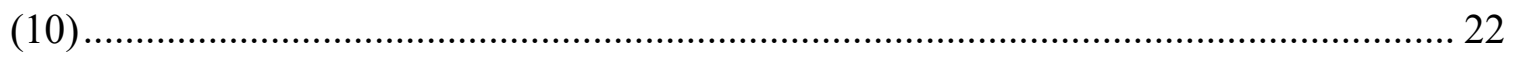

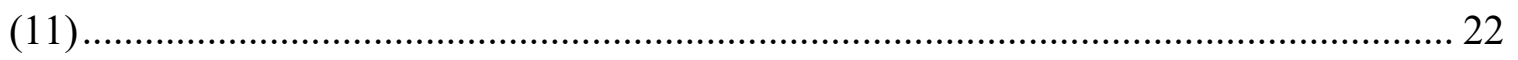




\section{CHAPTER 1. INTRODUCTION}

This chapter will discuss the background, research needs and problem statement, goals and objectives, as well as the organization of this thesis.

\section{$1.1 \quad$ BACKGROUND}

Many major cities, such as New York City, have seen great economic prosperity but are now forced to live with the reality that comes with this success. The success of a major city and its population growth together invariably impacts transportation, society, and ultimately all individuals. Transportation issues, including congestion and increased vehicle emissions, can be mitigated with careful planning (Heaslip et al., 2015; Soltani-Sobh, 2015; Soltani-Sobh et al., 2016; Motamed, 2016; Sharifi and Shabaniverki, 2016) but the end is an inescapable truth; the transportation infrastructure can only serve a finite volume of users at a given time. Herein lies an issue faced by today's world. As successful cities aged, many have reached or exceeded their infrastructures' practical limits which force them to find other ways to deal with their population's needs.

It is clear that the solution to the transportation problems of today and tomorrow will be overcome through the use of policy as well as innovative strategies, one of which may be telecommuting. Throughout the literature, telecommuting takes many forms but this thesis adopted the conventions as proposed by Asgari (2015); Asgari separated workers into four

groups based on their telecommuting behavior: primary (full-day), ancillary (regular partday), passive (non-regular part-day), and non-telecommuters. 


\subsection{RESEARCH NEEDS AND PROBLEM STATEMENT}

As a whole there is a definitive need to truly understand the impacts of telecommuting in order to enable proper planning efforts. The current lack of understanding stems from the fact that the estimation of telecommuting impacts is probably subject to a number of insufficiencies. In an attempt to improve these estimations, this thesis employs stochastic frontier models in order to explore this technique as well as to understand the impact of telecommuting on the time-space prism of individuals. The work herein follows a general trend moving from an aggregate to disaggregate level of data in order to paint a more detailed picture of telecommuting and transportation as a whole.

\subsection{GOALS AND OBJECTIVES}

The goal of this thesis is to contribute to the literature related not only to telecommuting and time-space constraints, but also to that of stochastic frontier modeling. More specifically, this thesis seeks to analyze the impacts of telecommuting patterns on the time-space distribution of daily activities. Time-space prisms will be constructed in order to aid the author's understanding of the time-space distribution of activities. Only the prisms of workers will be considered. In order to construct these prisms, the author will first model the prisms' vertices and arrival/departure times, then will compare these to the prisms.

It should be noted that this thesis will not attempt to address the definition of telecommuting, nor does it attempt to suggest a unified definition. Rather, the thesis will adopt the definition of telecommuter previously used on this particular dataset (Asgari and Jin, 2015). Furthermore, as this particular modeling technique has scantly been used for the 
express purpose of exploring telecommuting, the author views this work as one which may serve as a starting point and reference for further research.

\subsection{THESIS ORGANIZATION}

The remainder of this thesis is organized as follows: Chapter 2 explores the current literature as it relates to telecommuting, time-space, time-space constraints, as well as the relationship between telecommuting and time-space; Chapter 3 focuses on the methodology used in this thesis which includes a discussion of stochastic frontier modelling; Chapter 4 discusses the data used for this thesis and its characteristics; Chapter 5 discusses the model estimation results; Chapter 6 provides the author's summary and conclusions. 


\section{CHAPTER 2. LITERATURE REVIEW}

An extensive review was conducted during the construction of this thesis. The related literature was then compiled and explored thoroughly; the remainder of this chapter provides a review of the literature related to telecommuting, the concept of time-space, time-space prisms, as well as the relationship between telecommuting and time-space prisms.

\subsection{TELECOMMUTING}

In its earliest forms, telecommuting first became possible with the rise of technology; more specifically, the improvement of information and communications technologies (ICT) such as cellular phones, fax machines, and personal computers. Some of the earliest work involving telecommuting, or teleworking, was noted in 1974. The authors of that study, investigated the use of telecommuting as a means to reduce the peak-time demand associated with traditional commuting (Nilles et al., 1974). The results of this study, and others like it, opened the door for the implementation of telecommuting. Due in large part to these early studies, telecommuting gained credence and was further explored as a method to improve other areas as, productivity (Turnbull et al., 1996) and employment facilitation for disadvantaged or disabled people (Crimando and Godley, 1985). Guidance from the literature and research projects led to the implementation of telecommuting programs, in both the private and public sector, throughout the United States by the 1990's.

This prompted a shift in the research whereby studies moved away from testing its potential and began to investigate the propensity of people to use telecommuting 
(Bernardino et al., 1993 Hamer et al., 1991; Mannering and Mokhtarian, 1995; Belanger, 1999); a trend which has continued since then (Grippaldi, 2002; Helminen and Ristimaki, 2007; Haddad et al., 2009; Mosa, 2011). While the effectiveness of telecommuting is still studied today (Zhu, 2011), many studies have elected to explore other areas such as modelling techniques (Wenjing and Zhicai, 2009; Mohammadian and Doherty, 2005), vehicular emissions (Walls and Safirova, 2004; Vu, 2007), daily activity scheduling (Asgari et al., 2016), demand management (Vu and Vandebona, 2008; Asgari et al., 2016), and crash reduction (Pirdavani et al., 2013).

Due to its potential, the United States government has taken many steps to incorporate telecommuting including the signing of the Telework Enhancement Act in December 2010. In doing so, the Office "transformed Federal telework to unleash its potential as a strategic intervention for supporting agency effectiveness" (Telework.gov). According to the Office, this Act "enables a more systematic implementation of telework in Federal agencies". This policy was followed by a Presidential Memorandum in June 2014 entitled, Enhancing Workplace Flexibilities and Work-Life Programs. The memorandum sought "to help attract, empower and retain a talented and productive workforce in the 21 st century".

As elaborated in the agency's studies, the percentage of federal employees that teleworked increase from 5.72\% in 2009 to $7.50 \%$ in 2013 (OPM, 2013; OPM, 2014). The 2014 report also indicated that federal teleworkers were equally likely to be male and female, were not in a supervisor role $(81 \%)$, and were 40 years or older $(\sim 75 \%)$. However, barriers are continuously being lowered to increase the number of teleworkers especially those younger age groups. For example, federal workers in the youngest age 
group (20-29) reported an increase in telework from 17 percent in 2011 to 23 percent in 2013; a similar trend was also cited for teleworking barriers of non-supervisors, supervisors, and managers/executives. As was shown by its recent declarations, as well as federal precedent, the United States government views telecommuting favorably and even views it as an important recruitment and retention tool (OPM, 2014).

Since its inception, telecommuting has also undergone changes in how it is defined. This definition is directly influenced by four major characteristics: the location, duration, intensity, and presence of sufficient technology. The first of these, location, generally refers to the fact that employees can work from home, any location the employee sees fit, or designated locations. Duration refers to the portion of the work day in which the employee telecommutes. Intensity refers to the number of day the employee telecommutes. Technology refers broadly to the reduction of barriers associated with the employee not physically being present, such as teleconferencing or electronic mail. Due to this, and the availability of data, researchers have struggled to agree upon a unified definition for telecommuting. For example, one study could define telecommuting as a person who works from home any day of the week while another defines it as any form of work not done in the office. If the sample data was provided to the studies in this simple example, the two studies would likely come to vastly different conclusions. As this thesis focuses on other topics, rather than attempting to resolve the definition of telecommuting, the author adopted the conventions as proposed by Asgari (2015); Asgari separated commuters into four groups: primary, ancillary, passive, and nontelecommuters. Such classification of telecommuting basically stems from two major dimensions of telecommuting activity: First, whether or not telecommuting is a long- 
range regular plan in workers' schedules, and second, whether or not telecommuting activity totally replaces daily travel to work (Asgari and Jin 2014, 2015).

\subsection{THE CONCEPT OF TIME-SPACE}

The inclusion of time-space into regional science, and later engineering, was first conceived by Hägerstrand (1970). In its inception, he explained that as an individual moves from one location to the next, each location can be defined as a specific point in space and time. These locations are also connected by paths which cannot be broken; they begin at birth and end at death. When these paths are viewed in the three-dimensional context of time-space, it is possible to see how constraints act upon individuals.

In his time, and even today, three general time-space constraints were identified: capability constraints, coupling constraints, and authority constraints. To explain this, he considered rings which surround, are fixed, and move in unison with an individual. At no point will the individual ever be able to escape or move away from the center of these rings. It is important to state that these rings are viewed only in the space region timespace, that is the ring cover physical distance and its diameter is not related to time; see Figure 2-1. When this is considered it can be understood that the projection of these rings into the third dimension, time, will produce a tube which represents an individual's constraints through time-space as a whole; a more in depth discussion of this tube and time-space constraints will be provided later in this text. 


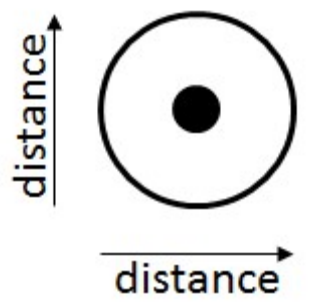

Figure 2-1: Hägerstrand's Constraint Rings

The inner-most ring, representing capability constraints, is well-defined. In the case of an able-bodied human, this ring extends to the length of his or her reach. This ring will grow as an individual grows larger with age, but remains constant from the individual's perspective. Based on this, it is clear that an adult has a much larger ring than an infant, therefore the adult has less capability constraints placed on him or her. Although only slightly, tools or other similar devices do have the potential to expand this inner-most ring. Likewise, two identical adults may have different sized rings based on one's capability to use a tool, or to use a tool more effectively than the other.

When the time dimension is considered, an interesting aspect of this ring's movement is realized; this ring will tend to have some sort of patterns. An example of a potential pattern could be an individual's need to sleep each day. Therefore, the individual will likely move through time but not through space at reoccurring times and for potentially predictable durations.

Outside of this ring, the coupling constraints ring can be found. Unlike the previous, this ring tends to be less definite. In the past, this ring extended to the audio and visual extend of an individual. Today, this ring has been vastly expanded through technologies such as video conferencing and other similar capabilities. Interestingly, this ring also varies in size. For example, the ring will be much smaller when an individual is 
within a building versus in an open field. Similarly, when new technologies are not available the ring will also decrease.

The third and final ring, representing the authority constrains, tends to be omnipresent. This ring can be thought of as a tangible location in time-space which is controlled by an external individual or group. The size of this ring is therefore strictly determined by those that are in control. Further, these can exist in a hierarchy of authority constraints. Within this hierarchical organization, each subordinate individual's ring is controlled, or at least effected, by all individuals above. An example of this could be a military officer. The officer may command his/her subordinates while in turn command their subordinates, and all the will the officer is also a subordinate to his/her commanding officer. Now that the various constraints have been explained, it is important to explore their effect on time-space as well as on time-space prisms.

As previously mentioned, the rings which represent the different constraints were viewed only in the two dimensions of space. When one of the space dimensions is replaced with time, the time-space prism is revealed as shown in Figure 2-2.

\subsection{THE TIME-SPACE PRISM}

In this figure (Figure 2-2), the widest part of the prism is exactly the diameter of the aforementioned rings. This prism represents the physical boundaries one assumes based on the time-space constraints and is confined by time-space walls on all sides. It can be observed from Figure 2-2 that the slopes of the prism represent the time travelled over a given distance; in essence, the right two time-space barriers represent the inverse of speed while the left two represent the negative inverse value of speed. Also, the upper and 
lower-most points (vertices) represent the trip beginning and end, respectively. In this idealized figure the slope of each line is constant, but this is not likely to occur when realworld conditions are considered (Hägerstrand, 1970). In reality these lines would be comprised of multiple lines, each of which having a different slope; this indicates different speeds. With this understanding it is clear that as an individual's ability to move at a higher speed increases, so will the width of the individual's prism. Such has been the case throughout the progression of mankind's transportation vehicles. However, it is important to realize the consequence of multiple individuals maneuvering through timespace simultaneously.

Considering that each individuals' trip is represented by a prism, and the timespace provided by modern infrastructure is finite, it becomes evident that there will be overlapping of multiple individuals' prisms. Within the context of transportation infrastructure, this overlapping manifests as congestion. Therefore, although an individual has the ability to travel more rapidly, it does not mean that his/her prism will continue to widen continuously due other's ability to do the same. Although, within the context of transportation, overlapping of individuals' time-space prisms are associated with a negative repercussion, such is not always the case. In fact, this overlapping allows for humans to do many constructive things such as engage in higher education, host meetings, and enjoy each other's company. 


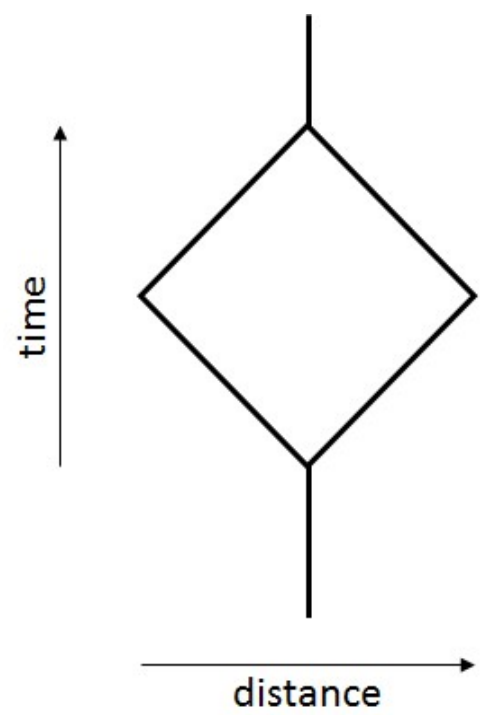

Figure 2-2: Time-Space Prism

Based on the time-space construct, there are several undeniable facts about the time-space prism. The first of these is that the lines shown in the figure are continuous and as such cannot be broken. Also, it is not possible to move outside the prism (Hägerstrand, 1970). Time-space also does not allow for an individual to move strictly in time or space; simply, one cannot move horizontally or vertically as this would indicate that he/she is moving from one place to another without moving in time, or vice-versa. Further, an individual's movement is unidirectional in the sense that he/she must always move forward in time-space and can never be at the same location in time-space more than once. Finally, as an individual moves within the finite area of a time-space prism, the size of the prism is reduced permanently; see Figure 2-3. 


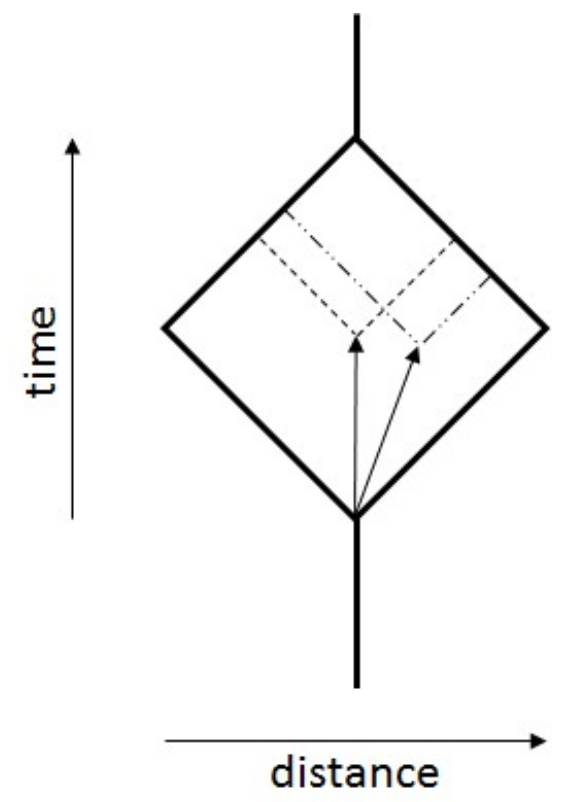

Figure 2-3: Movement within the Time-Space Prism

\subsection{TIME-SPACE CONSTRAINTS}

As indicated by the literature surrounding time-space constraints, also referred to as spatio-temporal constraints, generally fall into the three aforementioned categories and cause an individual to allocate his/her time accordingly. The most basic temporal constraint is the day; each day is comprised of only 24 hours and entire day must be partitioned for many different activities. Assuming that the individual must eat and sleep, the rest of the day remains for the individual to accomplish whatever he/she desires. Frequently, more temporal restrictions are placed on individuals who work, attend school, and other regimented activities. When these temporal constraints are considered in parallel with the spatial constraints imparted by fixed locations, such as work and home location, an individual's potential paths through time-space become rather limited. Further, as an individual engages in more activities, his/her time-space constraints will 
increase. In essence, these constraints force individuals to select, prioritize, and plan activities as well as decide when the activity should take place.

From the transportation point of view, time-space constraints play a role in controlling how users access transportation systems and how they engage in trips. For example, an individual may choose to leave home earlier in the morning when taking his daughter to school to be sure to make it to his meeting on time. Similarly, a person may select an alternate route in anticipation of congestion. In both of these examples, the individual needs to move from one location to another at a given time and as such these decisions must be factored into the individual's time-space path for the entire day.

\subsection{TELECOMMUTING AND TIME-SPACE}

In this section, the relationship between telecommuting and time-space constraints will be explored. As previously mentioned, the definition of telecommuting varied between these studies. However, in order to explore the aforementioned relationship, the author of this thesis accepted each study's definition. Therefore, the definition of telecommuting will vary from the definition adopted by this thesis, but only in this section.

In nearly all scenarios, telecommuting has the potential to reduce time-space constraints associated with commuting trips. However, this reduction varies due in large part to the telework policies established by employers. For example, a public-sector telecommuter may be required to work during typical work hours whereas a privatesector telecommuter may only be required to work a number of hours per day. In this simple example the public-sector telecommuter no longer has the need to commute each day, but is still required to work during specified hours which likely only reduces the 
constraints slightly. Conversely, the constraints of the private sector telecommuter are greatly reduced by eliminating the commute as well as affording him/her the ability to work the hours he/she finds most suitable. It is also worth noting that the telecommuter may never be free of the traditional commute to work as one will likely still be expected to visit the workplace at given intervals.

The impact of telecommuting can most appropriately be examined at the aggregate and disaggregate level; societal and personal, respectively. When considering the aggregate level, it is more difficult to understand the effect of telecommuting on timespace constraints. As a whole, the literature reviewed of aggregate level studies indicated that telecommuting is inversely related to overall delay and congestion (Schintler, 2001; Choo et al., 2005; Vu and Vandebona, 2007a; Vu and Vandebona, 2007b); more plainly, as telecommuting increased, delay and/or congestion decreased. While the studies did not agree upon the level of impact which telecommuting had on delay and congestion, they all displayed similar trends. As the effect on an individual's time-space constraints is more difficult to understand at the aggregate level, when compared to the disaggregate level, an examination of the literature related to disaggregate level studies was deemed appropriate.

As indicated by the literature, several obstacles faced by workers such as technology, commute duration, and commute length have the potential to encourage telecommuting. Different forms of telecommuting, such as those mentioned in this thesis, should all so be explored as these groups may have very different impacts on trip behaviors and patterns. Another aspect considered by the literature was the potential of telecommuting to reduce the number of trips as well as its effectiveness as a congestion 
mitigation strategy were noted in the literature, but were not included herein as these topics were outside the scope of this thesis.

The rapid pace of technology has transformed the workplace in many ways, especially in the realm of communication technologies. Such technologies have enabled workers and the workplace to evolve into an almost omnipresent entity. An example of this can be noted in the case of video conferencing. Not only has this enabled organizations to expand globally, it has reduced the need to be physically present. The work done by Mokhtarian (2003) illustrated that the growth and adaptation of these types of technologies has enabled more work-related activities to be conducted via various forms of telecommuting. However, while this may reduce the barriers to telecommuting, this alone may not be the only consideration effecting the choice to telecommute; preconceived notions about workplace relationships and other factors may impact the choice to telecommute as well (Mokhtarian and Salomon 1997).

Similarly, commute length and duration may also play an integral role in the choice of telecommuting. In fact, the relationship between distance of an individual's commute, as well as duration, have been studied and generally agree that telecommuting becomes more probable as these two increase (Pendyala et al., 1991; Mokhtarian et al., 2004; Zhu, 2011; Helminen and Ristimaki 2007). Moreover, it was shown that while the commute distance and duration for telecommuters' commuting trips increased, the total distance traveled decreased. Also, telecommuters had less commuting trips, less peaktime trips, less vehicle miles travelled, and a smaller activity space; this was observed on all days, not just work days (Pendyala et al., 1991). However, the literature indicated that the effect of these two factors varies. For example, Helminen and Ristimaki (2007) found 
that commuting less than 80 kilometers ( $\sim 50$ miles) did not increase the propensity to telecommute greatly, but commuting more than 100 kilometers $(\sim 62$ miles $)$ did. More specifically, this study found that increasing commuting trips by 10 kilometers ( $\sim 6$ miles) increased the propensity to telecommute by $25 \%$.

Other researchers have studied the impact of different types of telecommuting on travel behavior. For example, Wells et al. (2001) revealed that personal vehicle usage was more likely than public transportation usage for telecommuters on commuting days than on non-commuting days. Also, the location and time distribution of personal trips was significantly impacted, to differing degrees, due to full-time or part-time telecommuting. A similar result was also noted by Jiang (2008). In this study models indicated that telecommuting's impact on the mode of transportation was positive, but insignificant.

While a more complete understanding of the impact of telecommuting at the aggregate and disaggregate level is equally important, the advancement of technology has facilitated the exploration of activity based modeling. This has served as an impetus, as noted in the literature, for studies to consider telecommuting at the disaggregate level. As such, this thesis followed this trend and explored the relationship of telecommuting and time-space constraints at the disaggregate level between differing types of telecommuters. 


\section{CHAPTER 3. MODELING METHODOLOGY}

This chapter will discuss stochastic frontier modelling, its formulation, and its application within the context of this thesis. The ensuing chapter is by no means a comprehensive review, rather it explores the fundamentals of the modelling technique.

\subsection{STOCHASTIC FRONTIER MODELING}

Adopted in the modeling approach are the inequalities,

Origin Vertex: $\tau_{o} \leq t_{o}$

Terminal Vertex: $t_{t} \leq \tau_{t}$

where,

$\tau_{o}$ is the location along a time axis of the origin vertex of a prism

$t_{o}$ is the beginning time of the trip

$\tau_{t}$ is the location along a time axis of the terminal vertex

$t_{t}$ is the end time of the trip

Here it is assumed that $\tau_{o}$ and $\tau_{t}$ is unobserved. From the inequalities,

$$
\begin{aligned}
& t_{o}=\tau_{o}+u_{o} \\
& t_{t}=\tau_{t}+u_{t}
\end{aligned}
$$

where $u_{o}$ and $u_{t}$ are the nonnegative random variables 
The general form of the stochastic frontier model (Aigner et al. 1977), which applies to relationships such as those presented above in Equations (3) and (4), may be written as a cost function:

$Y_{i}=\beta^{\prime} X_{i}+\varepsilon_{i}=\beta^{\prime} X_{i}+v_{i}+u_{i}$

where,

$i$ denotes the observation

$Y_{i}$ is the observed dependent variable

$\beta$ is a vector of coefficients

$X_{i}$ is a vector of explanatory variables

$v_{i}$ is the noise term, $-\infty<v_{i}<+\infty$

$u_{i}$ is the innefficiency term, $u_{i} \geq 0$

$\beta^{\prime} X_{i}+v_{i}$ can be viewed as the location of origin vertex with random element $v_{i}$

It is important to explain that the noise terms relates to statistical noise within the data while the inefficiency term relates to an individual's ability to meet his frontier. Similarly, a model for a terminal vertex can be formulated as a production function as follows:

$Y_{i}=\beta^{\prime} X_{i}+\varepsilon_{i}^{*}=\beta^{\prime} X_{i}+v_{i}-u_{i}$

In econometric literature on stochastic frontier models $v_{i}$ is typically assumed to be normal, and a truncated (half) normal distribution is often used for $u_{i}$. In this case, Aigner et al. (1977) gave the distribution of $\varepsilon_{i}$ in the cost frontier model as (Aigner; Waldman). 
$h\left(\varepsilon_{i}\right)=\frac{2}{\sqrt{2 \pi} \sigma}\{1-\Phi(\varepsilon \lambda / \sigma)\} e^{\left[-\frac{\varepsilon_{i}^{2}}{2 \sigma^{2}}\right]},-\infty<\varepsilon_{i}<+\infty$

and the distribution of $\varepsilon_{i}{ }^{*}$ in the production frontier model as

$h\left(\varepsilon_{i}^{*}\right)=\frac{2}{\sqrt{2 \pi} \sigma}\left\{1-\Phi\left(\varepsilon_{i}^{*} \lambda / \sigma\right)\right\} e^{\left[-\frac{\varepsilon_{i}^{* 2}}{2 \sigma^{2}}\right]},-\infty<\varepsilon_{i}^{*}<+\infty$

where,

$$
\begin{aligned}
& \sigma^{2}=\sigma_{u}^{2}+\sigma_{v}^{2} \\
& \lambda \quad=\frac{\sigma_{u}}{\sigma_{v}} \\
& \sigma_{u}^{2}=\frac{\lambda^{2} \sigma^{2}}{1+\lambda^{2}} \\
& \sigma_{v}^{2}=\frac{\sigma^{2}}{1+\lambda^{2}} \\
& v \sim N\left(0, \sigma_{v}^{2}\right)
\end{aligned}
$$

and $\mathrm{u}$ has the density function,

$$
g(u)=\frac{2}{\sqrt{2 \pi} \sigma_{u}} e^{\left[-\frac{u^{2}}{2 \sigma_{u}^{2}}\right]}, u \geq 0
$$

Although this error density function causes the likelihood function to be not entirely well-behaved, the work done by Waldman (1980) enables its use. The work stated that a positive third moment of the model indicates that "the least squares estimates and $\hat{\lambda}=0$ represent a local maximum of the likelihood". Empirical evidence, as shown by Olsen et al. (1980), also suggests that the global maximum is also represented by this 
point. However, a negative third moment suggest that a greater likelihood value can be found elsewhere; generally, where $\hat{\lambda}>0$.

Stochastic frontier models will be employed this thesis. In this application, the trip observed starting/ending time will correspond to the dependent variable $\left(\mathrm{Y}_{\mathrm{i}}\right)$ and the participants' individual attributes will be the independent variables $\left(\mathrm{X}_{\mathrm{i}}\right)$; this satisfies equation (1) and (2).

As demonstrated by the literature (Kitamura et al., 2000; Kitamura et al., 2002), it may not be possible to distinguish if $\beta^{\prime} X+v_{i}$ in fact represents Hägerstrand's strict definition of the prism constraints. More plainly, if one believes a particular point in timespace is a vertex of his prism, then he is bound by his belief rather than actual constraints. Therefore, he may believe that his morning commute cannot begin before a certain time but he is not actually forced to leave at that time; in reality, his constraints may allow him to leave a bit earlier than he believes is possible.

In order to reduce the possibility of this, all models estimated were done so with empirical data. The models were estimated irrespective of the subjects' understanding of time-space and/or time constraints. As this study is not concerned with the ambiguity of this, it was assumed that $\beta^{\prime} X+v_{i}$ in corresponds to the vertices of the time-space prisms.

Generally, it is assumed that the arrival time at work (morning terminal vertex) and the evening departure time from work (evening origin vertex) are strictly determined by the employer and other related factors. Due to this, these vertices are least likely to be affected by an individual's or household's attributes. However, the departure time from home (morning origin vertex) and arrival time at home (evening terminal vertex) are not constrained by these same factors. Therefore, these vertices are clearly more influenced 
by an individual's or household's attributes. While there are many other methods which can be used to conduct similar analyses, the major benefit of stochastic frontier analysis is that it easily enables the user to consider the effect of time and the physical environment simultaneously. This ability to consider both of these, set this type of analysis apart from most other methods currently in use.

\subsection{METHODS}

Stochastic frontier models, as shown above, will be employed in this thesis. In this application, the trip observed starting/ending time will correspond to the dependent variable $\left(\mathrm{Y}_{\mathrm{i}}\right)$ and the participants' individual attributes will be the independent variables $\left(\mathrm{X}_{\mathrm{i}}\right)$; this satisfies equation 1 and 2. All modeling conducted for this thesis will be accomplished through R's “frontier" package (Coelli and Henningsen, 2013).

When the Stochastic Frontier package (frontier) is used within the R environment, the packages estimates $\sigma^{2}$ and $\gamma$. Here $\sigma^{2}=\sigma_{u}^{2}+\sigma_{v}^{2}$, where $\sigma_{u}^{2}$ is the scale parameter of the inefficiency term and $\sigma_{v}^{2}$ is the variance parameter of the noise term; $\gamma=\sigma_{u}^{2} / \sigma^{2}$. This $\gamma$ parameter lies between zero and one and enables drawing important conclusions about the inefficiency term $u$ and noise term $v$. For example, when $\gamma=0$ the inefficiency term is irrelevant and the model's results the same as an ordinary east squares model. When $\gamma=1$ the noise term is irrelevant; all deviations from the frontier can be explained by technical inefficiency. As $\sigma_{u}^{2}$ is not equal to the variance of the inefficiency term, $\gamma$ cannot be assumed to be the proportion of the total variance due to inefficiency. Rather, the variance of the inefficiency term $u$ is 
$\operatorname{Var}(u)=\sigma_{u}^{2}\left[1-\frac{\frac{\mu}{\sigma_{u}} \phi\left(\frac{\mu}{\sigma_{u}}\right)}{\Phi\left(\frac{\mu}{\sigma_{u}}\right)}-\left(\frac{\frac{\mu}{\sigma_{u}} \phi\left(\frac{\mu}{\sigma_{u}}\right)}{\Phi\left(\frac{\mu}{\sigma_{u}}\right)}\right)^{2}\right]$

where,

$\Phi=$ cumulative distribution function

$\phi=$ probability density function of the standard normal distribution

When the inefficiency term follows a positive half-normal distribution and $\mu=0$, equation (10) reduces to equation 10.

$\operatorname{Var}(u)=\sigma_{u}^{2}\left[1-(2 \phi(0))^{2}\right]$

From this, it is possible to estimate the total variance is due to inefficiency as the proportion of the total variance is equal $(\operatorname{Var}(u) /(\operatorname{Var}(u)+\operatorname{Var}(v)))$ (Henningsen, 2014). 


\section{CHAPTER 4. DATASET AND SAMPLE CHARACTERISTICS}

A large dataset was provided for the author's use when conducting this research. From this large sample, the author retained only what was needed and then proceeded to process the data for its use in modelling. This chapter will discuss the large dataset, the refined data used for this thesis, and the sample's characteristics.

\subsection{DATASET DESCRIPTION}

The New York Metropolitan Transportation Council (NYMTC) and the North Jersey Transportation Planning Authority (NJTPA) co-sponsored the 2010-2011 Regional Household Travel Survey (RHTS). This survey collected demographic characteristics and travel behavior of the residents of 28 counties from New York, New Jersey, and Connecticut. Ultimately, this dataset was collected in order to update NYMTC's travel demand model and the New York Best Practice Model (NYBPM). More specifically, this included updating the regional and state travel demand model in order to better provide for the travel needs of the region.

The dataset was comprised of 43,558 participants from 18,965 households. During the data collection, the households recorded 143,925 linked trips. A sub-sample of 1,930 households provided travel data recorded by wearable global positioning system (GPS) devices. These devices were implemented in order to understand the magnitude and pattern of under-reporting of travel in the diary-based portion of the survey. Further, the goal was to estimate correction factors to be applied to the larger sample.

This massive data collection took place in different stages between September 2010 and November 2011. As in many other Regional Household Travel Surveys 
(RHTS), the 2010-2011 RHTS recruited participants to record their daily travel for an entire day; recruitment took place via telephone. Once a subject household agreed to participate, the household was assigned a particular day in which each member would record all activities. Of the 31,156 recruited households, 18,965 completed travel diaries.

On the physical collection of data, the sample design was scientifically constructed using the industry's standard instrumentation. The Council of American Survey Research Organization's (CASRO) requirements were also met for the written materials use for communication with survey subjects, the toll-free hotline, as well as data collection, processing, and reporting procedures.

The New York Best Practice Model study area covered households from 28 counties in the New York, New Jersey, and the Connecticut metropolitan area. The counties included in this study are shown below and the study area can be seen in Figure 4-1:

1. New York. Bronx, Duchess, Kings, Nassau, New York, Orange, Putnam, Queens, Richmond, Rockland, Suffolk, Westchester

2. New Jersey. Bergen, Essex, Hudson, Hunterdon, Mercer, Middlesex, Monmouth, Morris, Ocean, Passaic, Somerset, Sussex, Union, Warren

3. Connecticut. Fairfield, New Haven 


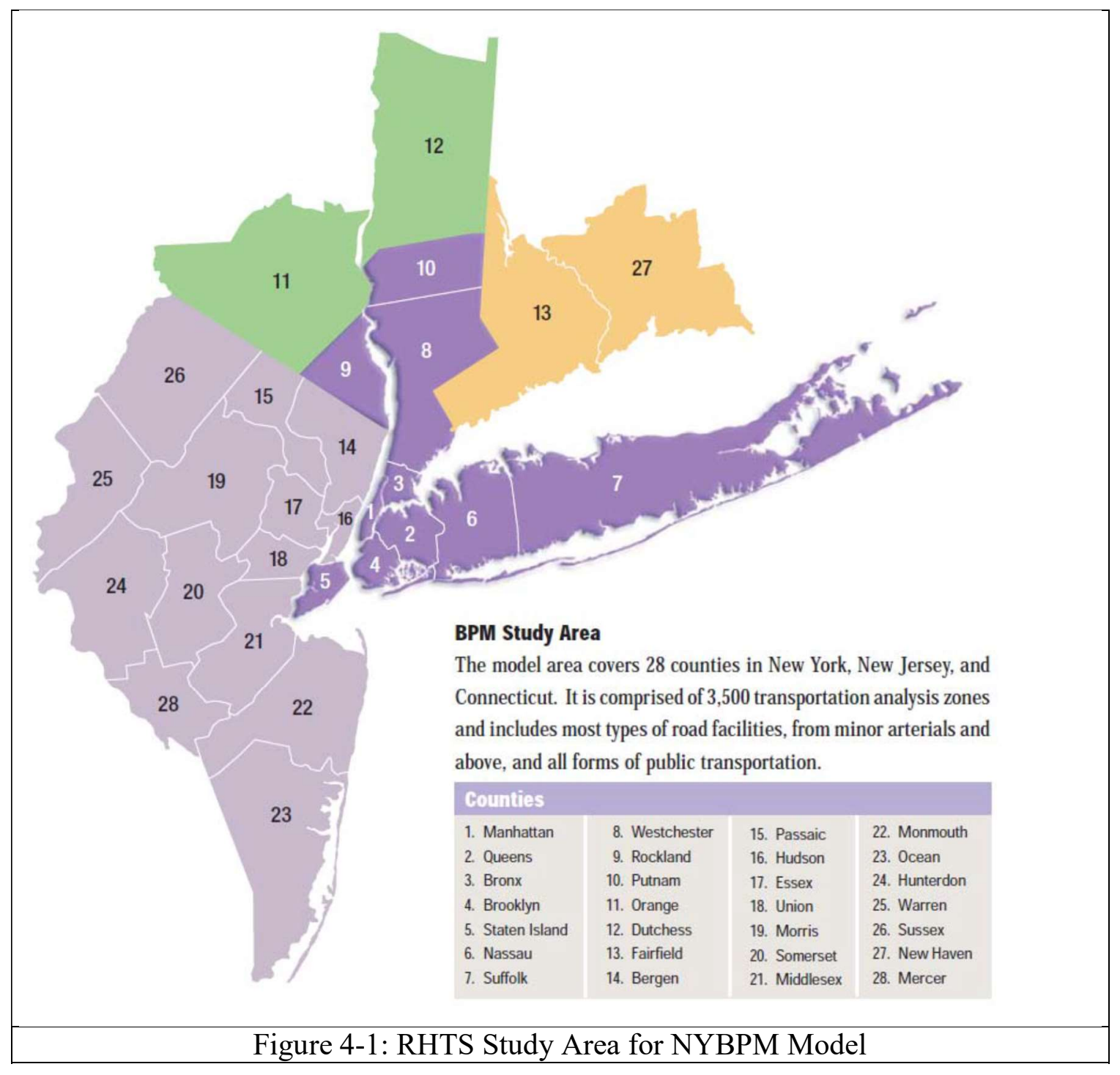

The data set includes the following 6 file types:

1. Household File. This file contained household-related demographic information including household size, number of vehicles, housing type, dominant household language, telephone ownership, and income. The files also contained summary data of each trip such as the number of places visited, number of children in the household, and number of household workers; the location of the household was also found here. The total number of records of households was 18,965. 
2. Person File. This file contained household member-related demographic information including age, gender, relationship status, employment status, student status, disability status, and license ownership. The approximate grade level, mode choice, travel time (if primary mode selected was bicycle), and school location was also contained in this file. There were also worker-related data in this file including industry, occupation, transportation mode, travel time to work, quantity and location of work days, work start/end time, employer-related transportation benefits, compressed work week information, and the location of the workplace in this file. A total of 43,558 people was contained in this file.

3. Vehicle File. This file contained information related to the household vehicles, if present; this contained the vehicle's year, make, model, body type, fuel type, and E-ZPass subscription status. There were 29,043 vehicles in this file.

4. Place File. This file contained information related to all the places visited; data was only recorded by all members of the household during the specified 24-hour period. Included in this file was the location type, activity type, mode choice, and presence of other household members. Detailed location information including name, address, city, and geocoding information for all 231,715 places was also contained here.

5. Unlinked Trips File. In this file, each segment of a trip is considered individual; the mode used was also recorded. The total number of entries was 188,199 trip segments. 
6. Linked Trips File. In this file, trips were aggregated to represent one trip rather than a series of trip segments. As before the mode was recorded for all 143,925 linked trips.

This RHTS was conducted with planning in mind and as such was design to be similar to other available datasets, while also differing from them. By doing this, the survey can both be supplemented and serve a supplement to other datasets. Further, this enables verification of the data via cross-validation techniques.

\subsection{DATA PREPARATION}

For the work presented in this thesis, the aforementioned sample was reduced to include only those participants that were workers. These workers were then separated into four classes of telecommuters; this stratification follows the trend set by Asgari (2015). The four groups of telecommuters were separated based on the subject's participation in telecommuting and additional daily commutes.

Primary, ancillary, and passive telecommuters were all identified by participation in telecommuting, but their level of involvement varied; non-telecommuters did not participate in telecommuting. Primary telecommuters differed from the other telecommuters because they regularly participated in telecommuting and had no additional daily commuting. Conversely, ancillary and passive telecommuters did have additional daily commuting. The major different between ancillary and passive telecommuters was that ancillary were regular telecommuters while passive 
telecommuters were non-regular telecommuters. Applying these definitions, the sample size of each telecommuting group was as follows:

- Primary Telecommuter: 1,751 participants (3.93\%)

- Ancillary Telecommuter: 797 participants (1.79\%)

- Passive Telecommuter: 1,143 participants (2.57\%)

- Non-Telecommuter: 40,835 participants (91.71\%)

- Total Sample: 44,526 participants

Table 4-1: Telecommuting Form Definitions

\begin{tabular}{|lc|c|c|}
\cline { 2 - 4 } \multicolumn{1}{c|}{} & $\begin{array}{c}\text { Any form of } \\
\text { telecommuting }\end{array}$ & $\begin{array}{c}\text { Frequency of } \\
\text { telecommuting }\end{array}$ & $\begin{array}{c}\text { Additional daily } \\
\text { commuting }\end{array}$ \\
\hline $\begin{array}{l}\text { Primary } \\
\text { Telecommuter }\end{array}$ & Yes & Regular & No \\
\hline $\begin{array}{l}\text { Ancillary } \\
\text { Telecommuter }\end{array}$ & Yes & Regular & Yes \\
\hline $\begin{array}{l}\text { Passive } \\
\text { Telecommuter }\end{array}$ & Yes & Non-Regular & Yes \\
\hline $\begin{array}{l}\text { Non- } \\
\text { Telecommuter }\end{array}$ & No & N/A & N/A \\
\hline
\end{tabular}

As previously mentioned, all people are bound by constraints. This principle, along with engineering judgment, was used to classify activities into mandatory and nonmandatory. For this thesis, the author concluded that all activities which could not be rescheduled and/or impart a concrete time-space constraint were mandatory. An example of a mandatory activity is work, whether it takes place in an office or at home. The complete list of activities and their classification can be found in the following table (Table 4-2). 
Table 4-2: Mandatory/Non-Mandatory Activities

\begin{tabular}{|l|l|}
\hline Activity & Classification \\
\hline Working at Home (For Pay or Volunteer) & Mandatory \\
\hline Dropped off Passenger from Car & Mandatory \\
\hline Picked up Passenger from Car & Mandatory \\
\hline Work/Doing my Job & Mandatory \\
\hline Other Work-Related Activities at Work & Mandatory \\
\hline Volunteer Work/Activities & Mandatory \\
\hline Volunteer Work/Activities & Mandatory \\
\hline All Other Activities at School & Mandatory \\
\hline Work-Related & Mandatory \\
\hline Airport - Business & Mandatory \\
\hline Airport - Personal & Mandatory \\
\hline Eat Meal Out at Restaurant/Restaurant/Dinner & Non-Mandatory \\
\hline Shopping (Online, Catalog or by Phone) & Non-Mandatory \\
\hline Any Other Activities at Home & Non-Mandatory \\
\hline Change Travel Mode/Transfer & Non-Mandatory \\
\hline Get Gas & Non-Mandatory \\
\hline Drive Through (ATM, Bank, Fast Food, etc.) & Non-Mandatory \\
\hline Service Private Vehicle & Non-Mandatory \\
\hline Grocery/Food Shopping & Non-Mandatory \\
\hline Shopping for Major Purchases or Specialty Items & Non-Mandatory \\
\hline Household Errands & Non-Mandatory \\
\hline Personal Business & Non-Mandatory \\
\hline Health Care & Non-Mandatory \\
\hline Civic or Religious Activities & Non-Mandatory \\
\hline Outdoor Recreation & Non-Mandatory \\
\hline Indoor Recreation & Non-Mandatory \\
\hline Entertainment & Non-Mandatory \\
\hline Social/Visit Friends/Relatives & Non-Mandatory \\
\hline Loop Trip & Non-Mandatory \\
\hline Other (Specify) & Non-Mandatory \\
\hline & \\
\hline & \\
\hline & Pand \\
\hline
\end{tabular}

Descriptive statistics of the data used for this thesis were explored and can be seen below (Table 4-3). All values which carry the percent symbol represent a percent, all other values represent the average value; a discussion of this table is presented in the following section. 
Table 4-3: Descriptive Statistics

\begin{tabular}{|c|c|c|c|c|c|c|}
\hline & \multirow[b]{2}{*}{ Primary } & \multirow[b]{2}{*}{ Ancillary } & \multirow[b]{2}{*}{ Passive } & \multirow[b]{2}{*}{$\begin{array}{l}\text { Non- } \\
\text { Tele. } \\
\end{array}$} & \multirow[b]{2}{*}{ Total } \\
\hline & & & & & & \\
\hline & Age & 49.13 & 48.92 & 47.46 & 46.67 & 46.82 \\
\hline & Male & $46.60 \%$ & $54.83 \%$ & $46.89 \%$ & $46.95 \%$ & $47.08 \%$ \\
\hline & Driver's License & $96.29 \%$ & $94.60 \%$ & $97.81 \%$ & $94.40 \%$ & $94.56 \%$ \\
\hline \multirow{7}{*}{ Race } & White & $88.12 \%$ & $86.07 \%$ & $81.80 \%$ & $79.49 \%$ & $80.00 \%$ \\
\hline & African American & $3.14 \%$ & $5.02 \%$ & $5.07 \%$ & $7.90 \%$ & $7.59 \%$ \\
\hline & Asian & $4.91 \%$ & $7.53 \%$ & $6.12 \%$ & $5.81 \%$ & $5.81 \%$ \\
\hline & Native American, Native Alaskan & $0.00 \%$ & $0.00 \%$ & $0.44 \%$ & $0.24 \%$ & $0.23 \%$ \\
\hline & Pacific Islander & $0.00 \%$ & $0.00 \%$ & $0.00 \%$ & $0.12 \%$ & $0.11 \%$ \\
\hline & Multiracial & $0.51 \%$ & $0.00 \%$ & $1.57 \%$ & $1.64 \%$ & $1.57 \%$ \\
\hline & Hispanic, Mexican & $3.31 \%$ & $1.38 \%$ & $4.99 \%$ & $4.80 \%$ & $4.69 \%$ \\
\hline \multirow{24}{*}{$\begin{array}{l}\text { Household } \\
\text { Structure }\end{array}$} & Household Size & 2.78 & 2.43 & 2.86 & 2.75 & 2.75 \\
\hline & Number of Household Workers & 1.81 & 1.70 & 1.82 & 1.82 & 1.82 \\
\hline & Number of Household Students & 0.89 & 0.70 & 0.92 & 0.77 & 0.78 \\
\hline & Number of Household Children & 0.69 & 0.46 & 0.65 & 0.55 & 0.56 \\
\hline & Number of Household License Holders & 1.95 & 1.75 & 2.00 & 1.97 & 1.97 \\
\hline & Number of Household Vehicles & 2.01 & 1.83 & 1.94 & 1.95 & 1.95 \\
\hline & No. Persons age 0 to $5 \mathrm{yrs}$. in the house & 0.14 & 0.10 & 0.15 & 0.16 & 0.16 \\
\hline & No. Persons age 6 to 11 yrs. in the house & 0.30 & 0.18 & 0.24 & 0.21 & 0.21 \\
\hline & No. Persons age 12 to $15 \mathrm{yrs}$. in the house & 0.23 & 0.19 & 0.26 & 0.17 & 0.18 \\
\hline & No. Persons age 16 to $17 \mathrm{yrs}$. in the house & 0.08 & 0.11 & 0.12 & 0.08 & 0.08 \\
\hline & No. Persons age 18 to 24 yrs. in the house & 0.14 & 0.06 & 0.17 & 0.19 & 0.19 \\
\hline & No. Persons age 25 to 34 yrs. in the house & 0.17 & 0.26 & 0.24 & 0.29 & 0.28 \\
\hline & No. Persons age 35 to 49 yrs. in the house & 0.68 & 0.64 & 0.75 & 0.64 & 0.65 \\
\hline & No. Persons age 50 to 64 yrs. in the house & 0.87 & 0.74 & 0.75 & 0.84 & 0.84 \\
\hline & No. Persons age 65 to 79 yrs. in the house & 0.12 & 0.12 & 0.14 & 0.12 & 0.12 \\
\hline & No. Persons age 80 and older in the house & 0.01 & 0.03 & 0.05 & 0.03 & 0.03 \\
\hline & 1 Adult, No Kids & $13.42 \%$ & $21.96 \%$ & $15.22 \%$ & $15.44 \%$ & $15.47 \%$ \\
\hline & 2+ Adult, No Kids & $45.29 \%$ & $52.20 \%$ & $49.52 \%$ & $52.09 \%$ & $51.76 \%$ \\
\hline & 1 Adult, Youngest Kids 16-19 & $0.00 \%$ & $0.00 \%$ & $0.00 \%$ & $0.00 \%$ & $0.00 \%$ \\
\hline & 2+ Adult, Youngest Kids 16-19 & $0.00 \%$ & $0.00 \%$ & $0.00 \%$ & $0.00 \%$ & $0.00 \%$ \\
\hline & 1 Adult, Youngest Kids 5-16 & $2.23 \%$ & $0.50 \%$ & $0.17 \%$ & $1.54 \%$ & $1.52 \%$ \\
\hline & 2+ Adult, Youngest Kids 5-16 & $29.53 \%$ & $20.45 \%$ & $26.60 \%$ & $19.88 \%$ & $20.44 \%$ \\
\hline & 1 Adult, Youngest Kids 0-5 & $0.00 \%$ & $0.25 \%$ & $0.00 \%$ & $0.26 \%$ & $0.24 \%$ \\
\hline & $2+$ Adult, Youngest Kids $0-5$ & $9.54 \%$ & $4.64 \%$ & $8.49 \%$ & $10.79 \%$ & $10.57 \%$ \\
\hline \multirow{4}{*}{ Income } & Low income: $<\$ 50,000$ & $11.88 \%$ & $12.92 \%$ & $17.59 \%$ & $15.81 \%$ & $15.65 \%$ \\
\hline & Medium income: $\$ 50,000-\$ 150,000$ & $53.63 \%$ & $56.21 \%$ & $65.53 \%$ & $58.36 \%$ & $58.32 \%$ \\
\hline & High income: $<\$ 150,000$ & $26.90 \%$ & $24.22 \%$ & $13.91 \%$ & $21.45 \%$ & $21.52 \%$ \\
\hline & Other/unknown & $7.60 \%$ & $6.65 \%$ & $2.97 \%$ & $4.39 \%$ & $4.52 \%$ \\
\hline \multirow{5}{*}{$\begin{array}{c}\text { Work } \\
\text { Start } \\
\text { Time } \\
\text { Variability }\end{array}$} & Start Time Cannot Vary & $24.56 \%$ & $18.95 \%$ & $48.03 \%$ & $48.11 \%$ & $46.66 \%$ \\
\hline & Within 15 Minutes or Less & $6.17 \%$ & $6.78 \%$ & $9.97 \%$ & $9.93 \%$ & $9.73 \%$ \\
\hline & 16 to 30 Minutes & $9.94 \%$ & $8.66 \%$ & $9.97 \%$ & $10.94 \%$ & $10.83 \%$ \\
\hline & 31 to 60 Minutes & $16.50 \%$ & $19.95 \%$ & $11.99 \%$ & $11.04 \%$ & $11.44 \%$ \\
\hline & More than 1 Hour & $42.83 \%$ & $45.67 \%$ & $20.03 \%$ & $19.99 \%$ & $21.34 \%$ \\
\hline \multirow{5}{*}{$\begin{array}{c}\text { Work } \\
\text { End } \\
\text { Time } \\
\text { Variability }\end{array}$} & End Time Cannot Vary & $16.56 \%$ & $15.93 \%$ & $31.58 \%$ & $33.99 \%$ & $32.92 \%$ \\
\hline & Within 15 Minutes or Less & $4.51 \%$ & $2.38 \%$ & $8.92 \%$ & $7.14 \%$ & $7.00 \%$ \\
\hline & 16 to 30 Minutes & $8.45 \%$ & $7.65 \%$ & $12.25 \%$ & $10.04 \%$ & $9.99 \%$ \\
\hline & 31 to 60 Minutes & $20.27 \%$ & $14.30 \%$ & $17.06 \%$ & $14.85 \%$ & $15.11 \%$ \\
\hline & More than 1 Hour & $50.20 \%$ & $59.72 \%$ & $30.18 \%$ & $33.99 \%$ & $34.99 \%$ \\
\hline
\end{tabular}


Table 4-3: Descriptive Statistics

\begin{tabular}{|c|c|c|c|c|c|c|}
\hline & $\mid$ Primary & Ancillary & Passive & $\begin{array}{l}\text { Non- } \\
\text { Tele. }\end{array}$ & Total \\
\hline \multirow{4}{*}{ Employer } & Private Company & $59.91 \%$ & $68.26 \%$ & $62.64 \%$ & $62.54 \%$ & $62.55 \%$ \\
\hline & Government & $16.85 \%$ & $14.43 \%$ & $23.53 \%$ & $25.76 \%$ & $25.15 \%$ \\
\hline & Non-Profit & $23.24 \%$ & $17.31 \%$ & $13.82 \%$ & $11.69 \%$ & $12.30 \%$ \\
\hline & Self-Employed & $0.00 \%$ & $0.00 \%$ & $0.00 \%$ & $0.00 \%$ & $0.00 \%$ \\
\hline \multirow{4}{*}{ Work Type } & Full-time one job & $60.31 \%$ & $72.02 \%$ & $62.73 \%$ & $76.11 \%$ & $75.07 \%$ \\
\hline & Full-time more than one job & $6.11 \%$ & $11.54 \%$ & $10.67 \%$ & $6.34 \%$ & $6.53 \%$ \\
\hline & Part-time one job & $23.02 \%$ & $10.54 \%$ & $22.13 \%$ & $15.92 \%$ & $16.26 \%$ \\
\hline & Part-time more than one job & $10.57 \%$ & $5.90 \%$ & $4.46 \%$ & $1.63 \%$ & $2.13 \%$ \\
\hline \multirow{23}{*}{ Occupation } & Management & $16.56 \%$ & $11.04 \%$ & $12.07 \%$ & $13.01 \%$ & $13.09 \%$ \\
\hline & Business and Financial Operations & $10.45 \%$ & $7.53 \%$ & $12.34 \%$ & $8.63 \%$ & $8.78 \%$ \\
\hline & Computer and Mathematical & $7.31 \%$ & $7.40 \%$ & $1.14 \%$ & $5.37 \%$ & $5.37 \%$ \\
\hline & Architecture, Engineering & $1.31 \%$ & $1.63 \%$ & $3.85 \%$ & $3.06 \%$ & $2.99 \%$ \\
\hline & Life, Physical, and Social Science & $3.37 \%$ & $2.38 \%$ & $1.92 \%$ & $1.78 \%$ & $1.85 \%$ \\
\hline & Community and Social Services & $3.54 \%$ & $1.88 \%$ & $3.32 \%$ & $3.60 \%$ & $3.56 \%$ \\
\hline & Legal & $1.31 \%$ & $6.02 \%$ & $2.71 \%$ & $3.35 \%$ & $3.30 \%$ \\
\hline & Education, Training, and Library & $22.50 \%$ & $22.08 \%$ & $23.62 \%$ & $16.74 \%$ & $17.24 \%$ \\
\hline & Arts, Design, Entertainment, Sports \& Media & $6.85 \%$ & $4.39 \%$ & $4.37 \%$ & $3.44 \%$ & $3.61 \%$ \\
\hline & Healthcare Practitioners and Technical & $2.34 \%$ & $3.64 \%$ & $3.59 \%$ & $5.17 \%$ & $4.99 \%$ \\
\hline & Healthcare Support & $5.25 \%$ & $6.52 \%$ & $5.69 \%$ & $5.57 \%$ & $5.58 \%$ \\
\hline & Protective Service & $0.11 \%$ & $0.00 \%$ & $0.35 \%$ & $0.78 \%$ & $0.73 \%$ \\
\hline & Food Preparation and Serving Related & $1.03 \%$ & $0.00 \%$ & $1.49 \%$ & $2.35 \%$ & $2.24 \%$ \\
\hline & Building, Grounds Cleaning \&Maintenance & $0.74 \%$ & $0.00 \%$ & $0.17 \%$ & $1.11 \%$ & $1.05 \%$ \\
\hline & Personal Care and Service & $1.14 \%$ & $0.00 \%$ & $2.71 \%$ & $1.75 \%$ & $1.72 \%$ \\
\hline & Sales and Related & $8.34 \%$ & $13.55 \%$ & $7.26 \%$ & $6.78 \%$ & $6.97 \%$ \\
\hline & Office and Administrative Support & $3.60 \%$ & $7.15 \%$ & $6.39 \%$ & $9.17 \%$ & $8.84 \%$ \\
\hline & Farming, Fishing, and Forestry & $0.91 \%$ & $0.00 \%$ & $0.17 \%$ & $0.13 \%$ & $0.16 \%$ \\
\hline & Construction and Extraction & $0.74 \%$ & $0.50 \%$ & $0.96 \%$ & $1.21 \%$ & $1.17 \%$ \\
\hline & Installation, Maintenance, and Repair & $1.31 \%$ & $1.76 \%$ & $2.45 \%$ & $2.54 \%$ & $2.48 \%$ \\
\hline & Production & $0.00 \%$ & $1.25 \%$ & $0.79 \%$ & $1.15 \%$ & $1.10 \%$ \\
\hline & Transportation and Material Moving & $1.26 \%$ & $0.00 \%$ & $2.62 \%$ & $3.20 \%$ & $3.05 \%$ \\
\hline & Military Specific & $0.00 \%$ & $1.25 \%$ & $0.00 \%$ & $0.12 \%$ & $0.13 \%$ \\
\hline \multirow{3}{*}{$\begin{array}{c}\text { Compressed } \\
\text { Work } \\
\text { Schedule }\end{array}$} & Type 1: $4 / 40$ & $3.54 \%$ & $7.40 \%$ & $4.55 \%$ & $3.31 \%$ & $3.42 \%$ \\
\hline & Type 2: $9 / 80$ & $0.29 \%$ & $2.76 \%$ & $0.44 \%$ & $1.31 \%$ & $1.27 \%$ \\
\hline & Type 3: No compressed schedule & $96.17 \%$ & $89.84 \%$ & $95.01 \%$ & $95.38 \%$ & $95.31 \%$ \\
\hline
\end{tabular}

In order to produce the distance-related figures (Figure 4-2 and Figure 4-3), the Law of Spherical Cosines was used to calculate the distance given the coordinates provided in the original dataset. While this does not account for trip-chaining, this calculation was primarily done to explore the relationship between the different telecommuters and the distance travelled. 
As is commonplace in this type of study, the data collection began at 3:00:00 AM and ended at 2:59:99 AM the following day. Based on the region and the observed trends, the day was split into six time periods: Before AM Peak, AM Peak, Midday, PM Peak, Evening, and Midnight. These time periods, or Time-of-Day, are shown in the following table (Table 4-4).

Table 4-4: Time-of-Day Definition

\begin{tabular}{|l|r|r|}
\hline \multicolumn{1}{|c|}{ Time-of-Day } & \multicolumn{1}{c|}{ Start } & \multicolumn{1}{c|}{ End } \\
\hline Before AM Peak & $3: 00$ AM & $5: 59$ AM \\
\hline AM Peak & $6: 00$ AM & $9: 30$ AM \\
\hline Midday & $9: 31$ AM & $3: 59$ PM \\
\hline PM Peak & $4: 00$ PM & $7: 30$ PM \\
\hline Evening & $7: 31$ PM & $12: 00$ AM \\
\hline Midnight & $12: 01$ AM & $2: 59$ AM \\
\hline
\end{tabular}

\subsection{SAMPLE CHARACTERISTICS}

From Table 4-3 it was clear that across all workers the average age was relatively constant (approximately 47 years of age), the majority of participants identified as White, and fell into the medium income bracket. In terms of household structure, all groups had a similar household size (2.75), number of workers (1.82), students (0.78), children (.56), license holders (1.97), and household vehicles (1.95). However, all groups are most likely to be a household of two adults and zero children, followed by a household of two adults with the youngest child being 5-16 years of age, then by a household of one adult and zero children.

As was expected, the majority of Passive and Non-Telecommuters could not vary their work start time, while the majority of Primary and Ancillary Telecommuters could vary their start time by over an hour; similar trend was noted for Primary and Ancillary 
Telecommuters in respect to work end time. However, Passive and Non-Telecommuters were equally likely to not vary their work end time at all and very their work end time by over an hour. It is worth noting that if Passive and Non-Telecommuters were unlikely to vary their start time and likely to vary their end time, this should be reflected in the total hours worked each week, but such was not the case in this sample; the average total weekly working hours for these two groups was 37.16 and 39.42, respectively. Primary Telecommuters tended to work the least (35.59) and Ancillary Telecommuters the most (44.57).

Most participants identified as being a full-time employee with one job, employed by a private company, and did not work any kind of compressed schedule. When the participants' occupations were explored, it was clear that the lion's share was identified as "Education, Training, And Library Occupations" followed closely by "Management Occupations" then "Office and Administrative Support Occupations" and "Business and Financial Operations Occupations". Contrary to some of the literature concerning telecommuting, the Primary Telecommuters had the shortest, while Ancillary Telecommuters had the longest commute time.

This distance, for mandatory and non-mandatory activities, of each participants' trips was calculated and split into the intervals shown in Figure 4-2. From this figure, it is possible to see some potential relationships between the distance travelled by each group. It was demonstrated that as the frequency of telecommuting decreased, the portion of trips less than 1 mile generally decreased; a similar trend was also noted for trips that were 1-5 miles. Conversely, as the frequency of telecommuting decreased, the portion of trips 5-10 miles and 10-20 miles generally increased. Interestingly, this mirrors some of 
the result of previous studies which demonstrated a relationship between telecommuting and the corresponding reduction in the activity space (Pendyala et al., 1991). No trend was noted for trips 20 miles or more.

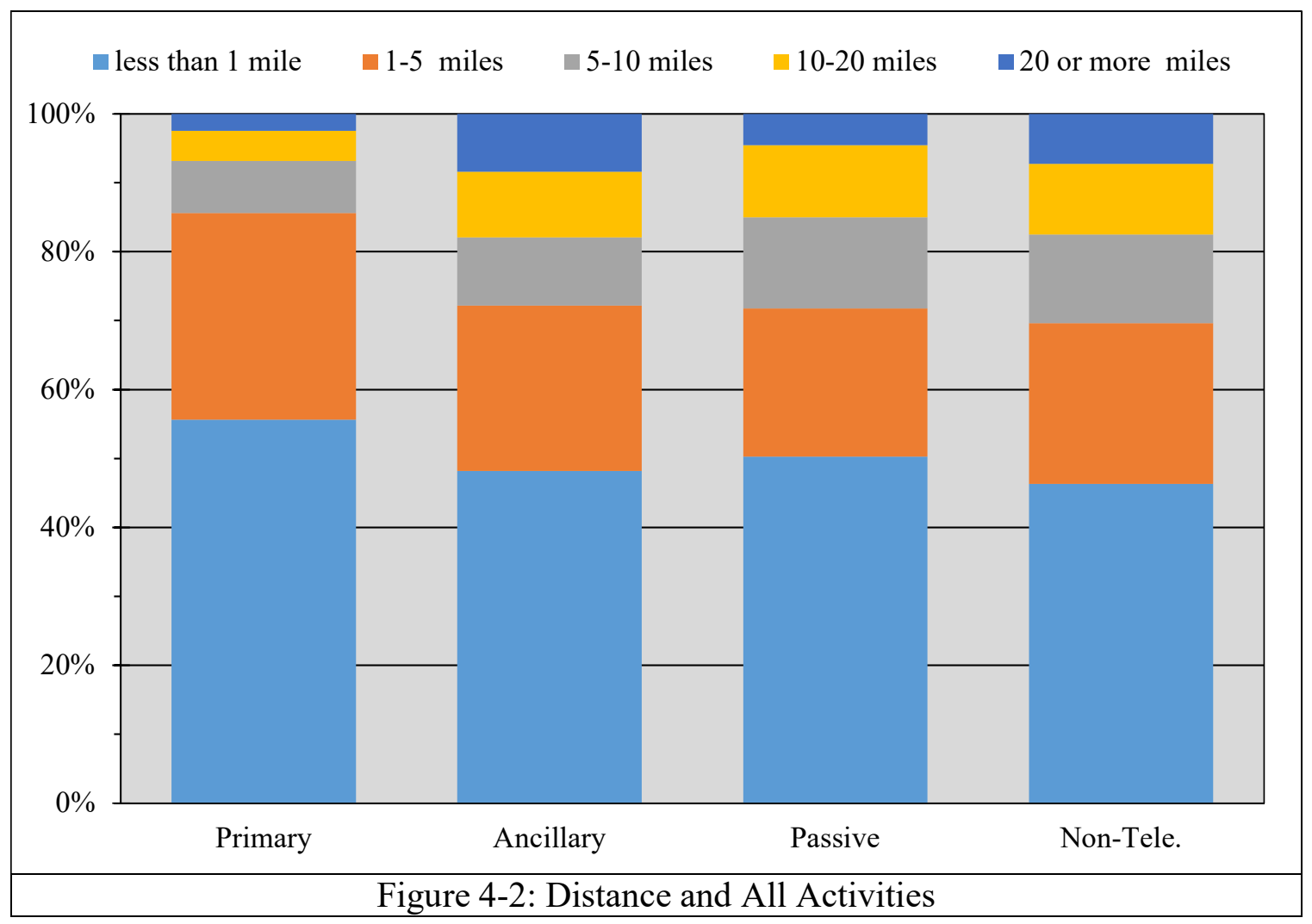

When these trips were separated into mandatory and non-mandatory, as previously defined, more interesting trends were noted. As shown in Figure 4-3a, a decrease in telecommuting for mandatory activities corresponded to an increased in trips less than 1 mile, 1-5 miles, 5-10 miles, and 10-20 miles. No trend was noted for trips 20 miles or more.

Figure 4-3b illustrated that as trips less than 1 mile increased as telecommuting decreased for non-mandatory activities. Conversely, trips that were 1-5 miles and 5-10 
miles decreased as telecommuting decreased for non-mandatory activities. Trips that were 10-20 miles and greater than 20 miles were generally constant as telecommuting decreased for non-mandatory activities.

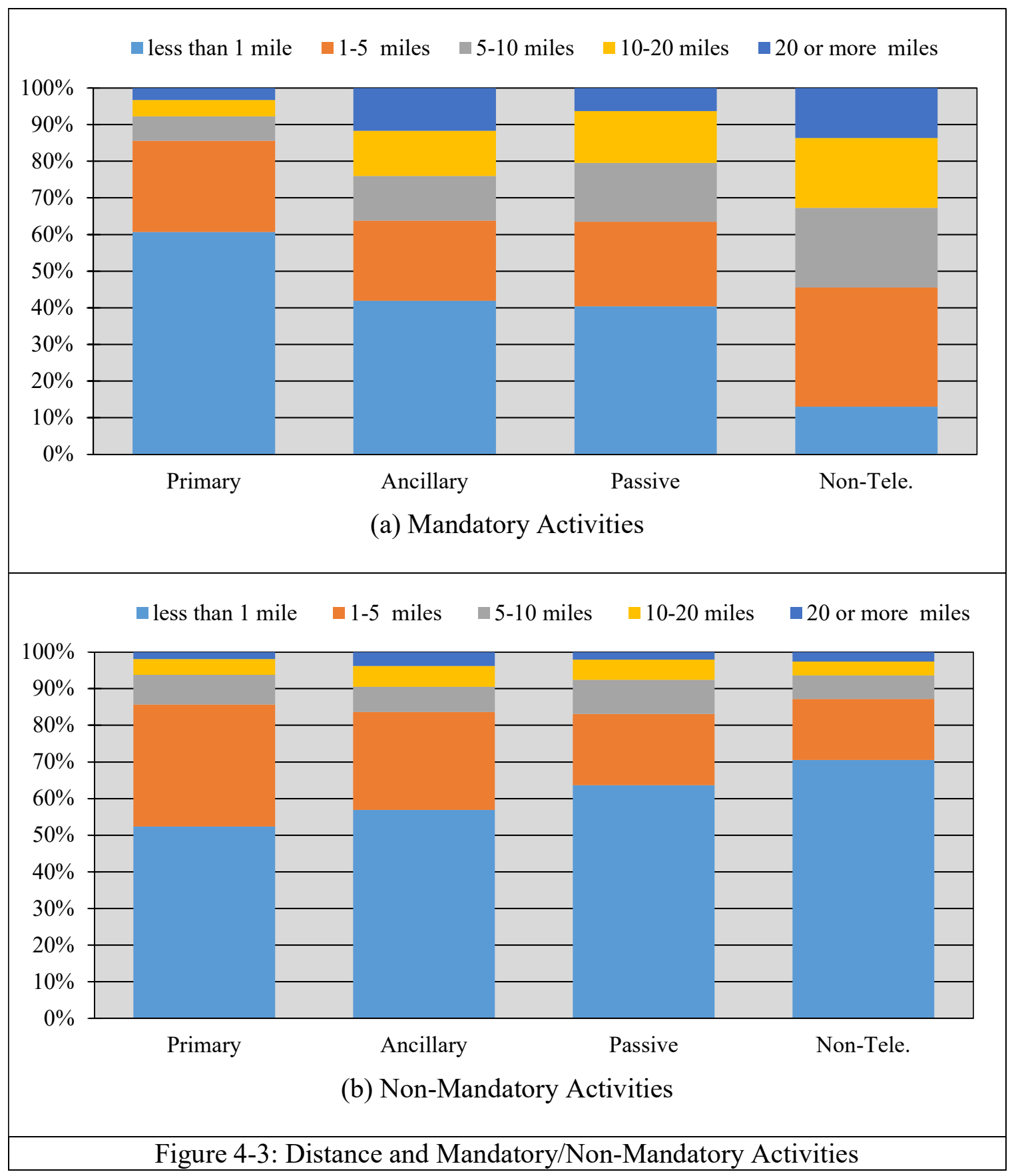


Figure 4-4 and Figure 4-5 illustrate the daily distribution of mandatory and nonmandatory activities for all groups, respectively. In these figures, the x-axis shows the time of day in minutes. For example, 0 minutes corresponds to 12:00 AM and 300 minutes corresponds to 5:00 AM. In this format, 1439 minutes corresponds to 11:59 PM, therefore any time after this corresponds to data from the next day. This can be explained as the data was collected from 3:00 AM of the first day to 3:00 AM of the next day.

All groups showed a spike in the portion of mandatory trips during the AM Peak period as well as a smaller spike during the PM Peak, as shown in Figure 4-4. However, Ancillary (b), Passive (c), and Non-Telecommuters (d) each had a spike which accounted for approximately $3 \%$ of all mandatory trips during the AM Peak period. Moreover, NonTelecommuters had the highest concentration of mandatory trips during this time. Interestingly, Ancillary, Passive, and Non-Telecommuters all had a spike during the PM Peak period, while the peak for Primary Telecommuters (a) was shift slightly early in the day. Also, the mandatory trips for Primary Telecommuters (a) tended to be more evenly distributed throughout the day when compared to the other groups. 


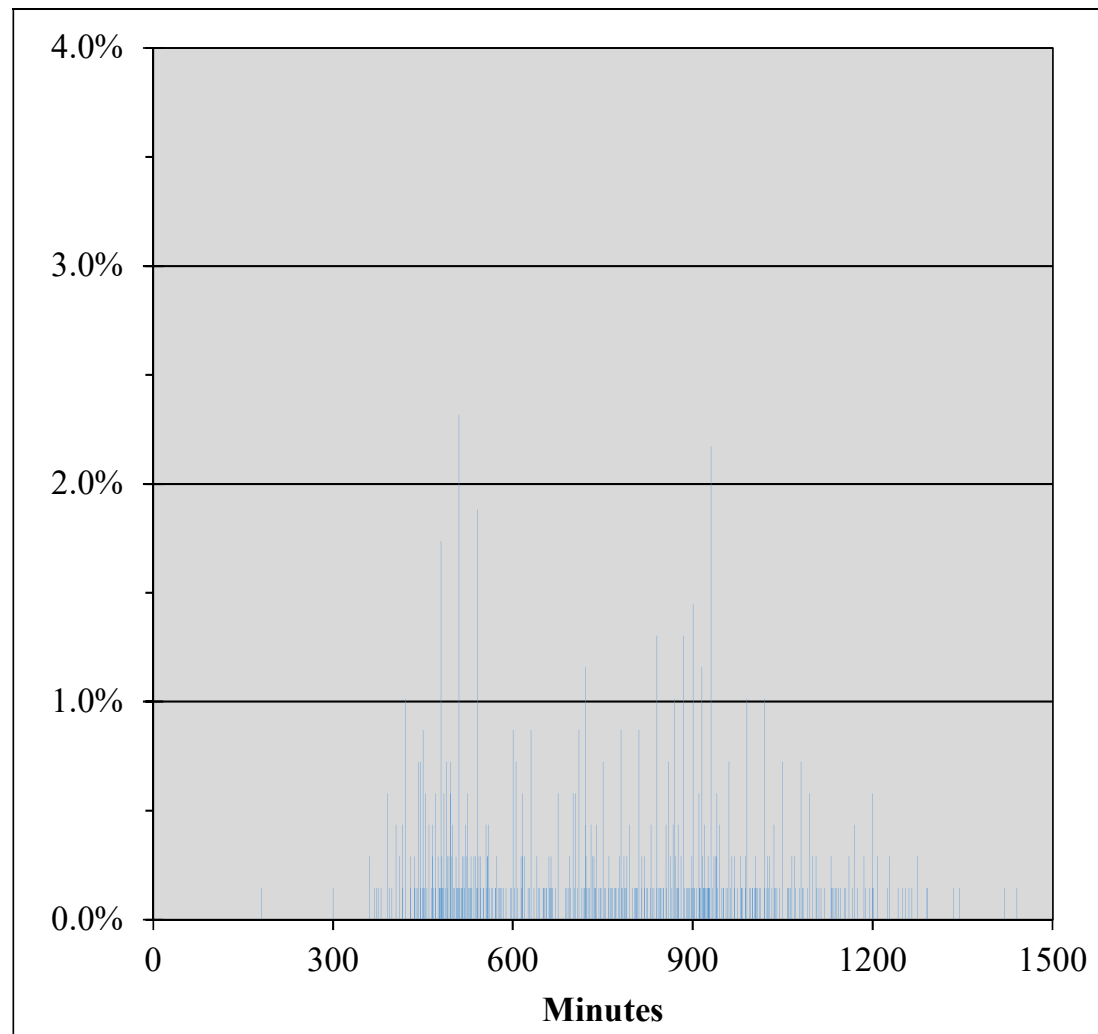

(a) Primary Telecommuters

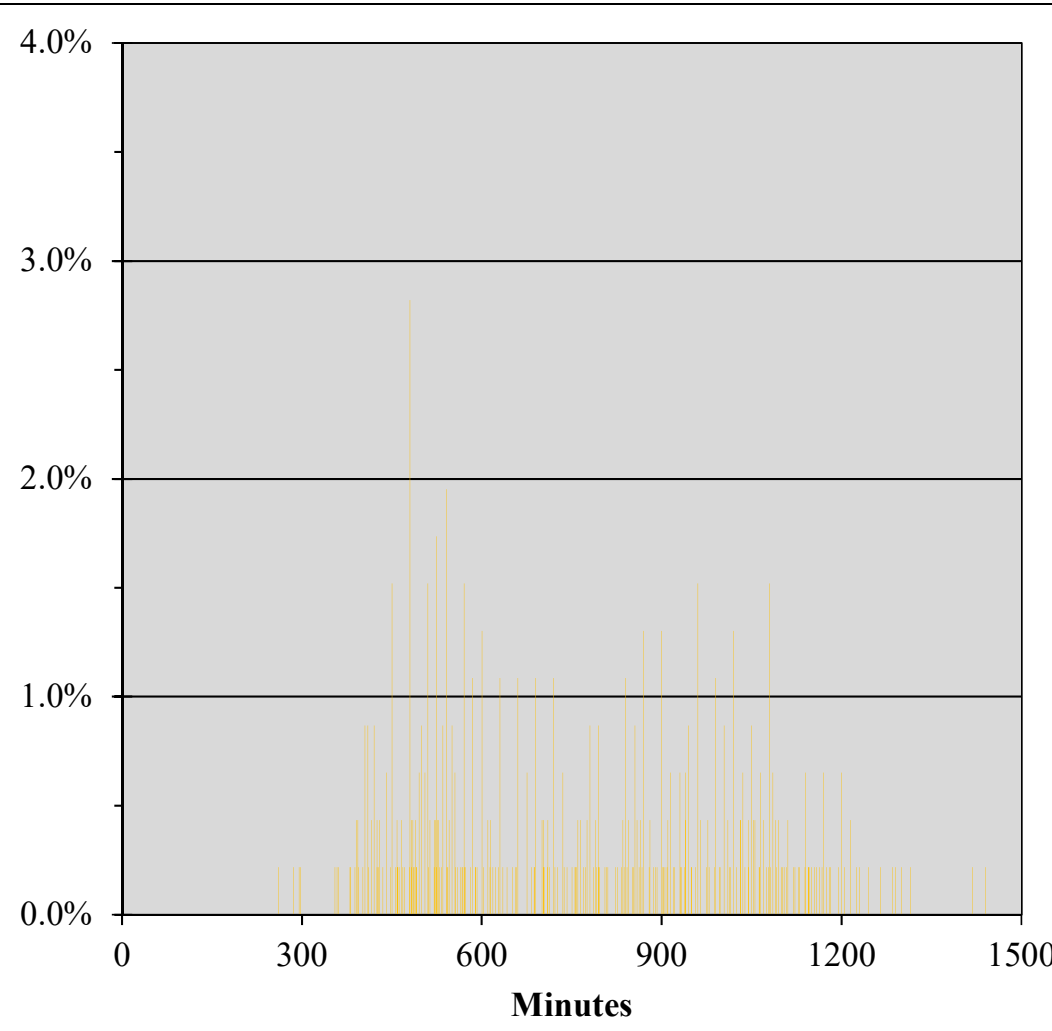

(b) Ancillary Telecommuters

Figure 4-4: Time versus Mandatory Activities 


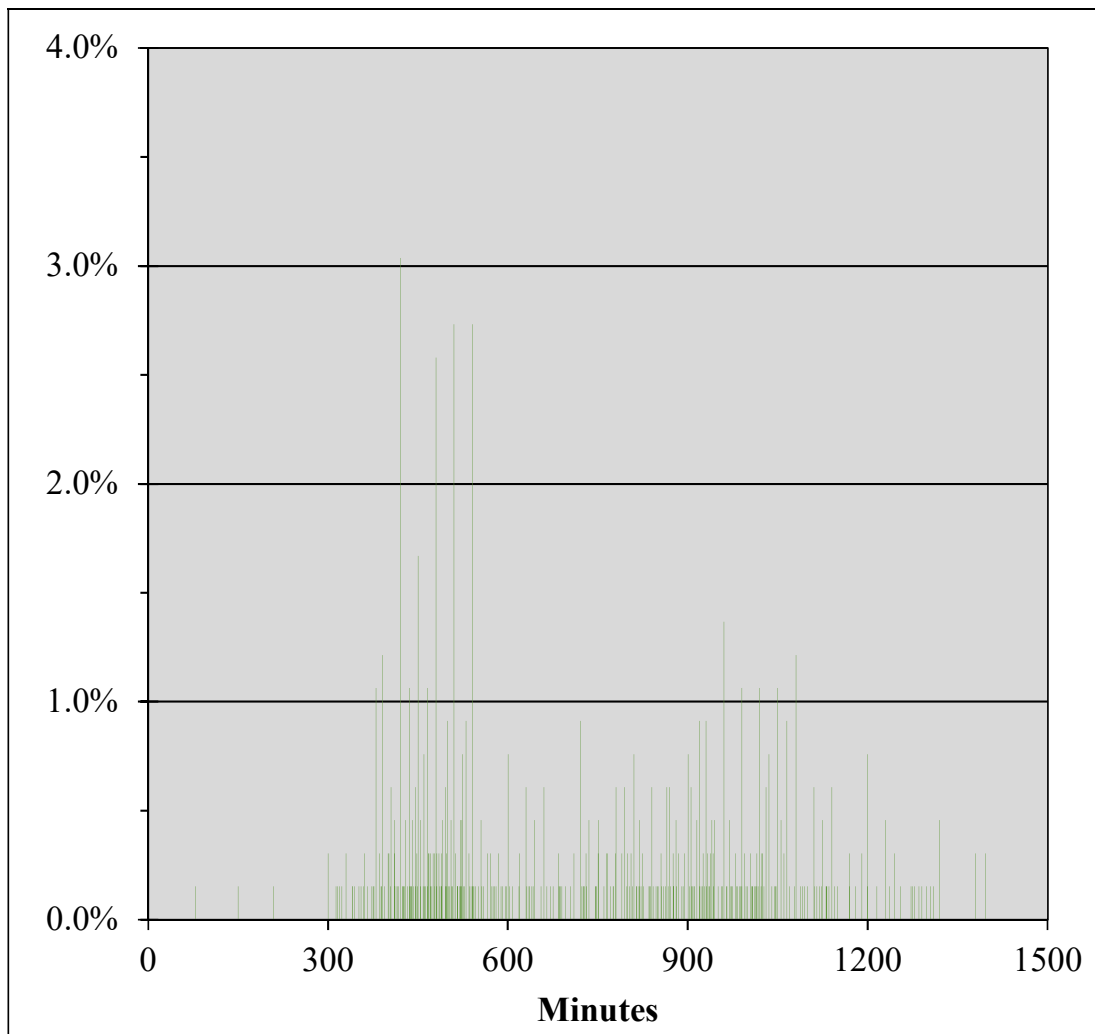

(c) Passive Telecommuters

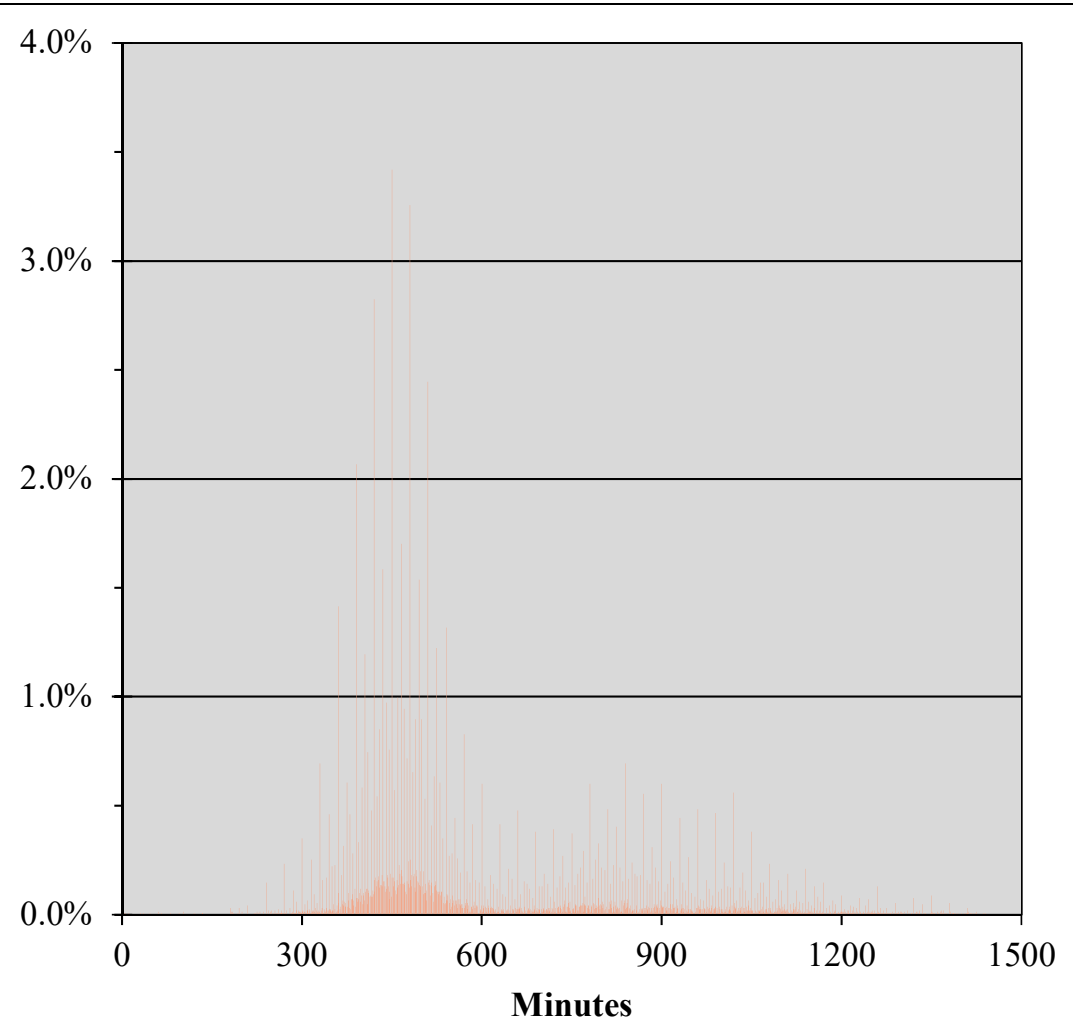

(d) Non-Telecommuters

Figure 4-4: Time versus Mandatory Activities 
Similar patterns were observed in Figure 4-5. In this figure, Primary Telecommuters (a) distributed non-mandatory trips more evenly throughout the day. Also, this figure shows that all groups tended to engage in non-mandatory activities in the afternoon or evening times. One explanation for this could be that all groups choose to do non-mandatory activities, such as shopping and going out to eat, after work. 


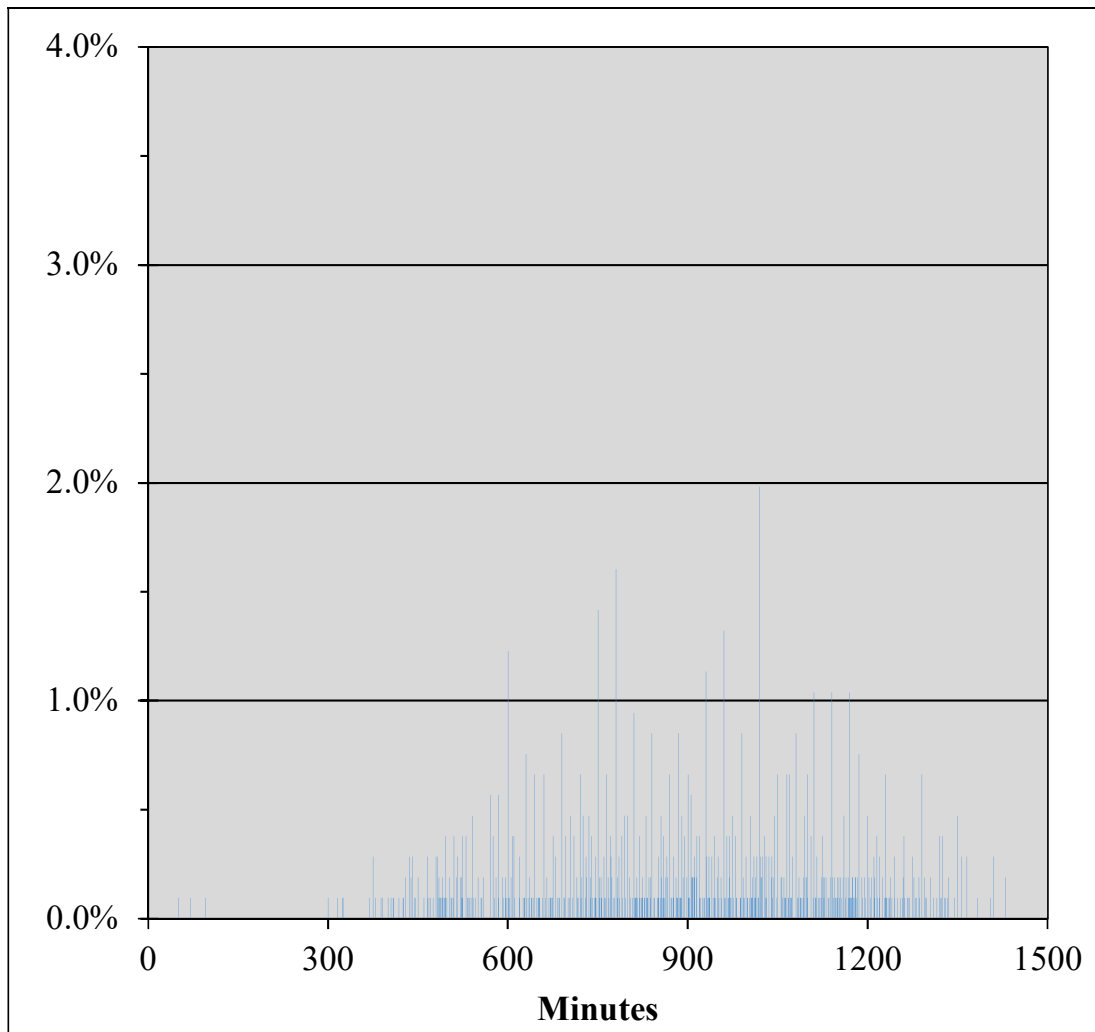

(a) Primary Telecommuters

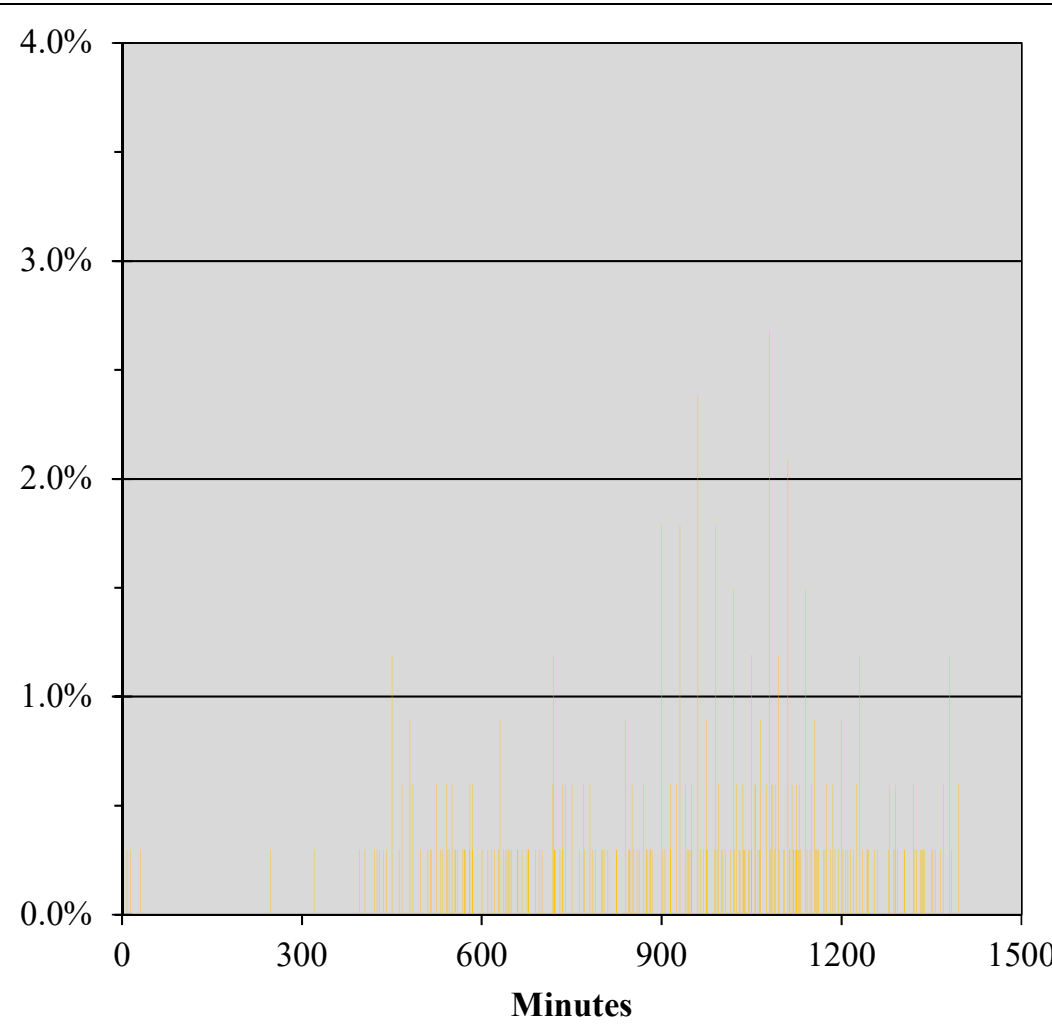

(b) Ancillary Telecommuters

Figure 4-5: Time versus Non-Mandatory Activities 


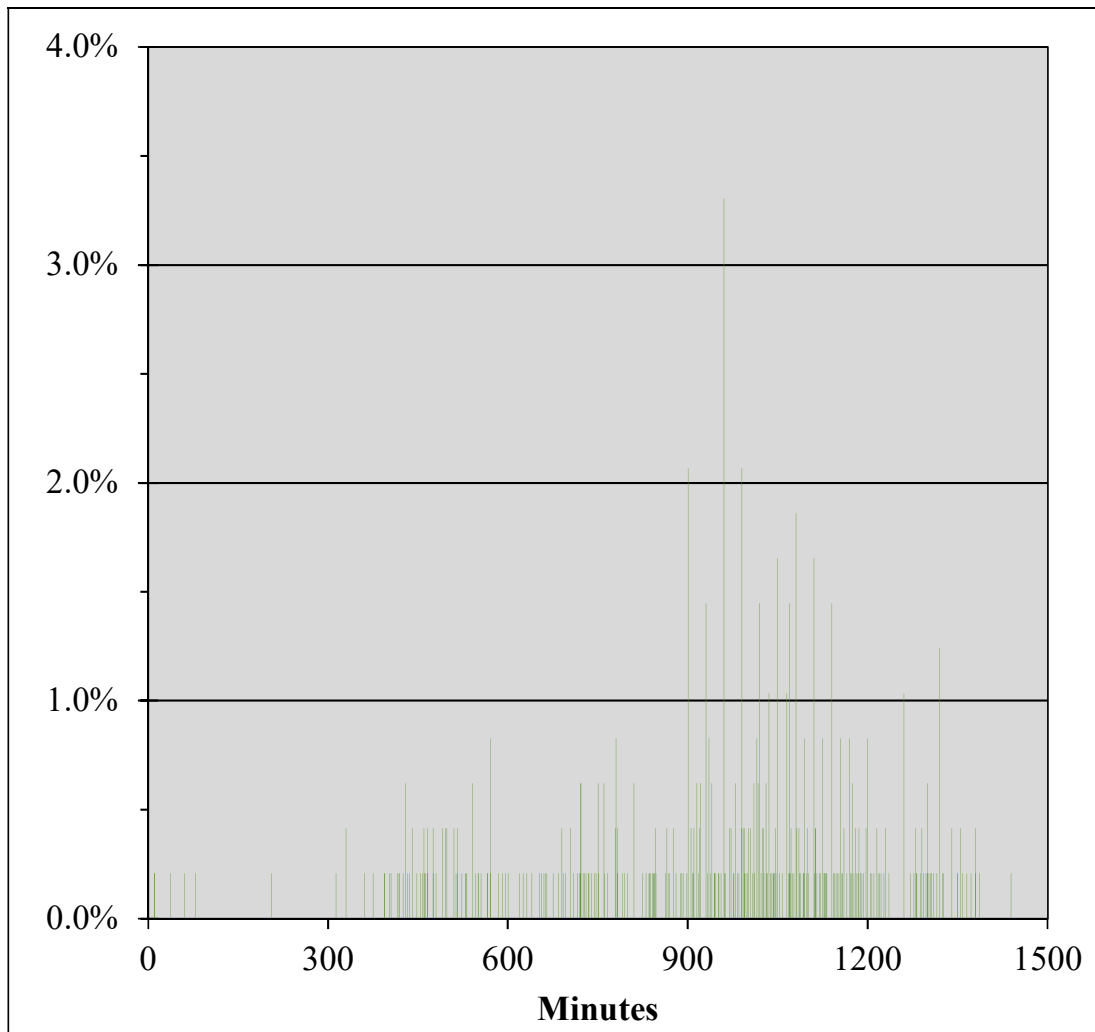

(c) Passive Telecommuters

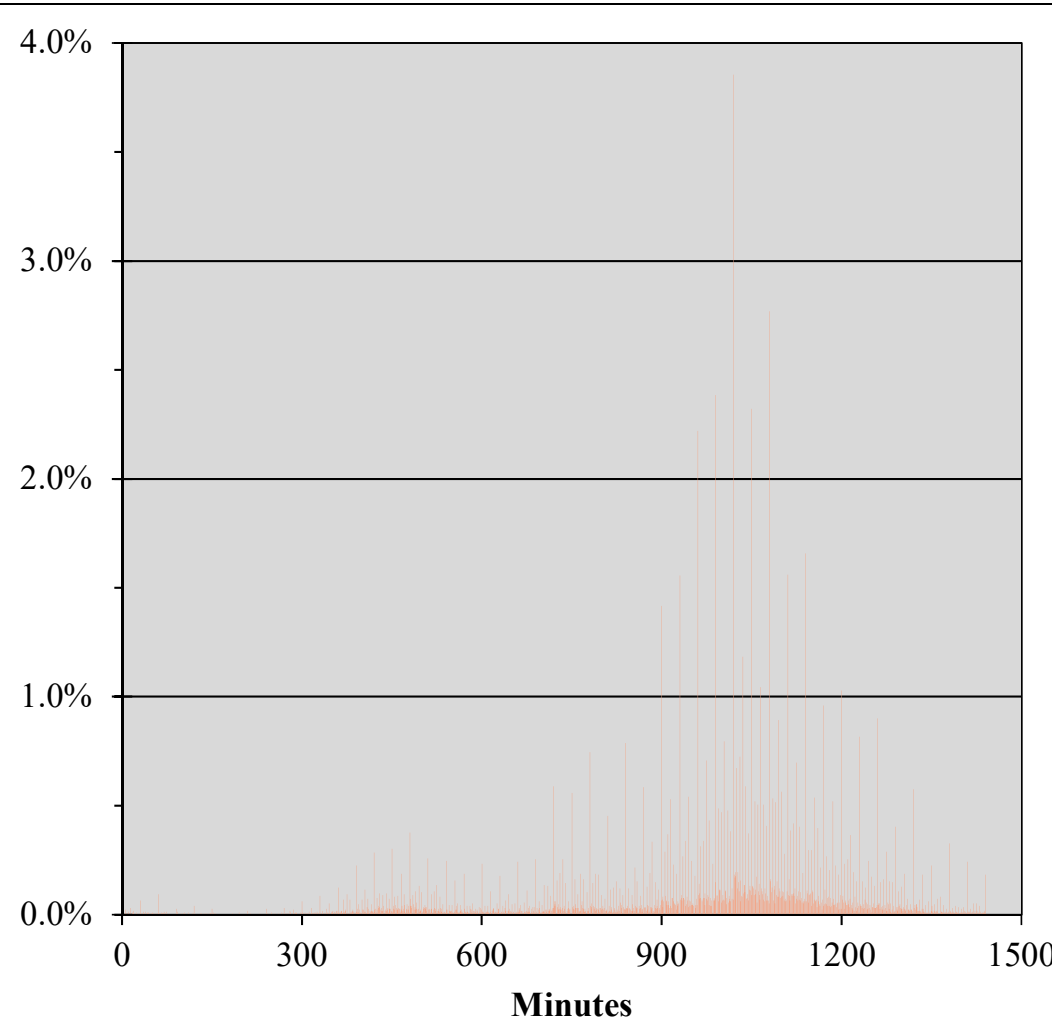

(d) Non-Telecommuters

Figure 4-5: Time versus Non-Mandatory Activities 
Figure 4-6 shows the proportion of trips, for all groups, separated by time of day. From this figure it is possible to see that as telecommuting increased, the proportion of Pre-AM Peak trips, AM Peak trips, and PM Peak trips all increased. Conversely, as telecommuting decreased, the proportion of Midday trips decreased. No obvious trends were observed for Evening and Midnight trips.

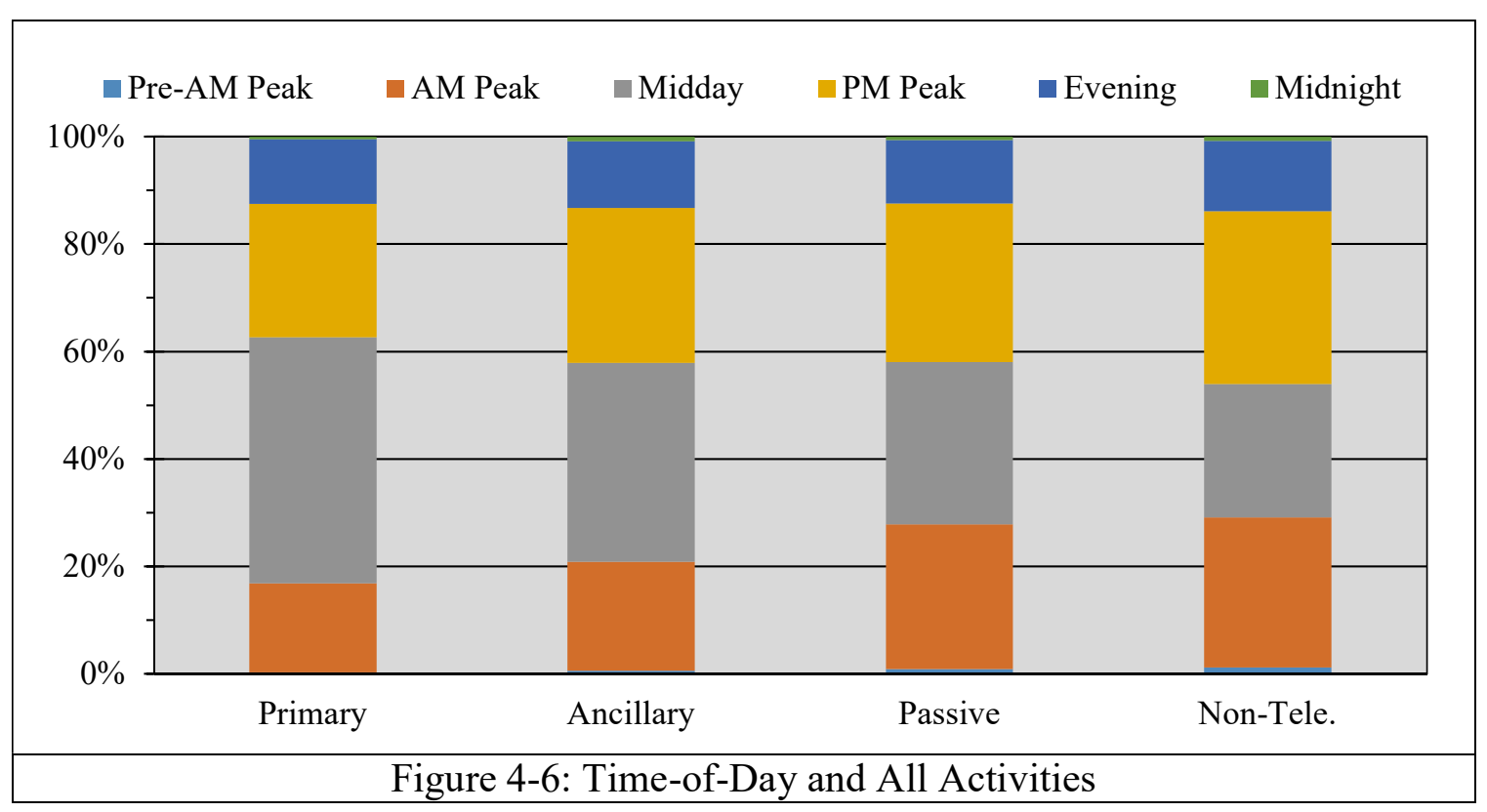

Mandatory and non-mandatory activities were separated by time of day in Figure 4-7a and b, respectively. In Figure 4-7a, there seems to be an increase in Pre-AM Peak and AM Peak trips as telecommuting decreased; Midday trips decreased as telecommuting decreased. No obvious pattern for PM Peak trips was noted. In Figure 4-7b, Midday trips decreased and PM Peak trips increased as telecommuting decreased. No obvious trend for Pre-AM Peak and AM Peak trips was noted. Interestingly, Evening and Midnight trips for all groups in Figure 4-7a were relatively constant; the same was observed in Figure 4-7b. 


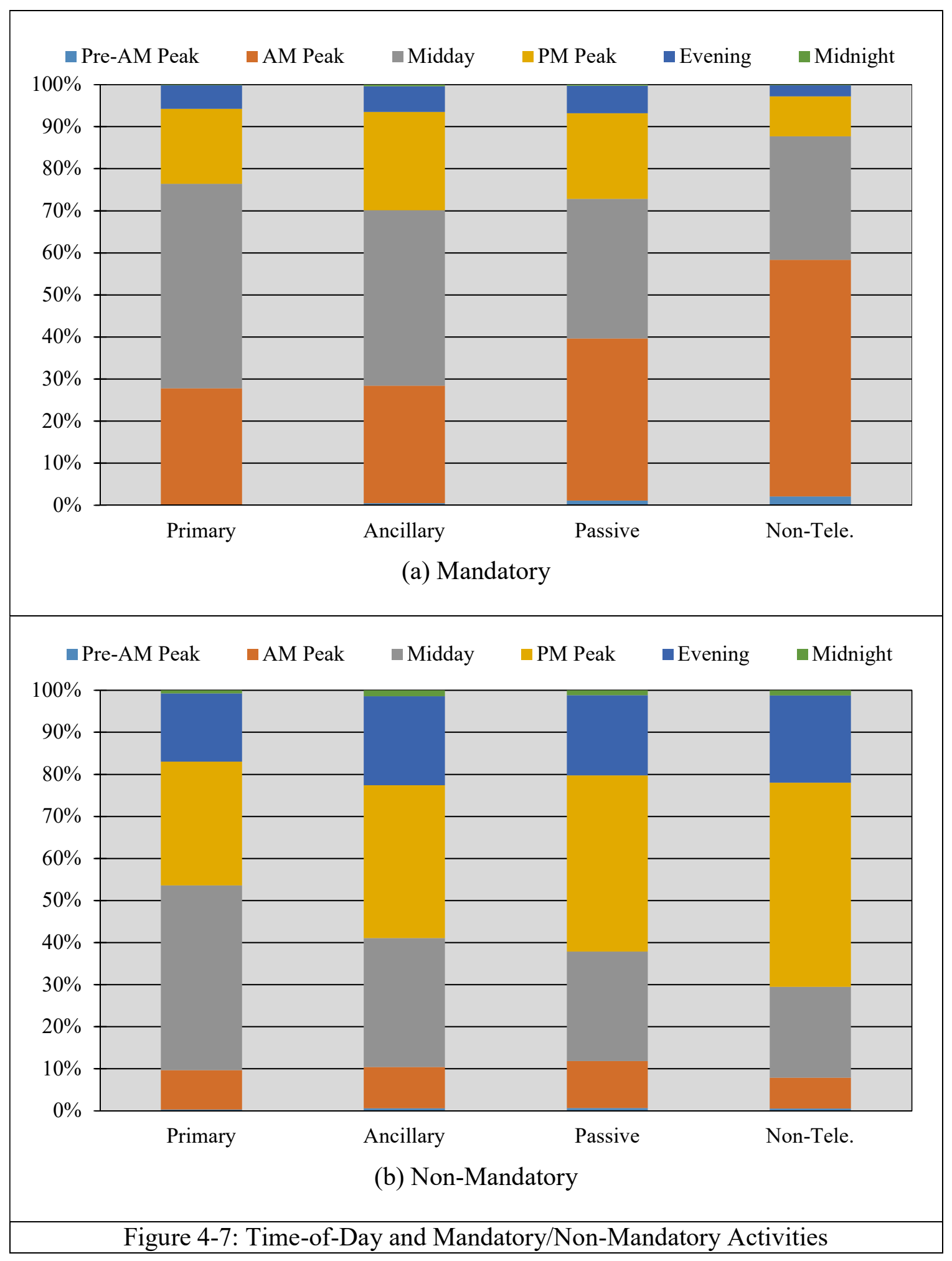


In order to explore the departure from home (morning origin vertex), arrival at work (morning terminal vertex), departure from work (evening origin vertex), and arrival at home (evening terminal vertex) the following figures (Figure 4-8, Figure 4-9, Figure 4-10, and Figure 4-11) were created. These figures depict the time of day, in hours, on the horizontal axis; the percentage of workers as well as the cumulative percentage is shown on the horizontal axis. The time of day ranges from 0 to 26 hours and it should be stated that 26 hours refers to 2:00 AM of the next day.

From Figure 4-8 it is clear that the Passive Telecommuters were most likely to leave home the earliest, and the Ancillary Telecommuters were most likely to leave home the latest. In fact, for all three groups, the vast majority of workers (80-90\%) were likely to leave home before 10:00 AM and nearly all (88-95\%) left home before 12:00 PM. It was assumed that all those who did not leave home before 12:00 PM were likely to be outliers, or worked in an industry which had an atypical working schedule. One example of this could be a nurse as they frequently work from 7:00 PM to 7:00 AM. 


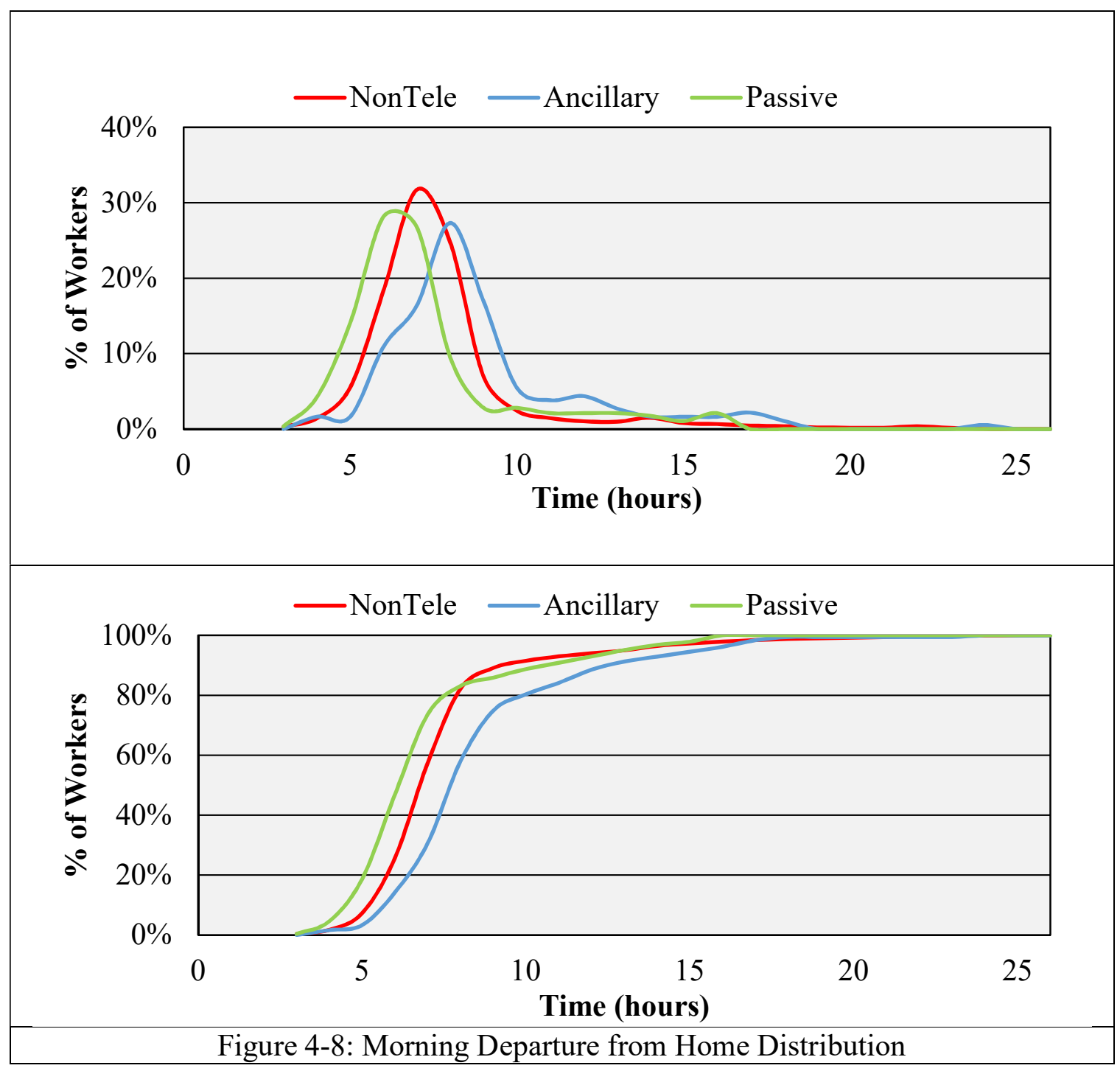

In Figure 4-9 it is clear to see that Passive and Non-Telecommuters were more likely to arrive at work earlier than Ancillary Telecommuters. By 10:00 AM 83\% of Passive and $89 \%$ of Non-Telecommuters had arrived at work, while only $59 \%$ of Ancillary Telecommuters had arrived at work. In reality, it would not be until 3:00 PM that $90 \%$ of Ancillary Telecommuters arrived at work. This may indicate that Ancillary Telecommuters behaviors may impact their time-space prism differently than Passive Telecommuters. 


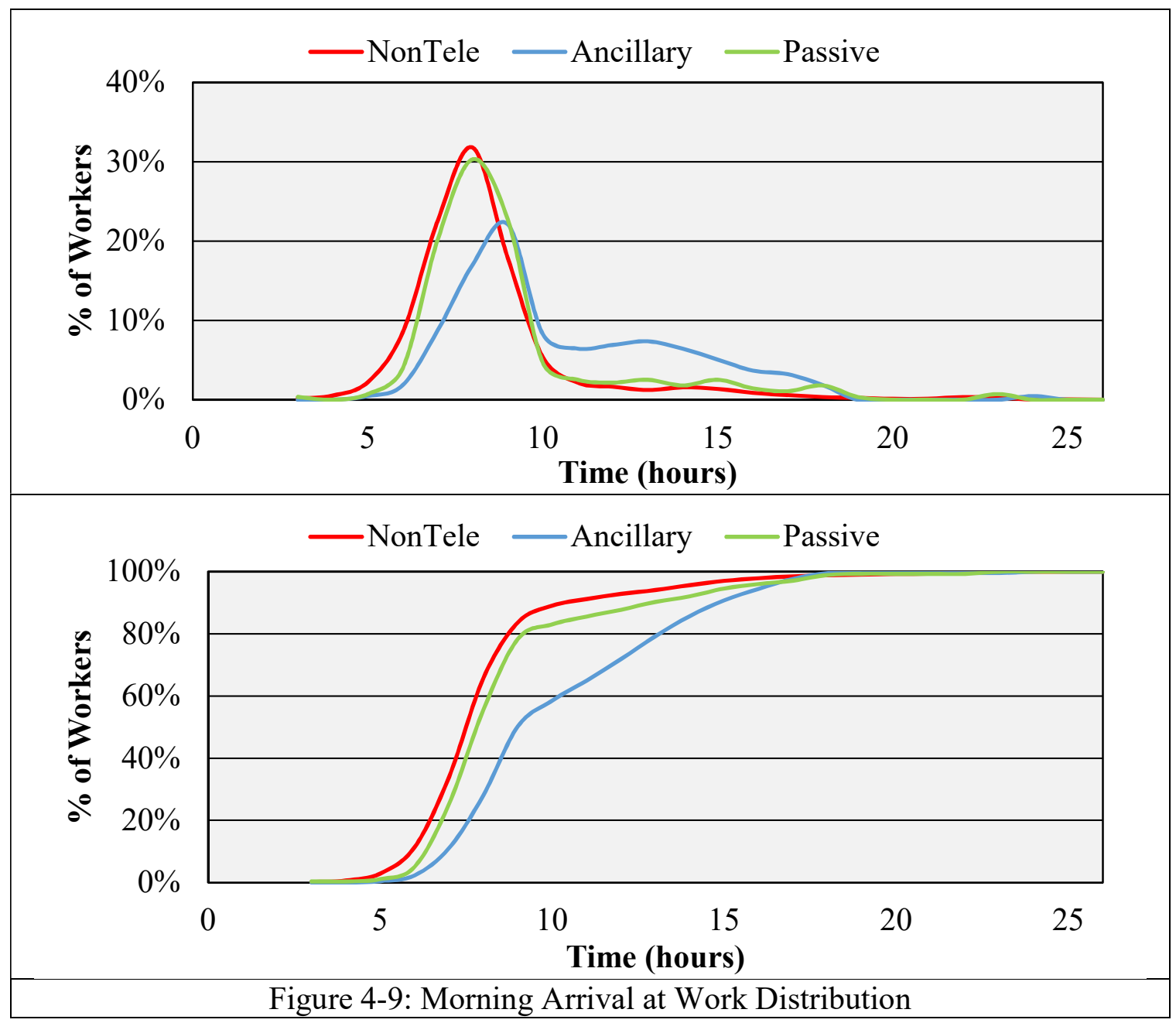

The departure time, from work to home, is shown in Figure 4-10. From this, it is possible to observed that approximately $50 \%$ of Non-Telecommuters left work between 4:00 PM and 8:00 PM while the same percentage of Ancillary and Passive Telecommuters left work 3:00 PM and 6:00 PM. Interestingly, nearly 95\% of all three groups left work between 9:00 PM and 10:00 PM. 


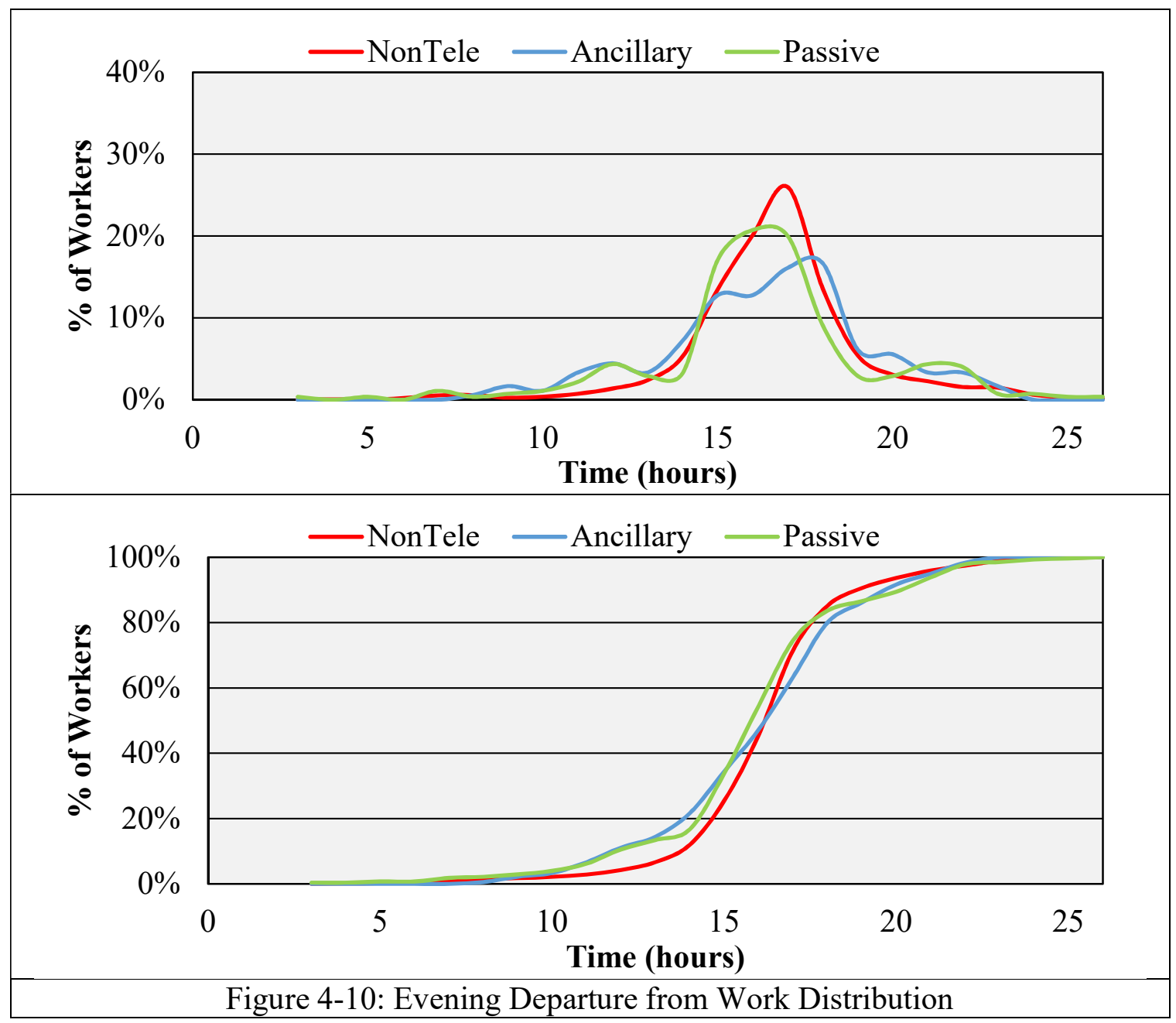

In Figure 4-11 it is clear that the arrival time at home is more dispersed through time. While approximately 50\% of Non-Telecommuters arrived at home between 4:00 PM and 7:00 PM, approximately the same amount of Ancillary and Passive Telecommuters arrived at home between 4:00 PM and 8:00 PM. Similarly, approximately 95\% of Non-Telecommuters arrived at home by 10:00 PM, while approximately the same amount of Ancillary and Passive Telecommuters arrived at home before 11:00 PM. 


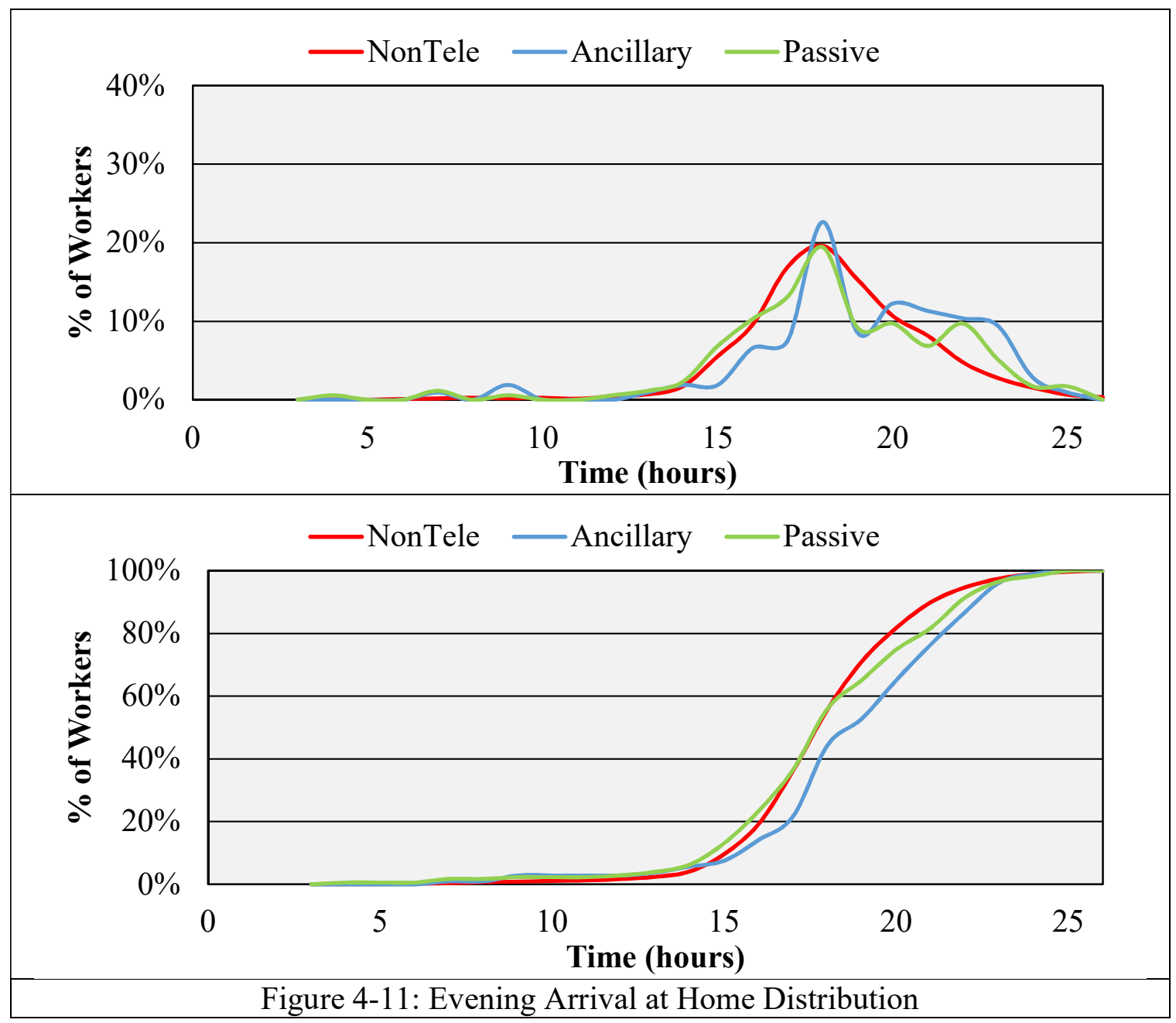

As a whole, it was noted that the morning departure from home and arrival at work were less dispersed than were the departure from work and arrival at home. This may indicate that the participants in this sample had similar working hours. In respect to the arrival at home, this is likely due to personal preferences or familial responsibilities. For example, one worker may have been inclined to go to a social event after work, while another decided to go straight home to cook dinner. 


\section{CHAPTER 5. MODEL ESTIMATION RESULTS}

In this section, the results of the models will be discussed. Models were constructed to explore the morning origin vertex, morning terminal vertex, evening origin vertex, and evening terminal vertex. Due to this, each group had 4 models to describe these four vertices; in total twelve models were constructed.

\subsection{MORNING ORIGIN VERTEX MODEL}

The morning origin vertex models in this section were constructed as stochastic cost functions, as indicated by the literature. In all three groups, the cost function was acceptable as indicated by the gamma value. As previously mentioned, gamma ranges from zero to one. in the case where gamma equals zero, the inefficiency term is irrelevant and the results should be equal to that of an ordinary least squares (OLS) estimation. When gamma equals one, the noise term becomes irrelevant and all variations from the cost function are due to inefficiency. In the context of this thesis, the noise term refers to statistical noise inherit to the data while the inefficiency term is related to an individual's ability to meet his frontier; one is considered efficient if his frontier is met.

As shown in Table 5-1, the portion of the total variance due to inefficiency (gammaVar) of the three models shown below was $88.33 \%, 100.00 \%$, and $100.00 \%$ for Non-Telecommuters, Ancillary Telecommuters, and Passive Telecommuters, respectively. More simply, the vast majority of the variance experienced in these three models is clearly due to inefficiency and not noise.

Furthermore, for Ancillary and Passive Telecommuters the gamma term was equal to 1.00 , while the term was 0.95 for Non-Telecommuters; each of these terms was 
statistically significant. When this, and the variance discussed above, is considered it is clear that the three models were correctly constructed as stochastic cost functions rather than ordinary least squares models.

In terms of goodness-of-fit, each model displayed likelihood values similar to those of other similar studies and was significant as a whole. Further, a comparison of the MLE cost function's log-likelihood to the OLS log-likelihood value also shows that the MLE cost function provides a better approximation for all three models. Statistical testing revealed that all of the models were significantly different from its OLS counterpart.

Individual characteristics only impacted the morning origin vertex (MOV) of Non-Telecommuters and Ancillary Telecommuters. Both of these groups showed that being Hispanic and/or Mexican played an important role in determining the MOV. This may be attributed to the fact that this group generally may have employment which requires earlier start times. The MOV of Non-Telecommuters was also shifted earlier in the day due to age and sex. A possible explanation for this is that, traditionally, men tend to earn a higher income and as such must arrive at work earlier. Also, as one ages he becomes more accustomed to leaving to work earlier or simply it becomes easier for him.

Household characteristics impacted the MOV for all groups of telecommuters. The number of adults in the household led to an earlier MOV for Passive Telecommuters, which may indicate that the household is forced to leave earlier to carpool or engage in activities such as dropping children off at school. Interestingly, the number of household vehicles shifted the MOV of Non-Telecommuters, which may indicate that they left earlier to arrive at work on time and avoid traffic. 
Another trend worth noting was the presence of older household members. In particular, the number of household members 16-17, 18-24, and 65-74 years of age shifted the MOV later for Ancillary, Passive, and Non-Telecommuters respectively. One possible explanation of this could be that these age groups are more independent and have access to the region's public transportation system. Due to this, these groups would not rely on the worker to transport them and thus enable the worker to leave later. It is also worth noting that income shifted the MOV for Non-Telecommuters earlier for both low and medium income households. Further, as the income increased, the shift decreased. This trend may be due to the lower income worker's real, or perceived, need to arrive at work on-time.

When the work start- and end-time variability was considered, the three groups varied greatly. Passive and Non-Telecommuters both shifted their MOV earlier when their work start-time could not vary, but Passive Telecommuters had a greater shift. It is possible that this is due to real and/or perceived pressure on the worker to arrive at work on-time. Further, the Passive Telecommuter may experience this more severely as they make the commute less often than their Non-Telecommuting counterpart. When the end time could not vary, Passive Telecommuters shifted their MOV later in the day. This may be attributed to familial responsibilities which require a worker to engage in other activities such as dropping-off and picking-up young children. For Ancillary Telecommuters, the MOV relationship between end-time variability and MOV was inverse; as the end time variability increase, the shifting of the MOV earlier in the day decreased. This may be due to the fact that as the worker is less interested to arrive ontime, or early, to work when his end time may be later in the day. 
Interestingly, the type of employer only impacted the MOV of NonTelecommuters. Moreover, a government employee was likely to shift their MOV earlier than an employee of a private company. It is possible that due to the typical working hours of government offices, their employees feel the need to arrive on-time and as such shift their MOV earlier.

The work type of each group, specifically being a full-time employee with one job, shifted the MOV of Non-Telecommuters and Ancillary Telecommuters by 50.82 minutes and 82.20 minutes ( 1 hour and 22 minutes) respectively. This may indicate that the Ancillary Telecommuters felt more pressure to be at work on-time to make up for the times when they do not physically go to work, or they feel added pressure in order to attend meetings in the morning when compare to Non-Telecommuters. The Passive Telecommuters tended to shift their MOV nearly one hour (58.19 minutes) later when they were a part-time employee with multiple jobs. This may hint that they were more prone to delay their departure in order to address other responsibilities.

In terms of occupation, the three groups showed very different behaviors. NonTelecommuters shifted their MOV earlier (57.36 minutes) when they worked in building, grounds cleaning, or maintenance-related occupations and later (40.59 minutes) when they had legal occupations. Perhaps building, grounds cleaning, and maintenance-related occupations have earlier start times which required them to tend to their work before most people get to the office building and those in legal occupations have a more relaxed start time which enables them to arrive a bit later. Ancillary Telecommuters in business or financial operations occupations shifted their MOV earlier (33.90 minutes) and later (80.87 minutes) for those in arts, design, entertainment, sports, or media occupations. 
This may indicate that those in finance feel the need to get into work on-time, such as stock brokers, in order to prepare for the rest of the day, while those in entertainment do not as their preparations may only require them to apply cosmetics or other things to prepare for the rest of the day. Passive Telecommuters in transportation or materials moving occupations shifted their MOV earlier (106.47 minutes; 1 hour and 46 minutes) while those in protective service occupations shifted it later (243.09 minutes; 4 hours and 3 minutes). It is possible that those in transportation, such as truck drivers, benefit from reduced congestion by leaving earlier in the day. On the other hand, those in protective services, such as security guards, may start work later due to their employer's scheduling patterns.

It is worth noting that all three groups were likely to shift their MOV earlier due to trip duration. However, none of them shifted their MOV earlier by more than 2 minutes. Although it was only a slight shift, it seems that as the frequency of telecommuting increased, the shift due to trip duration decreased.

Table 5-1: Morning Origin Vertex Model

\begin{tabular}{|c|c|c|c|c|c|c|c|}
\hline & \multicolumn{2}{|c|}{ Non-Tele. } & \multicolumn{2}{|c|}{ Ancillary } & \multicolumn{2}{|c|}{ Passive } \\
\hline & & Coeff. & $z$ & Coeff. & $z$ & Coeff. & $z$ \\
\hline & Intercept & 528.69 & 51.74 & 474.85 & 306.93 & 420.62 & 154.90 \\
\hline $\bar{\sigma}$ & Age & -0.62 & -8.22 & & & & \\
\hline בี [ี [ & Male & -14.06 & -6.94 & & & & \\
\hline 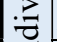 & Asian & 9.54 & 2.64 & & & & \\
\hline & Hispanic Mexican & -13.18 & -8.08 & -78.64 & -13.43 & & \\
\hline \multirow{7}{*}{ 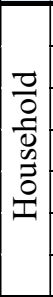 } & No. Household Adults & & & & & -15.50 & -19.38 \\
\hline & \begin{tabular}{|l|} 
No. Household Vehicles \\
\end{tabular} & -9.29 & -11.06 & & & & \\
\hline & No. Persons age 16 to $17 \mathrm{yrs}$ & & & 74.12 & 185.55 & & \\
\hline & \begin{tabular}{|l|} 
No. Persons age 18 to 24 yrs \\
\end{tabular} & & & & & 17.11 & 2.89 \\
\hline & \begin{tabular}{|l} 
No. Persons age 65 to $79 \mathrm{yrs}$ \\
\end{tabular} & 9.40 & 3.79 & & & & \\
\hline & Low income: below $50 \mathrm{~K}$ & -21.60 & -7.98 & & & & \\
\hline & Medium income: $50-150 \mathrm{~K}$ & -8.99 & -4.51 & & & & \\
\hline & Cannot Vary (Start Time) & -17.54 & -8.98 & & & -53.55 & -51.62 \\
\hline & Cannot Vary (End Time) & & & & & 41.31 & 21.29 \\
\hline
\end{tabular}


Table 5-1: Morning Origin Vertex Model

\begin{tabular}{|c|c|c|c|c|c|c|}
\hline & \multicolumn{2}{|c|}{ Non-Tele. } & \multicolumn{2}{|c|}{ Ancillary } & \multicolumn{2}{|c|}{ Passive } \\
\hline & Coeff. & $z$ & Coeff. & $z$ & Coeff. & $z$ \\
\hline 31 to 60 Minutes & - & & -8.88 & -21.02 & & \\
\hline More than 1 Hour & - & & -4.44 & -8.70 & & \\
\hline Private Company & -7.83 & -3.49 & & & & \\
\hline Government & -21.12 & -9.14 & & & - & \\
\hline Full-time one job & -50.82 & -5.64 & -82.20 & -121.58 & & \\
\hline Full-time more than one job & -46.90 & -4.86 & -69.24 & -35.47 & - & \\
\hline Part-time one job & -24.11 & -2.60 & & & - & \\
\hline Part-time more than one job & - & & -34.26 & -49.75 & 58.19 & 26.11 \\
\hline Business/ Financial Ops Occ. & - & & -33.90 & -104.68 & - & \\
\hline Computer/ Math. Occ. & 19.13 & 4.89 & - & & - & \\
\hline $\begin{array}{l}\text { Life/ Physical/ Social Science } \\
\text { Occ. }\end{array}$ & 13.07 & 4.43 & & & & \\
\hline Legal Occ. & 40.59 & 16.77 & & & & \\
\hline $\begin{array}{l}\text { Arts/ Design/ Enter. / Sports/ } \\
\text { Media Occ. }\end{array}$ & 34.81 & 15.38 & 80.87 & 58.48 & 21.88 & 9.01 \\
\hline Healthcare Support Occ. & - & - & - & & 38.98 & 3.76 \\
\hline Protective Service Occ. & - & & - & & 243.09 & 242.05 \\
\hline $\begin{array}{l}\text { Building/ Grounds Cleaning/ } \\
\text { Maintenance Occ. }\end{array}$ & -57.36 & -6.83 & & & & \\
\hline Sales/ Related Occ. & 8.43 & 3.71 & & & 74.03 & 39.66 \\
\hline Office/ Admin. Support Occ. & 19.97 & 6.18 & & & 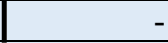 & \\
\hline Construction/ Extraction Occ. & -36.10 & -5.57 & & & & \\
\hline $\begin{array}{l}\text { Installation/ Maintenance/ } \\
\text { Repair Occ. }\end{array}$ & -23.58 & -6.19 & & & & \\
\hline Production Occ. & -40.57 & -12.22 & & & - & \\
\hline $\begin{array}{l}\text { Transportation/ Material } \\
\text { Moving Occ. }\end{array}$ & -38.32 & -7.26 & & & -106.47 & -46.26 \\
\hline Trip Duration & -1.15 & -29.68 & -0.62 & -14.87 & -0.84 & -12.80 \\
\hline sigmaSq & $47,840.00$ & $8,706.59$ & $81,660.00$ & $81,663.00$ & $105,990.00$ & $105,990.00$ \\
\hline gammaVar & $88.33 \%$ & & $100.00 \%$ & & $100.00 \%$ & \\
\hline gamma & 0.95 & 574.65 & 1.00 & $2,738,800.00$ & 1.00 & $8,820,200.00$ \\
\hline Log Likelihood L $(\beta)$ & $-78,419.21$ & & $-1,396.92$ & & $-2,174.65$ & \\
\hline Log Likelihood L(OLS) & $-79,900.50$ & & $-1,432.59$ & & $-2,262.02$ & \\
\hline Observations & \begin{tabular}{|l|}
12,566 \\
\end{tabular} & & 217 & & 336 & \\
\hline
\end{tabular}




\subsection{MORNING TERMINAL VERTEX MODEL}

The morning terminal vertex, when a person arrives at work, was not successfully estimated in this thesis, as shown in Table 5-2. The primary indication of this is the gamma value for each of the three models. These values were $0.02,0.01$, and 0.01 for Ancillary, Passive, and Non-Telecommuters respectively. Furthermore, statistical testing revealed that none of the models were significantly from its OLS counterpart; this is also alluded to by the similarity between the two log-likelihood, $\mathrm{L}(\beta)$ and L(OLS) values.

It is also worth noting that for these three models, the portion of the total variance due to inefficiency (gammaVar) of the three models shown below, was very low. This result indicates that less than $1 \%$ of the total variance was due to inefficiency; inversely $\sim 99 \%$ of the total variance can be attributed to noise in the data. This result is supported by the literature and it was noted that this vertex is not typically modelled successfully with a production function.

It is worth noting that recent work has been attempting to overcome the datarelated issues when using stochastic frontier analysis to estimate the morning terminal vertex as well as the evening origin vertex (Hafner, et al., 2015; Almanidis and Sickles, 2012).

The OLS version of each of these models was explored and found to have similar coefficients to those revealed by the stochastic frontier analysis. Therefore, the models shown below were explored as in the previous section.

Non-Telecommuters were more likely to arrive at work earlier as they aged which may indicate that they wake up earlier which allows them to arrive earlier. Male Passive Telecommuters were more likely to arrive at work earlier. One possible explanation for 
this is that they are likely the primary income of the household and feel pressure to arrive at work on-time. Hispanic Ancillary and Non-Telecommuters were more likely to arrive at work earlier. It is possible that these workers had jobs that required them to be at work earlier.

Non-Telecommuter households with students were more likely to arrive at work later which may be due to the fact that they have to drop the students off at school. NonTelecommuter households with more cars were more likely to arrive at work earlier due to the reliability of driving which may allow them to arrive earlier. Ancillary and Passive Telecommuter households with more adults were more likely to arrive at work earlier. Perhaps they do not have to worry about dropping-off the other adults due to their independence. Non-Telecommuter households with children or adults were more likely to arrive at work earlier. Maybe these households carpool or drop-off the other household members on the way to work which causes them to leave earlier and in turn arrive at work earlier. Ancillary and Non-Telecommuter households with elderly people were more likely to arrive at work later while Passive Telecommuters arrive earlier. This may be because Ancillary and Non-Telecommuters needed to attend to the elderly or join them on medical trips, but Passive Telecommuters were relieved of this duty.

For Non-Telecommuters, their arrival time at work shifted later as the start-time variability increased, while the opposite was observed for Ancillary Telecommuters. Maybe Non-Telecommuters felt less pressure to arrive at work earlier because they knew they would be leaving later anyways, but Ancillary Telecommuters felt more pressure to arrive at work earlier in order to be able to leave work earlier. For both Ancillary and Passive Telecommuters, the maximum start-time variability was associated with a later 
arrival at work. This may indicate that they felt less pressure to arrive at work earlier because they knew they would be leaving later anyways.

The arrival time at work shifted earlier as the end-time variability increased for both Passive and Non-Telecommuters, which may indicate that they felt more pressure to arrive at work earlier in order to be able to leave work earlier. The opposite was noted for Ancillary Telecommuters which could possibly mean that they felt less pressure to arrive at work earlier because they knew they would be leaving later anyways.

In terms of employer, Non-Telecommuters employed by the government, as opposed to employed by a private organization, were more likely to arrive at work earlier. Perhaps this is due to the relatively rigid hours of operations associated with government work

Non-Telecommuters that worked one full-time job were more likely to arrive at work earlier, perhaps due to real or perceived pressure to arrive at work earlier to maintain their employment status. Ancillary Telecommuters that worked one full-time job were more likely to arrive at work earlier, while those that worked one part-time job were more likely to arrive at work later. Maybe those with one full-time job felt more pressure to arrive at work earlier to maintain their employment and those with one fulltime job felt less pressure to arrive at work earlier. Passive Telecommuters that worked multiple part-time jobs were more likely to arrive at work later. It is possible that they arrived later because they had to travel from one job to another which delayed them.

In respect to occupation type, Passive and Non-Telecommuters in protective services were more likely to arrive at work later. This is likely due to the fact that they worked a later shift and as such arrived at work later. Ancillary Telecommuters in the 
entertainment industry were more likely to arrive at work later, which may indicate that they have more relaxed hours, or their start time is generally later. Ancillary and NonTelecommuters in construction and Passive Telecommuters in maintenance were more likely to arrive at work earlier. This is likely due to the fact that they generally start work earlier and they must be at work on-time.

It is worth noting that Ancillary and Passive Telecommuters that worked 80 hours in 9 days were more likely to arrive at work earlier. This may be due to the fact that they have time-sensitive responsibilities, primarily in the morning, which pressures them to arrive at work earlier.

As expected, both Ancillary and Non-Telecommuters with a longer trip duration were more likely to arrive at work earlier. They likely left home earlier in order avoid congestion and to ensure that they arrive at work earlier.

Table 5-2: Morning Terminal Vertex Model

\begin{tabular}{|c|c|c|c|c|c|c|c|}
\hline & \multicolumn{2}{|c|}{ Non-Tele. } & \multicolumn{2}{|c|}{ Ancillary } & \multicolumn{2}{|c|}{ Passive } \\
\hline & & Coeff. & $z$ & Coeff. & $z$ & Coeff. & $z$ \\
\hline & Intercept & 873.37 & 78.22 & 802.89 & 13.09 & 663.02 & 10.76 \\
\hline \multirow{7}{*}{$\frac{\pi}{\overparen{Z}}$} & Age & -1.42 & -8.85 & - & & & \\
\hline & Male & - & - & - & - & 62.91 & 2.92 \\
\hline & African American & 17.90 & 11.33 & - & - & - & \\
\hline & American Indian, Alaskan Native & -38.64 & -38.56 & - & - & 49.34 & 16.19 \\
\hline & Pacific Islander & -81.83 & -81.82 & - & - & & \\
\hline & Multiracial & - & & - & & 110.96 & 15.96 \\
\hline & Hispanic Mexican & -7.83 & -5.50 & -8.64 & -5.77 & - & \\
\hline \multirow{11}{*}{ 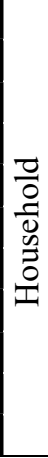 } & Number of Household Students & 5.17 & 3.02 & - & & - & \\
\hline & Number of Household Adults & - & - & -34.38 & -2.31 & -26.19 & -1.96 \\
\hline & Number of Household Vehicles & -9.53 & -7.35 & - & - & - & \\
\hline & No. Persons age 0 to 5 yrs & - & & - & - & -33.89 & -7.07 \\
\hline & No. Persons age 12 to $15 \mathrm{yrs}$ & -13.26 & -10.49 & - & - & - & \\
\hline & No. Persons age 25 to 34 yrs & -11.81 & -3.95 & - & - & - & \\
\hline & No. Persons age 35 to 49 yrs & -10.70 & -4.64 & - & - & - & \\
\hline & No. Persons age 65 to 79 yrs & 9.23 & 3.30 & - & - & - & - \\
\hline & No. Persons age 80 or older & 13.98 & 12.88 & 131.09 & 61.84 & -16.49 & -4.35 \\
\hline & 1 Adult, Youngest Kids 5-16 & -25.42 & -23.44 & -233.45 & -151.42 & - & \\
\hline & 1 Adult, Youngest Kids 0-5 & -23.52 & -23.23 & -145.53 & -52.91 & - & \\
\hline
\end{tabular}


Table 5-2: Morning Terminal Vertex Model

\begin{tabular}{|c|c|c|c|c|c|c|c|}
\hline & \multicolumn{2}{|c|}{ Non-Tele. } & \multicolumn{2}{|c|}{ Ancillary } & \multicolumn{2}{|c|}{ Passive } \\
\hline & & Coeff. & $z$ & Coeff. & $z$ & Coeff. & $z$ \\
\hline & $2+$ Adult, Youngest Kids $0-5$ & -10.99 & -7.02 & & & & \\
\hline & Cannot Vary (Start Time) & -41.62 & -22.24 & & & & \\
\hline & Within 15 Minutes & -32.53 & -14.66 & -94.45 & -11.04 & & \\
\hline & 16 to 30 Minutes & -26.47 & -13.75 & -132.39 & -6.89 & & \\
\hline & 31 to 60 Minutes & -25.29 & -9.77 & & & & \\
\hline & More than 1 Hour & & & 53.61 & 3.14 & 62.83 & 2.38 \\
\hline & Within 15 Minutes (End Time) & & & 58.85 & 7.42 & & \\
\hline & 16 to 30 Minutes & -8.59 & -4.74 & 66.07 & 3.81 & -64.27 & -2.65 \\
\hline & Private Company & -9.38 & -2.36 & & & - & \\
\hline & Government & -28.77 & -6.32 & & & & \\
\hline & Full-time one job & -120.98 & -36.96 & -49.40 & -2.51 & - & \\
\hline & Full-time more than one job & -75.98 & -18.32 & & & - & \\
\hline & Part-time one job & -71.67 & -23.35 & 48.02 & 1.72 & & \\
\hline & Part-time more than one job & - & & - & & 88.33 & 27.56 \\
\hline & Management Occ. & -2.94 & -1.82 & - & & - & \\
\hline & Business/ Financial Operations Occ. & -9.84 & -7.89 & -49.41 & -11.94 & - & \\
\hline & Computer/ Math. Occ. & -8.24 & -7.41 & -27.79 & -7.52 & - & \\
\hline & Architecture/ Engineering Occ. & -9.71 & -9.33 & -81.51 & -42.95 & -137.40 & -17.70 \\
\hline & Life/ Physical/ Social Science Occ. & - & & -12.44 & -6.28 & 31.96 & 27.47 \\
\hline 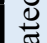 & Community/ Social Services Occ. & - & & - & & 46.67 & 1.70 \\
\hline $\bar{Q}$ & Legal Occ. & 33.63 & 26.59 & - & & - & \\
\hline 4 & Education/ Training/ Library Occ. & -27.74 & -11.39 & - & & - & \\
\hline$\tilde{z}^{0}$ & Arts/ Design/ Enter./ Sports/ Media Occ. & 33.18 & 15.96 & 103.05 & 5.39 & - & \\
\hline & Healthcare Support Occ. & - & & -66.51 & -14.07 & 121.74 & 5.01 \\
\hline & Protective Service Occ. & 106.81 & 106.27 & & & 157.68 & 134.30 \\
\hline & Food Preparation/ Serving Related Occ. & 58.60 & 31.84 & & & - & \\
\hline & $\begin{array}{l}\text { Building/ Grounds Cleaning/ } \\
\text { Maintenance Occ. }\end{array}$ & -9.84 & -9.67 & & & -309.31 & -278.17 \\
\hline & Personal Care/ Service Occ. & 7.90 & 7.54 & & & -49.08 & -12.73 \\
\hline & Sales/ Related Occ. & 14.83 & 8.46 & 43.69 & 7.45 & - & \\
\hline & Office/ Admin. Support Occ. & - & & -42.51 & -11.12 & - & \\
\hline & Farming/ Fishing/ Forestry Occ. & -48.66 & -48.21 & - & & -130.41 & -63.92 \\
\hline & Construction/ Extraction Occ. & -51.70 & -49.00 & -158.34 & -126.13 & - & \\
\hline & Installation/ Maintenance/ Repair Occ. & -4.07 & -3.60 & 80.68 & 58.39 & - & \\
\hline & Production Occ. & -22.11 & -21.78 & -48.44 & -37.81 & 17.30 & 5.19 \\
\hline & Transportation/ Material Moving Occ. & 23.70 & 21.97 & & & -82.80 & -43.34 \\
\hline & Military Specific Occ. & -3.00 & -3.00 & -11.62 & -1.73 & - & \\
\hline & Type 1: 4/40 & & & -72.26 & -15.07 & & \\
\hline & Type 2: $9 / 80$ & - & & -218.84 & -83.95 & -84.42 & -63.96 \\
\hline & Type 3: No compressed schedule & & & & & - & \\
\hline & Trip Duration & -0.87 & -16.08 & -0.68 & -1.97 & & \\
\hline & $\mathrm{maSq}$ & $31,502.00$ & $12,592.28$ & $28,182.00$ & $5,224.77$ & $39,900.00$ & $4,280.02$ \\
\hline & nmaVar & $0.40 \%$ & & $0.88 \%$ & & $0.54 \%$ & \\
\hline & nma & 0.01 & 0.96 & 0.02 & 0.25 & 0.01 & 0.19 \\
\hline & g Likelihood L $(\beta)$ & $-86,163.83$ & & $-1,416.17$ & & $-2,251.21$ & \\
\hline & g Likelihood L(OLS) & $-86,160.94$ & & $-1,416.14$ & & $-2,251.14$ & \\
\hline & servations & 13,091 & & 217 & & 336 & \\
\hline
\end{tabular}




\subsection{EVENING ORIGIN VERTEX MODEL}

The evening origin vertex, when a person departs from work, was not successfully estimated in this thesis, as shown in Table 5-3. The primary indication of this is the gamma value for each of the three models. These values were $0.04,0.03$, and 0.02 for Ancillary, Passive, and Non-Telecommuters respectively. Furthermore, statistical testing revealed that none of the models were significantly different from its OLS counterpart; this is also alluded to by the similarity between the two log-likelihood, $\mathrm{L}(\beta)$ and $\mathrm{L}(\mathrm{OLS})$, values.

Each of these models also displayed a very low portion of the total variance due to inefficiency (gammaVar); none surpassed $2 \%$ as shown below. In the case of Ancillary Telecommuters, $1.73 \%$ of the total variance was due to inefficiency and conversely $98.27 \%$ of the total variance can be attributed to noise in the data. Again, this result mirrors results for similar studies and is supported by the literature. Generally, this vertex is not typically modelled successfully with a cost function.

As previously mentioned, pioneering work is currently being conducted in an attempt to overcome the data related issues associated with modeling this vertex. However, the OLS version of each of these models was explored and found to have similar coefficients to those revealed by the stochastic frontier analysis. Therefore, the models shown below were explored as in the previous section.

In respect to individual characteristics, Non-Telecommuters were more likely to leave work earlier as they aged. This is possibly explained by the fact that they probably are better at managing their time so they leave earlier than younger people. Male Non- 
Telecommuters were more likely to leave work later, perhaps because they are the primary income and work later to support the family. Hispanic/Mexican Passive and Non-Telecommuters were more likely to leave work later, which may indicate that they work jobs that require them to leave later.

When the household characteristics were considered, several trends were observed. Ancillary and Non-Telecommuters with children left work earlier which is likely due to the need to tend to their children's needs. Passive Telecommuter households with more workers left work earlier. A possible explanation for this is that the household had multiple incomes which reduced the financial burden on the members which reduced the need to stay later at work. Non-Telecommuter households with more vehicles left work earlier. This may be due to the increased freedom and mobility associated with the availability of a vehicle. Ancillary Telecommuter households with young children, teens, or elderly left work earlier, and left later due the presence of young adults. Also, when multiple adults were present, they tended to leave work later. Perhaps the presence of children required Ancillary Telecommuters to leave work earlier, but when more adults were present the pressure on the primary household income to leave earlier was reduced. Non-Telecommuter households with no children left work later than those with children. A plausible explanation is that the households with no children had less familial responsibilities, were likely younger adults, and may have been more willing to work longer hours. Interestingly, Non-Telecommuter tended to leave work earlier as their income decreased. This may indicate that those with lower incomes had less job satisfaction and as such did not desire to work later. 
Non-Telecommuters with some start-time variability were likely to leave work later. A simple explanation for this is that they arrived at work later, so they stayed later. Ancillary Telecommuters no start-time variability were likely to leave work earlier. Similarly, a simple explanation is possible: they arrived at work on-time, so they left earlier. Passive Telecommuters with little start-time variability were likely to leave work earlier. Perhaps they felt that because they arrived at work nearly on-time, so they felt entitled to leave earlier as well. Passive Telecommuters with the most start-time variability were likely to leave work later. This is likely because the felt the need to stay at work later because they arrived at work later.

Non-Telecommuters with any end-time variability were likely to leave work earlier, but they left earliest if there was the least end-time variability. It is plausible that they may have had to leave earlier to attend to familial responsibilities such as preparing dinner. Ancillary Telecommuters with no end-time variability were likely to leave work earlier, but as the end-time variability increased so did their departure time. This group may have felt pressure to leave work earlier due to other responsibilities, but also felt obligated to stay later if necessary. Passive Telecommuters with some start-time variability were likely to leave work later which may indicate that they did not feel obligated to stay later because they felt they could complete their tasks the following day.

Non-Telecommuters employed by the government left work earlier, but Passive Telecommuters employed by the government left work later. It is possible that this is related to the type of work that each group was tasked with doing. For example, maybe the Non-Telecommuters worked in administration while they Passive Telecommuters worked in information technology so they had to work when the office was less active. 
In terms of employment type, Ancillary, Passive, and Non-Telecommuters that had multiple full-time jobs were more likely to leave later; those with one part-time job were likely to leave work earlier. It is possible that those with multiple full-time jobs may have been over working themselves and those with one part-time job may have been the second household income which reduced their need to stay at work later.

Non-Telecommuters in the legal industry were likely to leave work later, perhaps because this industry required its workers to work later to prepare for a court appearance. Ancillary Telecommuters working in the life, physical, or social science field were likely to leave work later, while Passive Telecommuters in the same field were likely to leave work earlier. It is possible that the Ancillary Telecommuters worked at a university which had classes that ended later, while Passive Telecommuters worked at a grade school which had classes that ended earlier. Passive Telecommuters working in protective services were likely to leave work later. This may indicate that their work schedule made them work the night shift so they left work later. Non-Telecommuters in the military industry were likely to leave work earlier. One possible explanation is that their government contracts were tied to specific work restrictions which caused them to leave earlier. Ancillary Telecommuters in business or financial operations were likely to leave work earlier. Perhaps they worked as a day-trader, and as such only worked while the stock exchange was open.

Passive and Non-Telecommuters that worked 80 hours in 9 days were more likely to leave work earlier, but Ancillary Telecommuters left later. Perhaps Passive and NonTelecommuters more evenly spaced their working hours over the working days, while the Ancillary Telecommuters did not. 
Again, as expected, Non-Telecommuters left work earlier due to their trip duration which is likely due to the fact that they left earlier to avoid congestion and arrive at home earlier for familial reason.

Table 5-3: Evening Origin Vertex Model

\begin{tabular}{|c|c|c|c|c|c|c|c|}
\hline & \multicolumn{2}{|c|}{ Non-Tele. } & \multicolumn{2}{|c|}{ Ancillary } & \multicolumn{2}{|c|}{ Passive } \\
\hline & & Coeff. & $z$ & Coeff. & $z$ & Coeff. & $z$ \\
\hline & Intercept & $1,088.30$ & 83.67 & 1144.90 & 22.79 & 1104.70 & 16.53 \\
\hline \multirow{6}{*}{ 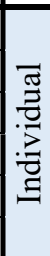 } & Age & -1.57 & -11.88 & & & - & \\
\hline & Male & 7.81 & 2.64 & & & - & \\
\hline & Asian & & & -119.41 & -16.84 & & \\
\hline & American Indian, Alaskan Native & 34.18 & 34.10 & & & 61.22 & 47.63 \\
\hline & Pacific Islander & -33.97 & -33.84 & & & & \\
\hline & Hispanic Mexican & 13.26 & 7.73 & & & 111.24 & 39.80 \\
\hline \multirow{14}{*}{$\begin{array}{c} \\
\\
\frac{0}{0} \\
0 \\
0 \\
0 \\
0 \\
\frac{0}{1} \\
\end{array}$} & No. Household Workers & & & & & -88.35 & -4.83 \\
\hline & No. Household Children & -9.56 & -3.42 & -140.40 & -10.23 & & \\
\hline & \begin{tabular}{|l|} 
No. Household Vehicles \\
\end{tabular} & -4.72 & -3.39 & & & & \\
\hline & No. Persons age 0 to 5 yrs & - & & -99.02 & -7.94 & & \\
\hline & \begin{tabular}{|l|} 
No. Persons age 16 to $17 \mathrm{yrs}$ \\
\end{tabular} & - & & -154.76 & -10.33 & & \\
\hline & No. Persons age 25 to 34 yrs & - & & 54.22 & 2.26 & & \\
\hline & No. Persons age 80 or older & - & - & -77.83 & -33.84 & & \\
\hline & 1 Adult, No Kids & 36.02 & 5.41 & & & & \\
\hline & $2+$ Adult, No Kids & 24.00 & 4.32 & & & & \\
\hline & $2+$ Adult, Youngest Kids 5-16 & - & & 223.63 & 16.28 & - & \\
\hline & 1 Adult, Youngest Kids 0-5 & 31.06 & 30.05 & & & - & \\
\hline & $2+$ Adult, Youngest Kids $0-5$ & 6.91 & 3.24 & 351.62 & 43.86 & & \\
\hline & Low income: below $50 \mathrm{~K}$ & -20.08 & -4.67 & - & & - & \\
\hline & Medium income: $50-150 \mathrm{~K}$ & -10.47 & -3.50 & - & & - & \\
\hline \multirow{18}{*}{ 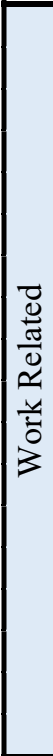 } & Cannot Vary (Start Time) & - & & -84.52 & -28.84 & 7 & \\
\hline & Within 15 Minutes & - & - & - & & -118.78 & -6.36 \\
\hline & 16 to 30 Minutes & 16.07 & 7.17 & - & & - & \\
\hline & More than 1 Hour & & & - & & 101.58 & 4.13 \\
\hline & Cannot Vary (End Time) & -25.99 & -9.62 & -42.78 & -16.29 & - & \\
\hline & Within 15 Minutes & -18.44 & -6.42 & 51.49 & 33.68 & 109.83 & 11.80 \\
\hline & 16 to 30 Minutes & -23.89 & -9.83 & 76.97 & 23.16 & - & \\
\hline & 31 to 60 Minutes & -8.80 & -4.07 & - & & - & \\
\hline & Government & -16.59 & -9.06 & - & & 71.98 & 3.42 \\
\hline & Full-time one job & 21.39 & 4.11 & - & & - & \\
\hline & Full-time more than one job & 27.42 & 6.07 & 16.58 & 1.98 & 93.92 & 11.50 \\
\hline & Part-time one job & -31.76 & -6.94 & -37.05 & -4.20 & -28.47 & -4.45 \\
\hline & Part-time more than one job & - & & -49.52 & -20.89 & - & \\
\hline & Management Occ. & 27.54 & 8.17 & & & & \\
\hline & Business/ Financial Operations Occ. & 40.63 & 22.81 & -203.46 & -19.67 & & \\
\hline & Computer/ Math. Occ. & 32.94 & 17.81 & -72.37 & -26.71 & & \\
\hline & Architecture/ Engineering Occ. & 19.09 & 10.66 & & & -53.01 & -11.88 \\
\hline & Life/ Physical/ Social Science Occ. & 24.02 & 17.15 & 113.34 & 78.58 & -354.57 & -152.15 \\
\hline
\end{tabular}


Table 5-3: Evening Origin Vertex Model

\begin{tabular}{|c|c|c|c|c|c|c|}
\hline & \multicolumn{2}{|c|}{ Non-Tele. } & \multicolumn{2}{|c|}{ Ancillary } & \multicolumn{2}{|c|}{ Passive } \\
\hline & Coeff. & $z$ & Coeff. & $z$ & Coeff. & $z$ \\
\hline Community/ Social Services Occ. & -5.66 & -4.45 & -27.75 & -8.62 & -22.22 & -4.02 \\
\hline Legal Occ. & 44.95 & 23.11 & - & & 41.55 & 6.40 \\
\hline Arts/ Design/ Enter./ Sports/ Media Occ. & 41.92 & 15.06 & - & 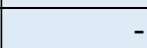 & 136.70 & 32.75 \\
\hline Healthcare Practitioners/ Technical Occ. & 16.88 & 6.69 & - & 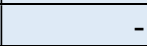 & & \\
\hline Healthcare Support Occ. & & & -182.07 & -83.04 & 107.84 & 40.57 \\
\hline Protective Service Occ. & -48.65 & -46.78 & - & - & 203.41 & 171.41 \\
\hline Food Preparation/ Serving Related Occ. & 33.30 & 16.15 & - & - & 68.46 & 35.89 \\
\hline $\begin{array}{l}\text { Building/ Grounds Cleaning/ } \\
\text { Maintenance Occ. }\end{array}$ & -19.29 & -18.12 & - & 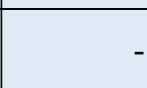 & & \\
\hline Personal Care/ Service Occ. & - & - & - & - & -17.13 & -6.28 \\
\hline Sales/ Related Occ. & 22.21 & 13.24 & - & - & 93.75 & 15.07 \\
\hline Office/ Admin. Support Occ. & 22.22 & 8.84 & - & - & -36.76 & -3.40 \\
\hline Farming/ Fishing/ Forestry Occ. & 14.86 & 14.54 & - & - & - & \\
\hline Construction/ Extraction Occ. & -19.58 & -16.73 & -69.55 & -25.91 & - & \\
\hline Installation/ Maintenance/ Repair Occ. & -20.98 & -11.51 & -63.88 & -16.23 & & \\
\hline Production Occ. & - & - & 98.94 & 41.38 & 7.47 & 5.51 \\
\hline Transportation/ Material Moving Occ. & -28.41 & -14.57 & - & - & -154.32 & -68.41 \\
\hline Military Specific Occ. & -57.61 & -57.58 & -107.37 & -86.99 & - & \\
\hline Type 1: $4 / 40$ & 11.35 & 9.29 & - & - & - & \\
\hline Type 2: 9/80 & -9.45 & -8.75 & 157.96 & 95.96 & -355.09 & -195.74 \\
\hline Trip Duration & -0.23 & -4.54 & - & & - & \\
\hline sigmaSq & $36,902.00$ & $6,871.03$ & $28,291.00$ & $10,810.89$ & $35,953.00$ & $9,178.91$ \\
\hline gammaVar & $0.74 \%$ & & $1.37 \%$ & & $0.93 \%$ & \\
\hline gamma & 0.02 & 1.45 & 0.04 & 0.29 & 0.03 & 0.22 \\
\hline Log Likelihood L $(\beta)$ & $-94,745.80$ & - & -868.22 & - & $-1,542.31$ & \\
\hline Log Likelihood L(OLS) & $-94,743.26$ & - & -868.21 & - & $-1,542.28$ & \\
\hline Observations & 14,224 & & 133 & - & 232 & \\
\hline
\end{tabular}




\subsection{EVENING TERMINAL VERTEX MODEL}

The evening terminal vertex models in this section were constructed as stochastic production functions, as indicated by the literature. In all three groups, the production function was acceptable as indicated by the gamma value.

In Table 5-4 the portion of the total variance due to inefficiency (gammaVar) of the three models was $100.00 \%, 90.08 \%$, and 58.80\% for Ancillary, Passive, and NonTelecommuters. In the case of Ancillary and Passive Telecommuters, the value confirms that the vast majority of the variance was due to inefficiency rather than noise in the data. Interestingly, Non-Telecommuters had a much larger portion of the variance related to noise in the data. Regardless of this, modeling this vertex with a production function was still deemed appropriate and will be discusses below.

The table also displays the gamma term for each model. As previously mentioned, when this term equals one, all variation is due to inefficiency; more specifically, an individual's ability/inability to reach his frontier. The largest value was attributed to Ancillary Telecommuters (1.00) followed by Passive Telecommuters (0.96) and NonTelecommuters (0.80) and each was statistically significant. Based on this, we can say with confidence that the three models were correctly constructed as stochastic cost functions rather than OLS models.

Based on the literature, the goodness-of-fit of each model displayed likelihood values similar to those of other similar studies and the models were significant as a whole. A comparison of the MLE production function's log-likelihood, $L(\beta)$, to the OLS loglikelihood, L(OLS), value also shows that the MLE production function provides a better approximation for all three models. The relationship between the portion of variance 
related to noise and MLE log-likelihood was also noted; here as the portion the variance associated with noise increased, the MLE log-likelihood value decreased. Statistical testing revealed that all of the models were significantly different from its OLS counterpart.

In terms of individual-related attributes, the ETV for Ancillary and NonTelecommuters were shifted earlier in the day due to age. The difference between the two may possibly be due to older employee's ability to manage their time and arrive at home earlier than younger employees. Also, male Passive and Non-Telecommuters tended to shift their ETV later. This may be due to the traditional household structure in which the male is the primary income; interestingly, the Passive Telecommuters left later than the Non-Telecommuters which may indicate that they have less time-space constraints.

The number of children and vehicles in the household shifted the ETV earlier for Non-Telecommuters. This can be attributed to the parents' need to care for their dependents and the freedom associated with owning a vehicle which may reduce the commute duration. The household income of this group of commuters also shifted the ETV earlier. As the lower income group shifted the ETV the earliest, among the income groups, it is possible that this shift is due to job dissatisfaction which prompts the worker to leave work earlier and arrive at home earlier. As expected households with one adult and no children, as well as those with two adults and no children, shifted their ETV later. This may indicate that as they are without children, they may engage in more social activities. The presence of other family members in the house, regardless of age, seemed to play an important role in shifting the ETV earlier for Ancillary and Passive 
Telecommuters. It is likely that these other individuals need to be cared for by the workers and as such, the worker arrives at home earlier.

The work start-time variability only impacted Passive Telecommuters' ETV. While those who had work times that varied with 15 minutes shifted their ETV earlier, those who had work times that varied more than 1 hour shifted their ETV later. This could possibly be explained by the fact that if the start time is relatively fixed, the end time is probably relatively fixed as well.

On the other hand, work end-time variability only impacted Non-Telecommuters. In this case, any kind of end-time variability resulted in the ETV shifting earlier. Interestingly, as the end-time variability increased, the ETV shift towards earlier in the evening decreased. This may be attributed to the workplace interactions whereby the managers ask subordinates to stay to finish work or some other task. Here, the timeconstraints are increased which delays the worker's arrival at home.

Being employed by the government also impacted the Passive and NonTelecommuters, but in very different ways. While the Passive Telecommuters shifted their ETV later, the Non-Telecommuters did the opposite. This can possibly be explained by the schedule and type of work done by each group. It is likely that the NonTelecommuters are required to be at the office during typical operating hours (9:00 AM - 5:00 PM), which can explain why their ETV is shifted earlier. The Passive Telecommuters could be engaged in work that can be done outside of typical operating hours, and as such their ETV is shifted later.

The job-type of Non-Telecommuters and Ancillary Telecommuters also impacted their ETVs. For Non-Telecommuters, working one full-time job or multiple full-time jobs 
shifted the ETV earlier. This may be attributed to the need to provide or care for family members at home. For Ancillary Telecommuters, working multiple full-time jobs shifted the ETV later. This may indicate that these people work more than 40 hours per week and work longer hours to do so which would obviously shift the ETV later.

Occupation also played a significant role in determining the ETV for all three groups. The ETV of Non-Telecommuters was shifted earlier due to military-related occupations and later due to food preparation or serving related occupations. It is possible that military-related work has strict contracts which mandate many things, including hours worked per week. Due to this, it may be possible that strict working schedules allow workers in this occupation to arrive at home earlier. On the other hand, restaurants usually prepare food for lunch or dinner which essentially shifts the worker's hours to later in the day and as such shift their ETV later. The ETV of Ancillary Telecommuters was shifted earlier due to computer or math related occupations, and later due to legal occupations. It is possible that the computer or math related occupations are in academia and as such have more freedom which enables them to arrive at home earlier, while legal occupations may have to work longer hours to prepare for a case which will delay them from arriving at home. The ETV of Passive Telecommuters was shifted earlier due to life, physical, or social science occupations, and later due to healthcare support occupations. Perhaps the first of these is a middle-school teacher whose work day ends earlier and the latter is an emergency medical technician (EMT) that has to work the night shift; both of these provide potential explanations for the observed ETV shift.

The only group impacted by compressed working schedules was the NonTelecommuters; in particular, working 40 hours in 4 days. One possible explanation is that 
as the workers only work four days, they have to work longer hours each day. As such they typically will arrive later at home.

It is worth noting that the trip duration did impact the ETV for both Ancillary and Non-Telecommuters. In both cases, as the duration increased so did the arrival time at home. This result may indicate that Ancillary Telecommuters live further from the CBD than Non-Telecommuters.

Table 5-4: Evening Terminal Vertex Model

\begin{tabular}{|c|c|c|c|c|c|c|c|}
\hline & \multicolumn{2}{|c|}{ Non-Tele. } & \multicolumn{2}{|c|}{ Ancillary } & \multicolumn{2}{|c|}{ Passive } \\
\hline & & Coeff. & $z$ & Coeff. & $z$ & Coeff. & $z$ \\
\hline & Intercept & $1,366.20$ & 183.24 & 1552.30 & 267.52 & 1332.90 & 42.99 \\
\hline \multirow{5}{*}{ 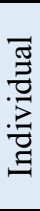 } & Age & -1.64 & -14.09 & -3.59 & -13.13 & & \\
\hline & Male & 15.94 & 5.10 & - & -1 & 96.21 & 4.63 \\
\hline & White & -12.29 & -3.26 & - & - & - & \\
\hline & Asian & - & - & -151.77 & -13.22 & - & \\
\hline & Pacific Islander & -58.66 & -2.11 & - & -1 & - & \\
\hline \multirow{12}{*}{ 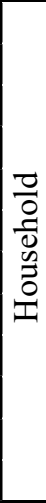 } & No. Household Children & -5.24 & -2.45 & - & - & - & - \\
\hline & No. Household Vehicles & -5.03 & -3.61 & - & - & - & \\
\hline & No. Persons age 0 to 5 yrs & - & - & - & - & -79.81 & -3.57 \\
\hline & No. Persons age 16 to 17 yrs & - & - & -104.05 & -12.05 & - & \\
\hline & No. Persons age 35 to 49 yrs & - & - & - & -1 & -42.79 & -2.84 \\
\hline & No. Persons age 50 to 64 yrs & - & - & - & - & -33.29 & -2.14 \\
\hline & No. Persons age 80 or older & - & - & -86.65 & -56.21 & - & \\
\hline & 1 Adult, No Kids & 39.41 & 9.01 & - & -1 & - & \\
\hline & $2+$ Adult, No Kids & 26.15 & 6.50 & - & - & - & \\
\hline & 1 Adult, Youngest Kids 5-16 & - & - & -315.27 & -205.17 & - & \\
\hline & Low income: below $50 \mathrm{~K}$ & -16.33 & -3.35 & - & - & - & \\
\hline & Medium income: $50-150 \mathrm{~K}$ & -7.41 & -2.21 & - & - & - & \\
\hline \multirow{14}{*}{ 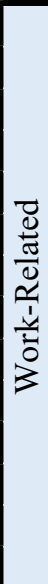 } & Within 15 Minutes (Start Time) & - & & - & - & -48.03 & -1.67 \\
\hline & More than 1 Hour & - & & - & - & 89.87 & 3.24 \\
\hline & Cannot Vary (End Time) & -32.33 & -9.08 & - & - & - & \\
\hline & Within 15 Minutes & -24.87 & -4.90 & - & - & - & \\
\hline & 16 to 30 Minutes & -24.10 & -5.22 & - & - & - & \\
\hline & 31 to 60 Minutes & -13.66 & -3.15 & - & - & - & \\
\hline & Government & -14.20 & -3.86 & - & - & 75.35 & 3.26 \\
\hline & Full-time one job & -14.94 & -3.94 & - & - & - & - \\
\hline & Full-time more than one job & -51.81 & -11.35 & 44.41 & 9.99 & - & \\
\hline & Business/ Financial Operations Occ. & 10.60 & 2.03 & -145.46 & -27.44 & - & - \\
\hline & Computer/ Math. Occ. & - & & -150.76 & -14.32 & - & \\
\hline & Architecture/ Engineering Occ. & - & & - & - & -117.49 & -3.38 \\
\hline & Life/ Physical/ Social Science Occ. & - & - & - & - & -310.41 & -6.77 \\
\hline & Community/ Social Services Occ. & -20.32 & -6.73 & -82.00 & -33.70 & - & \\
\hline
\end{tabular}


Table 5-4: Evening Terminal Vertex Model

\begin{tabular}{|c|c|c|c|c|c|c|}
\hline & \multicolumn{2}{|c|}{ Non-Tele. } & \multicolumn{2}{|c|}{ Ancillary } & \multicolumn{2}{|c|}{ Passive } \\
\hline & Coeff. & $z$ & Coeff. & $z$ & Coeff. & $z$ \\
\hline Legal Occ. & 22.16 & 6.19 & 91.74 & 5.21 & & \\
\hline Education/ Training/ Library Occ. & -25.97 & -6.06 & 42.77 & 18.53 & & \\
\hline $\begin{array}{l}\text { Arts/ Design/ Enter./ Sports/ Media } \\
\text { Occ. }\end{array}$ & 20.85 & 7.74 & -33.51 & -17.94 & & \\
\hline $\begin{array}{l}\text { Healthcare Practitioners/ Technical } \\
\text { Occ. }\end{array}$ & & & -20.14 & -11.88 & -89.00 & -2.31 \\
\hline Healthcare Support Occ. & & & & & 103.86 & 5.26 \\
\hline Protective Service Occ. & -41.56 & -3.00 & - & & - & \\
\hline $\begin{array}{l}\text { Food Preparation/ Serving Related } \\
\text { Occ. }\end{array}$ & 41.11 & 5.62 & & & 85.43 & 1.71 \\
\hline $\begin{array}{l}\text { Building/ Grounds Cleaning/ } \\
\text { Maintenance Occ. }\end{array}$ & -23.62 & -3.03 & & & & \\
\hline Construction/ Extraction Occ. & -43.76 & -10.77 & -27.13 & -13.28 & -211.33 & -3.66 \\
\hline $\begin{array}{l}\text { Installation/ Maintenance/ Repair } \\
\text { Occ. }\end{array}$ & -34.55 & -7.84 & & & -84.76 & -2.36 \\
\hline Production Occ. & -20.07 & -3.79 & & & & \\
\hline Transportation/ Material Moving Occ. & -23.20 & -3.88 & - & & -227.82 & -9.34 \\
\hline Military Specific Occ. & -67.61 & -3.05 & -118.44 & -78.13 & & \\
\hline Type 1: 4/40 & 17.44 & 4.58 & - & & - & \\
\hline Trip Duration & 0.48 & 10.33 & 1.08 & 10.05 & - & \\
\hline sigmaSq & $70,197.00$ & $67,959.73$ & $95,740.00$ & $95,739.84$ & $98,501.00$ & $7,475.19$ \\
\hline gammaVar & $58.80 \%$ & & $100.00 \%$ & & $90.08 \%$ & \\
\hline gamma & 0.80 & 155.01 & 1.00 & $672,770.31$ & 0.96 & 58.51 \\
\hline Log Likelihood L $(\beta)$ & $-94,223.88$ & & $\mid-862.14$ & & $-1,542.46$ & \\
\hline Log Likelihood L(OLS) & $-94,754.61$ & & -888.62 & & $-1,560.73$ & \\
\hline Observations & 14,224 & & 133 & & 232 & \\
\hline
\end{tabular}

In summary, this section discussed the modeling results of the exploration conducted in this thesis. Based on the results, the morning origin vertex and evening terminal vertex was successfully modeled for all groups by a production function and cost function, respectively. The morning terminal vertex and evening origin vertex were unsuccessfully modeled for all groups with a cost function and production function. These results are supported by the literature and reaffirm the potential and limitations of stochastic frontier analysis. As previously mentioned, ongoing research is being conducted to overcome the current limitations associated with the failed estimations. 


\subsection{TIME-SPACE PRISM ESTIMATION}

In order to explore the relationship of telecommuting on time-space constraints, the models from the previous sections were used to construct time-space prisms. The following prisms were constructed for a 25 year-old Hispanic male with one vehicle and medium income. He was a full-time employee that works for the government, in an arts occupation, with no start time variability and a 30-minute commute. Perhaps he works in a state or federal art museum. Considering all of this, the prisms shown below were constructed as if he was a Non-Telecommuter, Ancillary Telecommuter, and Passive Telecommuter; the morning prisms' vertices, evening prisms' vertices, daily prisms' vertices for each scenario are shown in Table 5-5, Table 5-6, and Table 5-7, respectively.

As shown in Table 5-5, Passive and Non-Telecommuters had the earliest and latest MOV, respectively. It is also clear that Ancillary and Non-Telecommuters had the latest and earliest MTV, respectively.

Table 5-5: Morning Prism Vertices

\begin{tabular}{|l|r|c|r|r|}
\hline \multirow{2}{*}{} & \multicolumn{2}{|c|}{ Morning Origin Vertex } & \multicolumn{2}{c|}{ Morning Terminal Vertex } \\
\cline { 2 - 5 } & \multicolumn{1}{|c|}{ Minutes } & Time & \multicolumn{1}{c|}{ Minutes } & \multicolumn{1}{c|}{ Time } \\
\hline Non-Telecommuter & 378.66 & $6: 19 \mathrm{AM}$ & 627.81 & $10: 46 \mathrm{AM}$ \\
\hline Ancillary Telecommuter & 367.53 & $6: 08 \mathrm{AM}$ & 893.48 & $2: 53 \mathrm{PM}$ \\
\hline Passive Telecommuter & 363.75 & $6: 04 \mathrm{AM}$ & 661.66 & $11: 02 \mathrm{AM}$ \\
\hline
\end{tabular}

In order to visualize the prisms for these three scenarios, the data found in Table 5-5 was used to construct the time-space prisms shown in Figure 5-1. The most obvious observation that can be made from this figure is that the Ancillary Telecommuter scenario had the least time-space constraints (widest prism) and the Non-Telecommuter scenario 
had the most time-space constraints (narrowest prism). Interestingly, the MOV did not vary greatly between the scenarios. In fact, the difference between the earliest and latest MOV was only 15 minutes. The clustering of the MOVs may reflect real or perceived employer-related constraints placed on the worker. One possible explanation for this is that the importance of arriving at work on-time is emphasized by the worker's superiors, or that he feels the need to arrive at work early in the morning in order to be effective, so he leaves home earlier. Unlike the MOV, the MTV was observed to vary greatly among the scenarios; the difference between the earliest and latest was over 4 hours. 


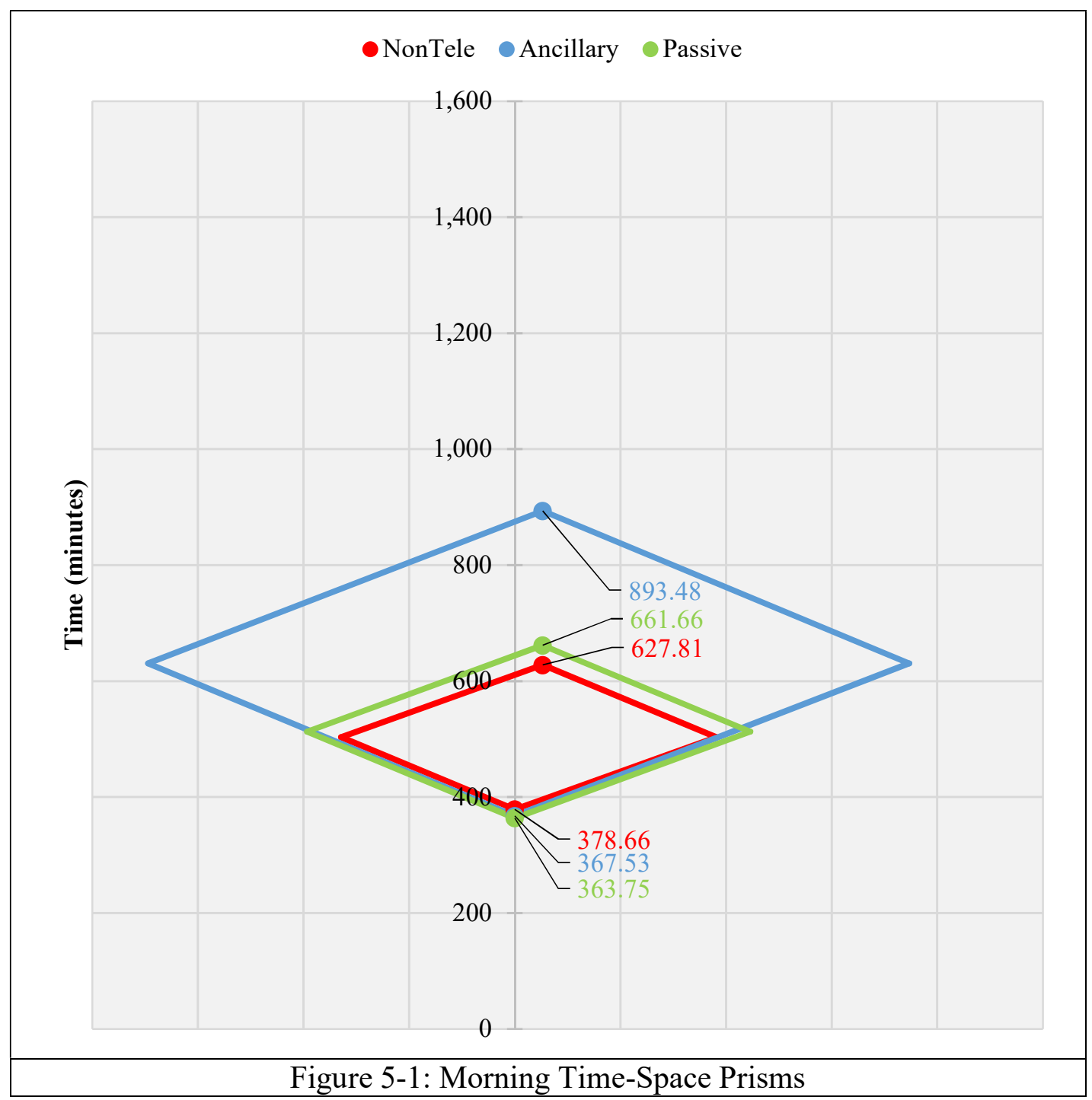

Based on Table 5-6, it is clear that the Non-Telecommuter scenario had the earliest EOV and ETV, while the Passive Telecommuter scenario had the latest EOV and ETV. This is interesting because it shows that as a Non-Telecommuter, the subject tended to leave work and arrive at home earliest. Further, as a Passive Telecommuter, he left work and arrived at home the latest. 
Table 5-6: Morning Prism Vertices

\begin{tabular}{|l|c|c|c|c|}
\hline \multirow{2}{*}{} & \multicolumn{2}{|c|}{ Evening Origin Vertex } & \multicolumn{2}{c|}{ Evening Terminal Vertex } \\
\cline { 2 - 5 } & \multicolumn{1}{|c|}{ Minutes } & \multicolumn{1}{c|}{ Time } & \multicolumn{1}{c|}{ Minutes } & Time \\
\hline Non-Telecommuter & $1,070.98$ & $5: 51 \mathrm{PM}$ & $1,321.10$ & $10: 00 \mathrm{PM}$ \\
\hline Ancillary Telecommuter & $1,137.35$ & $6: 57 \mathrm{PM}$ & $1,461.45$ & $12: 21 \mathrm{PM}$ \\
\hline Passive Telecommuter & $1,424.62$ & $11: 45 \mathrm{PM}$ & $1,504.47$ & $1: 04 \mathrm{AM}$ \\
\hline
\end{tabular}

From Figure 5-2, it is evident that the Ancillary Telecommuter scenario had the least time-space constraints (widest prism) and the Passive Telecommuter scenario had the most time-space constraints (narrowest prism). Interestingly, the size difference between the Ancillary and Non-Telecommuter prism was not that great, while the difference between the Non-Telecommuter and Passive Telecommuter prism was very large. Based on this, it is possible to assume that the man in this example may have engaged in different activities on his way home as an Ancillary or Non-Telecommuter, but chose to go directly home as a Passive Telecommuter. 


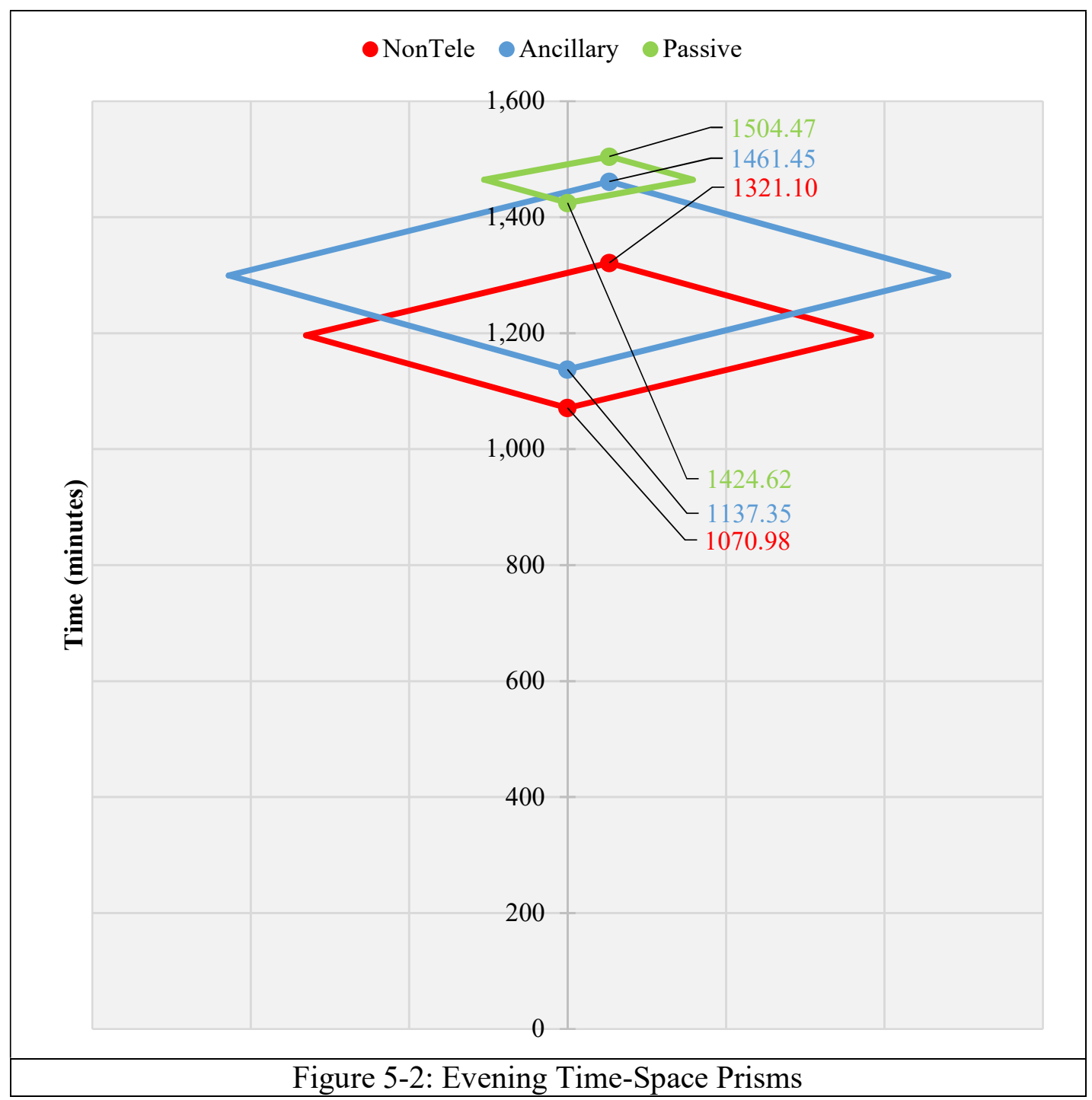

Here, in Table 5-7, it is evident that the Passive Telecommuter scenario had the earliest MOV and latest ETV; the Non-Telecommuter scenario had the latest MOV and earliest ETV. 
Table 5-7: Daily Prism Vertices

\begin{tabular}{|l|r|c|r|r|}
\hline \multirow{2}{*}{} & \multicolumn{3}{|c|}{ Morning Origin Vertex } & \multicolumn{2}{c|}{ Evening Terminal Vertex } \\
\cline { 2 - 5 } & \multicolumn{1}{c|}{ Minutes } & Time & \multicolumn{1}{c|}{ Minutes } & \multicolumn{1}{c|}{ Time } \\
\hline Non-Telecommuter & 378.66 & $6: 19 \mathrm{AM}$ & $1,321.10$ & $10: 00 \mathrm{PM}$ \\
\hline Ancillary Telecommuter & 367.53 & $6: 08 \mathrm{AM}$ & $1,461.45$ & $12: 21 \mathrm{PM}$ \\
\hline Passive Telecommuter & 363.75 & $6: 04 \mathrm{AM}$ & $1,504.47$ & $1: 04 \mathrm{AM}$ \\
\hline
\end{tabular}

From this table, and the estimated models, the time-space prisms in Figure 5-3 were constructed. The figure shows that the Passive Telecommuter scenario had the least time-space constraints (widest prism) and the Non-Telecommuter scenario had the most time-space constraints (narrowest prism). Interestingly, the MOV among the three scenarios did not vary greatly. It is possible that this is due to the employer's requirements. For example, maybe the museum he works at opens early in the morning and he needs to be there to address certain issues. On the other hand, the ETV did vary greatly between the scenarios. Perhaps in the Non-Telecommuter Scenario he worked more typical working hours, but in the Ancillary and Passive Telecommuter scenario he worked more hours or engaged in work-related activities before arriving at home. 


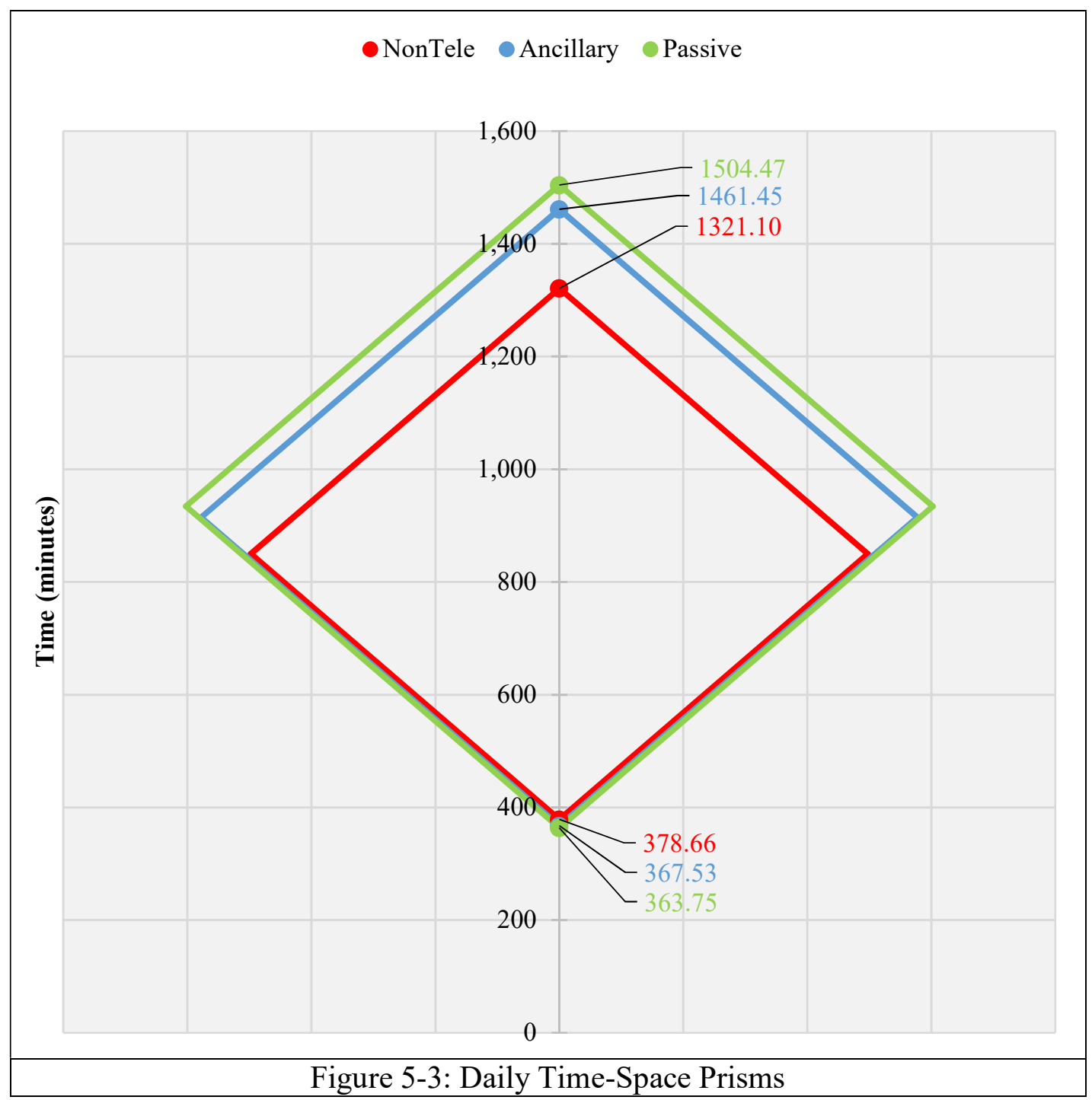

In this section, this study discussed the formulation of the stochastic frontier models which were used to estimate the various time-space vertices and time-space prisms of a male subject. Based on this exploration, a few major points were revealed:

- The departure time from home to work (MOV) did not vary greatly due to the use of telecommuting. This is possibly due to the fact that most occupations have similar work schedules. 
- Telecommuters (Ancillary and Passive) tended to depart from home slightly earlier than Non-Telecommuters. This was attributed to the fact that the Ancillary and Passive Telecommuters have more real or perceived pressure to arrive at work on-time and as such leave home slightly earlier.

- Non-Telecommuters tended to arrive at home the earliest, followed by Ancillary and Passive Telecommuters. A possible explanation for this is that they have a more rigid schedule which enables them to leave work and arrive at home earlier.

- Telecommuting relaxed time-space constraints, and increased the time-space prism's width, in respect to the morning, evening, and daily time-space prism. The only exception to this was the evening time-space prism associated with Passive Telecommuting. The general trend, of reduced time-space constraints, was attributed to the flexibility afforded to these two groups via the deployment of telecommuting.

- Telecommuters (Ancillary and Passive) tended to have later work start and end times. A possible explanation is that these two groups took advantage of telecommuting which enabled them to work the hours that were more suited to their lifestyles. 


\section{CHAPTER 6. CONCLUSION AND RECOMMENDATION}

In this section the author will summarize the exploration conducted in this thesis, explain its contributions, discuss some of its limitations, and provide some recommendations for future studies.

\subsection{SUMMARY}

The past few decades have brought on a vigorous interest in telecommuting as a potential transportation demand management (TDM) strategy. In large part, this interest can be attributed to its potential to alter transportation behaviors; more specifically, some believe it has the potential to reduce the total number of daily trips or the at least shift the existing trips to reduce peak-time demand. Due to this, this thesis sought to explore the relationship between time-space constraint, the distribution of daily activities, and the location of time-space vertices of individuals with varying degrees of telecommuting.

A review of the literature revealed the overarching principles of telecommuting, time-space prisms, time-space constraints, as well as the relationship between telecommuting and time-space constraints. In this review, it became evident that there is little consistency, regarding the definition of telecommuting between studies; this prompted the author to adopt the aforementioned definitions. It also revealed that the actual impact of telecommuting is still intensely scrutinized as it has the potential to reduce daily trips, but also may facilitate the frequency of more trips within a contracted activity space. Finally, it demonstrated that stochastic frontier analysis had the potential to provide accurate and significant estimations of a time-space prism's vertices in order to understand the variation across telecommuter and non-telecommuters. 
Due to this, stochastic frontier analyses were conducted for three groups: Ancillary, Passive, and Non-Telecommuters. These models were formulated in accordance with the literature and various socio-demographic data were used as explanatory variables. These data were obtained from the Regional Household Travel Survey (RHTS) 2010-2011. The survey covered 28 counties across New York, New Jersey, and Connecticut. In total, survey data and daily activity diaries were obtained for 43,558 individuals.

The modeling conducted during this thesis concluded that morning origin (departure from home to work) and evening terminal (arrival at home from work) vertices are successfully modeled with the cost and production functions, respectively. In both cases work-related attributes were observed to have the largest coefficients used to determine the mean expected departure time and the mean expected arrival time. The morning terminal (arrival at work from home) and evening origin (departure from work to home) vertices should more likely be modeled with ordinary least squares models.

Through the estimations, this thesis uncovered many interesting behaviors. First, the departure time from home to work (MOV) did not vary greatly due to the use of telecommuting, which may be due to the fact that most occupations have similar work schedules. Also, telecommuters (Ancillary and Passive) tended to depart from home slightly earlier than Non-Telecommuters. This was primarily attributed to the fact that they Ancillary and Passive Telecommuters have more real or perceived pressure to arrive at work on-time and as such leave home slightly earlier. Non-Telecommuters generally tended to arrive at home the earliest, followed by Ancillary and Passive Telecommuters. A possible explanation for this is that they have a more rigid schedule which enables 
them to leave work and arrive at home earlier. In general, telecommuting relaxed timespace constraints, and increased the time-space prism's width, in respect to the morning, evening, and daily time-space prism. The only exception to this was the evening timespace prism associated with Passive Telecommuting. The general trend, of reduced timespace constraints, was attributed to the flexibility afforded to these two groups via the employment of telecommuting.

\subsection{CONTRIBUTIONS}

This thesis was able to provide contributions to the literature surrounding telecommuting and stochastic frontier analysis. First, the study reinforced that work-related variables tend to be the most influential on the departure time from home to work and the arrival time at home from work. This highlights the need for data to be collected with special attention on the collection of work-related data. Also, the study reaffirmed the current limitation of stochastic frontier analysis to estimate the arrival time at work from home and the departure time to home from work. In turn, this demonstrates the need for the improvement of stochastic frontier analysis and/or the creation of a compliment/supplement to this type of analysis.

\subsection{LIMITATIONS}

The major limitation of this study was related to the data. While the sample was large, the vast majority of the individuals were non-telecommuters. It is unclear whether the sample accurately represents the geographic location, or if the sample was biased. Also, when the trip duration was included in the models, it did not have a large impact on the 
models. As this variable is generally accepted as an important one when an individual is considering telecommuting, it may indicate that this area's population has a differing value of time for commuting trips. For example, if the individuals were more reliant on public transportation, they sample may value reliability of time which could explain why the aforementioned trend.

Another limitation was the fact that stochastic frontier analysis was unsuccessful at estimating the morning terminal and evening origin vertices. Finally, while the methodology could be applied elsewhere, the transferability of the results to other areas is not likely feasible. However, the results may serve as a starting point or frame of reference for other similar studies.

\subsection{RECOMMENDATIONS FOR FUTURE RESEARCH}

Based upon the results of the aforementioned analyses, as well as the literature surround the topic, the author provides several recommendations for future studies. The first of these is to suggest that a more concrete definition of telecommuting should be adopted. This definition should be rigorous enough to include current forms of telework as well as flexible enough to adapt to emerging and newer forms. Establishing this would greatly propel the study and understanding of telecommuting as a whole. Once this definition is agreed upon, new data collections should be undertaken in order to explore their effect on time-space constraints and time-space prism vertices.

Another area which can benefit from improvements is stochastic frontier analysis in the context of telecommuting. Not only would this benefit the analysis as a whole, but it may enable wider use of this type of analysis in the exploration of telecommuting as 
well as other transportation related subjects. If this and the previous issue, is resolved then the author believes that a similar methodology could be implemented into activitybased modeling to provide transportation planners and officials a useful tool to guide the implementation of telecommuting-related transportation demand management strategies. 


\section{REFERENCES}

Aigner, D., C. A. K. Lovell, and P. Schmidt. Formulation and Estimation of Stochastic Frontier Production Function Models. Journal of Econometrics, Vol. 6, 1977, pp. 2137.

Almanidis, P. and R. C. Sickles, 2012. "the Skewness Issue in Stochastic Frontiers Models: Fact or Fiction?" Exploring Research Frontiers in Contemporary Statistics and Econometrics, pp 201-207.Asgari, H, "On the Impacts of Telecommuting over Daily Activity/Travel Behavior: A Comprehensive Investigation through Different Telecommuting Patterns" (2015). FIU Electronic Theses and Dissertations. Paper 2182. http://digitalcommons.fiu.edu/etd/2182

Asgari, H. and X. Jin, 2015. 'Analysis of Telecommuting Behavior: Substitution or Supplementary? Combining Lifestyle Choice with Daily Engagement'. TRB $94^{\text {th }}$ Annual Meeting Compendium of Papers, Paper\#15-0283.

Asgari, H., and X. Jin, 2015. 'Towards a Comprehensive Telecommuting Analysis Framework; Setting the Conceptual Outline", Transportation Research Record, Journal of Transportation Research Board, No. 2496, pp.1-9.

Asgari, H., X. Jin and Y. Du, 2016. 'Examining the Impacts of Telecommuting on the Time-Use of Non-Mandatory Activities', Transportation Research Record (TRR), Journal of the Transportation Research Board, No. 2566, DOI: 10.3141/2566-09, in press.

Asgari, H., X. Jin and Y. Du, 2016. 'Investigation of Commute Departure Time to Understand the Impacts of Part-Day Telecommuting on the Temporal Displacement of Commute Travel', TRB 95 ${ }^{\text {th }}$ Annual Meeting Compendium of Papers, Paper\#161662 .

Asgari, H., X. Jin, and A. Mohseni, 2014. 'Choice, Frequency, and Engagement - A Framework for Telecommuting Behavior Analysis and Modeling'. Transportation Research Record: Journal of the Transportation Research Board, No. 2413, pp. 101109.

Belanger, F., 1999. “Workers' Propensity to Telecommute: An Empirical Study”. Journal of Information and Management, 35(3), pp. 139-153.

Bernardino, A., Ben Akiva, M. and I. Salomon, 1993. "Stated Preference Approach to Modeling the Adoption of Telecommuting". Transportation Research Record, 1413, pp. 22-30.

Choo. S, Mokhtarian, P. L. and I. Salomon, 2005. "Does Telecommuting Reduce Vehicle miles Traveled? An Aggregate Time Series for the US". Transportation. Vol. 32, no. 1, pp. 37-64. 
Crimando, W. and S.H. Godley, 1985. "The Computer's Potential in Enhancing Employment Opportunities of Persons with Disabilities". Rehabilitation Counseling Bulletin, 28, pp. 275-282.

Grippaldi, Joseph J., 2002. "An Empirical Study of Attitudes towards Telecommuting among Government Finance professionals". UNLV Theses/Dissertations/Professional Papers/Capstones. Paper 515.

Haddad, H., Lyons, G. and K. Chatterjee, 2009. "An Examination of Determinants Influencing the Desire for and Frequency of Part-day and Whole-day Homeworking", Journal of Transport Geography, 17, pp. 124-133.

Hafner, C. M., H. Manner and L. Simar, 2015. "The "wrong skewness" problem in stochastic frontier models: A new approach" Universite Catholique de Louvain Working Paper.

Hamer, R., Kroes, E. and H. Van Ooststroom, 1991. "Teleworking in the Netherlands: An Evaluation of Changes in Travel behavior". Transportation 18, pp. 365-382.

Heaslip, K., Bosworth, R., Barnes, R., Sobh, A. S., \& Thomas, M. Do Changing Prices 19 Portend a Shift in Fuel Consumption, Diminished Greenhouse Gas Emissions, and Lower 20 Fuel Tax Revenue? MPC-15-278. North Dakota State University - Upper Great Plains 21 Transportation Institute, Fargo: Mountain-Plains Consortium, 2015.

Helminen, V. and M. Ristimaki, 2007. "Relationships between Commuting Distance, Frequency and Telework in Finland". Journal of Transport Geography, 15, pp. 331342.

Henningsen, A., 2014. "Introduction to Econometric Production Analysis with R". Department of Food and Resource Economics, University of Copenhagen. Retrieved from: https://files.itslearning.com/data/ku/103018/teaching/lecturenotes.pdf

Hägerstrand, T. What about People in Regional Science? Papers of the Regional Science Association, Vol. 24, 1970, pp. 7-21.

Jiang, Y., 2008. "The Impact of Telecommuting on the Journey to Work: A Two-Sample Instrumental Variable Approach". Dissertation chapter, University of Maryland.

Kitamura, R., T. Yamamoto, K. Kishizawa, and R. M. Pendyala. Stochastic Frontier Models of Prism Vertices. In Transportation Research Record: Journal of the Transportation Research Board, No. 1718, TRB, National Research Council, Washington, D.C., 2000, pp. 18-26.

Mannering, J.S. and P.L. Mokhtarian, 1995. "Modeling the Choice of Telecommuting Frequency in California; An Exploratory Analysis". Technological Forecasting and Social Change, 49, pp. 49-73. 
Mohammadian, A. and S. Doherty, 2005. "A Mixed Logit Model of Activity Scheduling Time Horizon Incorporating Spatial-Temporal Flexibility Variables". Transportation Research Record, 1926, pp. 33-40.

Mokhtarian, P.L. and I. Salomon, 1997. "Emerging Travel Patterns: Do Telecommunications Make a Difference?” Invited resource paper for the 8th Meeting of the International Association for Travel Behaviour Research, Austin, TX. Chapter 7 in: In Perpetual Motion: Travel Behaviour Research Opportunities and Application Challenges, Hani S. Mahmassani, ed., Pergamon Press/Elsevier, 2002, pp. 143-182.

Mokhtarian, P.L., 2003. "Telecommunications and Travel: The Case for Complementarity". Journal of Industrial Ecology 6(2), Special Issue on ECommerce, the Internet, and the Environment, pp. 43-57.

Mokhtarian, P.L., Collantes, G.O. and C. Gertz, 2004. "Telecommuting, Residential Location, and Commute Distance Traveled: Evidence from State of California Employees". Environment and Planning A, 36, pp. 1877-1897.

Mosa, A., 2011. "Modeling the Impacts of Information and Communication Technologies and Virtual Activities on Activity and Travel Behavior, Case Study of Cairo, Egypt", Transportation Research record, 2231, pp. 102-109.

Motamed, M. "Developing a real-time freeway incident detection model using machine learning techniques", PhD dissertation, University of Texas at Austin, May 2016.

Nehra, Ram S., "Modeling time space prism constraints in a developing country context" (2004). Graduate Theses and Dissertations. http://scholarcommons.usf.edu/etd/1178

New York Metropolitan Transportation (NYMTC), North Jersey Transportation Planning Authority (NJTPA), 2013. "2010-2011 Regional Household Travel Survey Data User's Manual”.

Nilles, J.M., Carlson, F.R., Paul, G.Jr. and G.J. Hanneman, 1974. "Development of policy on the Telecommunications-Transportation Tradeoff". University of Southern California and the National Science Foundation, Report NSF-RA-5-74-020.

Olson, J.A., P. Schmidt and Donald M. Waldman, 1980, A Monte Carlo study of estimators of stochastic frontier production functions, Journal of Econometrics 13, 67782.

Parsons Brinckerhoff Quade \& Douglas, Inc., Cambridge Systematics, Inc. and Nustats International, 2000. "RT-HIS Regional Travel-Household Interview Survey". Prepared for the New York Metropolitan Transportation (NYMTC), North Jersey Transportation Planning Authority (NJTPA)

Pendyala, R. M., T. Yamamoto, and R. Kitamura. On the Formulation of Time-Space Prisms to Model Constraints on Personal Activity-Travel Engagement. Transportation, Vol. 29, 2002, pp. 73-94. 
Pendyala, R.M, Konstadinos, G.G. and R. Kitamura, 1991. "Impacts of Telecommuting on Spatial and Temporal Patterns of Household travel". Transportation (18), pp. 383409.

Pirdavani, A., Brijs, T., Bellemans, T., Kochan, B. and G. Wets, 2013. "Assessing the Impacts of a Teleworking Policy on Crash Occurrence: The Case of Flanders, Belgium”. 92nd TRB Annual Meeting Compendium of Papers DVD, pp. 1-18.

Schintler, L.A., 2001. "Trip Reduction Study: The Impact of Telecommuting Delay in the Washington, D.C. Area”. The School of Public policy, George Mason University.

Sharifi, M.S. and H. Shabaniverki, 2016. "Modeling Crash Delays in a Route Choice Behavior Model for Two-Way Road Networks". Journal of Geotechnical and Transportation Engineering, Volume 2, Issue 1, pp.19-25.

Sobh, Ali Soltani, 2015. Transportation Economics and Energy. All Graduate Theses and Dissertations. Paper 4165. http://digitalcommons.usu.edu/etd/4165.

Soltani-Sobh, A., K. Heaslip, R. Bosworth, R. Barnes, and Z. Song. Do Natural Gas Vehicles Change Vehicle Miles Traveled? An Aggregate Time-Series Analysis. Presented at 95th Annual Meeting of the Transportation Research Board, Washington, D.C., 2016.

Tim Coelli and Arne Henningsen (2013). frontier: Stochastic Frontier Analysis. R package version 1.0. http://CRAN.R-Project.org/package=frontier.

Turnbull K. F., Hall K. M., Lewis C. and C. A. Weatherby, 1996. "Telecommuting programs in Texas, Case studies". Research report 1446-F, Research study number 0-1446, Texas Transportation Institute.

United States Office of Personnel Management. Status of Telework in the Federal Government-Report to Congress, February 2011, https://www.telework.gov/reportsstudies/reports-to-congress/2010-report-to-congress.pdf

United States Office of Personnel Management. Status of Telework in the Federal Government-Report to Congress, November 2015, https://www.telework.gov/reports-studies/reports-to-congress/2014-report-tocongress.pdf

Vu, S. T. and U. Vandebona, 2007a. "A Model for Analysis of Impacts of Telecommuting on Network Travel Time". Australasian Transport Research Forum (ATRF), 30 Melbourne, Victoria, Australia, Vol 30.

Vu, S. T. and U. Vandebona, 2007b. "Telecommuting and Its Impacts on Vehicle-km Travelled". Proceedings of International Congress on Modelling and Simulation, the University of Canterbury, Christchurch, New Zealand, pp. 253-260. 
$\mathrm{Vu}, \mathrm{S}$. T. and U. Vandebona, 2008. "Evaluation of Impacts of Telecommuting in Traffic Assignment". 30th Conference of Australian Institutes of Transport Research, December 10-12, Perth WA Australia.

Vu, S.T., 2007c. "Analysis of Impacts of Telecommuting for Reduction of Environmental Pollution". Conference of Australian Institutes of Transport Research (CAITR), 29 , Adelaide, South Australia, Australia.

Waldman, D. M. A. Stationary Point for the Stochastic Frontier Likelihood. Journal of Econometrics, Vol. 18, 1982, pp. 275-279.

Walls, M. and E. Safirova, 2004. "A Review of the Literature on Telecommuting and Its Implications for Vehicle Travel and Emissions". Discussion Papers DP-04-44, Resources for the Future.

Wells, K., Douma, F., Loimer, H., Olson, L. and C. Pansing, 2001. "Telecommuting Implications for Travel Behavior, Case Studies from Minnesota". Transportation Research record, 1752, pp. 148-156.

Wenjing, W. and J. Zhicai, 2009. “Activity-Travel Behavior Analysis Based on Structural Equation Model". International Conference on Electronic Commerce and Business Intelligence (ECBI), pp. 486-490.

Zhu, P., 2011. "Telecommuting Travel Behavior and Residential Location Choice: Can Telecommuting Be an Effective Policy to Reduce Travel Demand?". Ph.D. Dissertation, University of Southern California. 
VITA

MARIO BENITO ROJAS IV, E.I.

\section{EDUCATION \& EMPLOYMENT}

$\begin{array}{ll}\text { 2009-2013 } & \text { B.S. Business Administration } \\ \text { 2013-2015 } & \text { B.S. Civil Engineering } \\ & \text { Project Engineer } \\ & \text { A\&P Construction Transportation Engineers } \\ & \text { Miami, Florida } \\ \text { 2015-2016 } & \text { M.S. Civil Engineering } \\ \text { 2014-Present } & \text { Undergraduate/Graduate Research Assistant } \\ & \begin{array}{l}\text { Department of Civil and Environmental Engineering } \\ \text { Florida International University, Miami, Florida }\end{array}\end{array}$

\section{PUBLICATIONS AND PRESENTATIONS}

Rojas, M. B., E. Sadeghvaziri and X. Jin. A Comprehensive Review of Travel Behavior and Mobility Pattern Studies Using Mobile Phone Data. Presented at Transportation Research Bboard 95 ${ }^{\text {th }}$ Annual Meeting, Washington, D.C., 2016.

Rojas, M. B., E. Sadeghvaziri and X. Jin. A Comprehensive Review of Travel Behavior and Mobility Pattern Studies Using Mobile Phone Data. Accepted for Publication in the Transportation Research Record, Washington, D.C., 2016.

Sadeghvaziri, E., M. B. Rojas and X. Jin. Exploring the Potential of Mobile Phone Data in Travel Behavior Analysis. Accepted for Publication in the Transportation Research Record, Washington, D.C., 2016.

Jin, X., Z. Zhang, and M. B. Rojas (2014). A synthesis of the "State-of-the-Practice for Advancing Planning and Operations Integration Opportunities within Transportation Agencies". Florida Department of Transportation- Systems Planning Office. http://www.dot.state.fl.us/research-center/Completed_Proj/Summary_PL/FDOT-BDV29977-16-rpt.pdf

Rojas IV, M. B. (2012). Why do negotiations tend to fail in a cross cultural milieu: The China Norway Affair? The Undergraduate Research Journal for the Human Sciences $11^{\text {th }}$ ed. http://www.kon.org/urc/v11/rojas2.html

Rojas IV, M. B. (2011). The Evolution of Affirmative Action. The Undergraduate Research Journal for the Human Sciences $11^{\text {th }}$ ed. http://www.kon.org/urc/v11/rojas.html 